\author{
ZENTRUM \\ FÜR BIODIVERSITÄT UND NACHHALTIGE LANDNUTZUNG \\ SEKTION \\ BIOdIVERSITÄT, ÖKOLOgIE UND NATURSCHUTZ \\ - Centre of Biodiversity and Sustainable Land Use - \\ SECTION: BIOdIVERsity, ECOlogy and NatURE Conservation
}

\title{
Soil animal food webs in temperate forests: effects of forest management on trophic structure as indicated by molecular gut content, stable isotope and fatty acid analyses
}

\author{
Dissertation zur Erlangung des Doktorgrades der \\ Mathematisch-Naturwissenschaftlichen Fakultäten der \\ Georg-August-Universität Göttingen
}

vorgelegt von

Diplom-Biologin

Olga Ferlian

aus

Wrocław

Göttingen, Mai 2014 
Referentin/Referent:

Korreferentin/Korreferent:

Tag der mündlichen Prüfung:
Prof. Dr. Stefan Scheu

PD Dr. Mark Maraun

20. Juni 2014 
I think I spider! 


\section{Table of Contents}

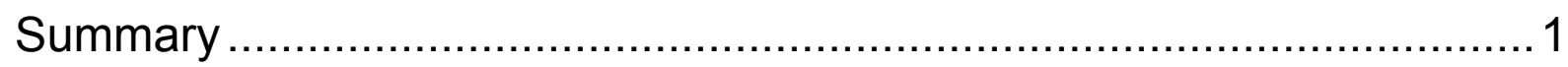

Chapter 1

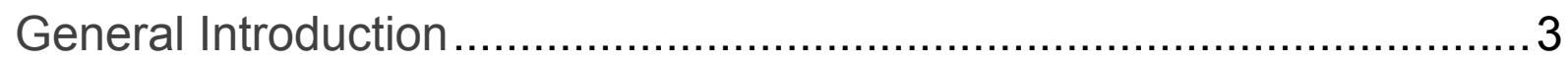

\section{Chapter 2}

Shifts in trophic interactions with forest type in soil generalist predators as indicated by complementary analyses of fatty acids and stable isotopes

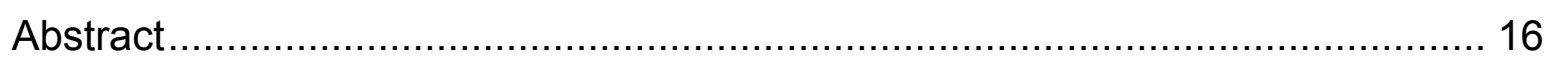

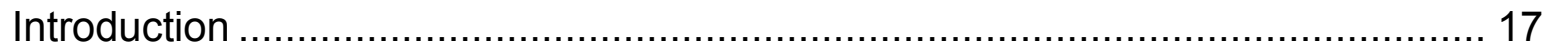

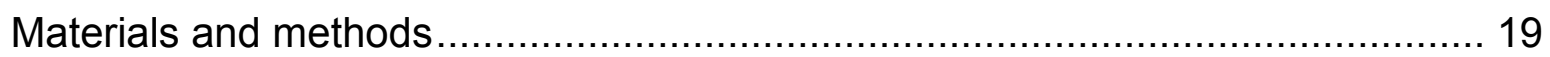

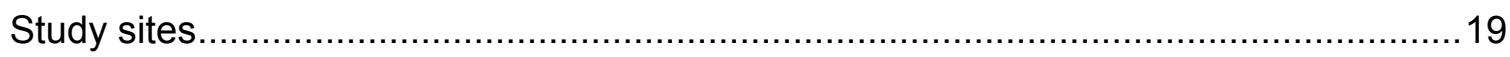

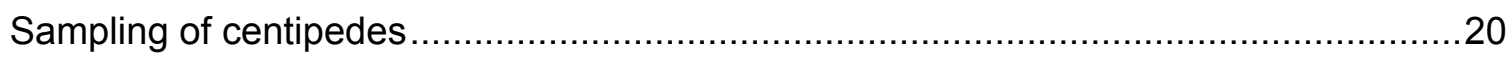

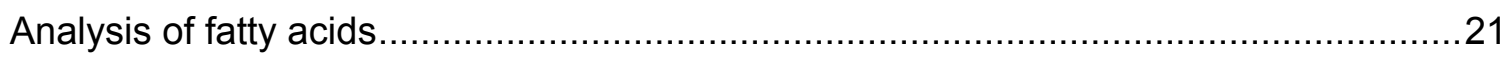

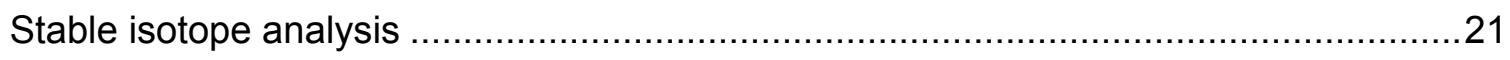

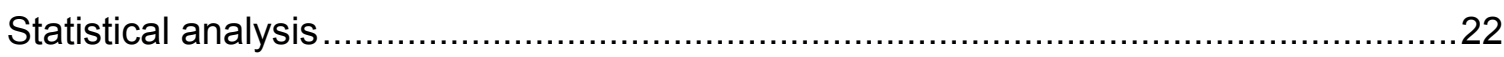

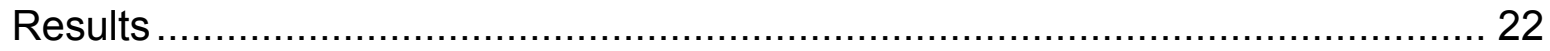

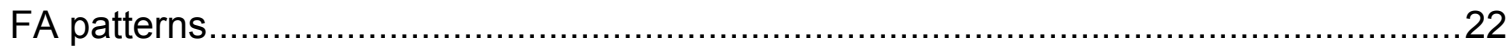

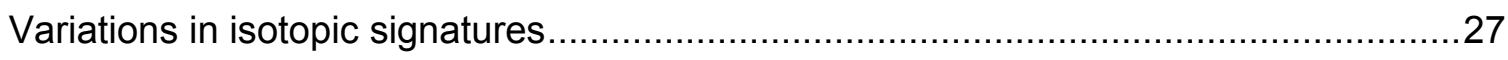

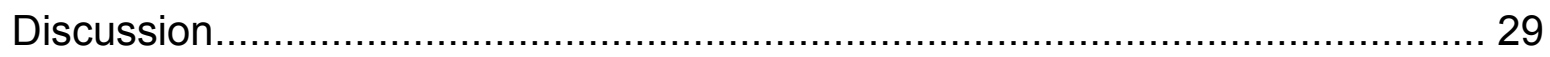

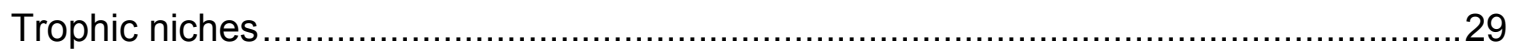

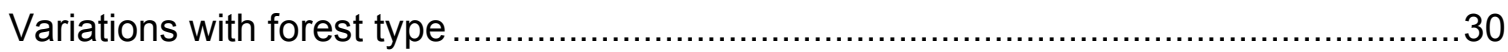

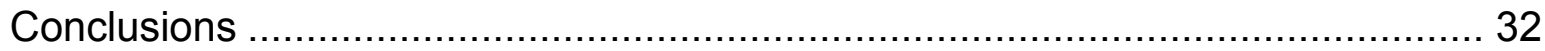

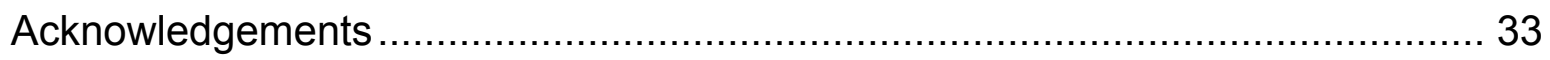

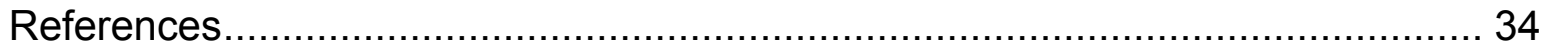

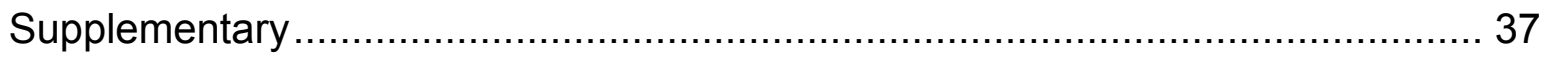




\section{Chapter 3}

Variations in prey consumption of centipede predators in forest soils as indicated by molecular gut content analysis.

Introduction Materials and methods

\section{Chapter 4}

Carbon food resources of earthworms of different ecological groups as indicated by ${ }^{13} \mathrm{C}$ compound-specific stable isotope analysis .

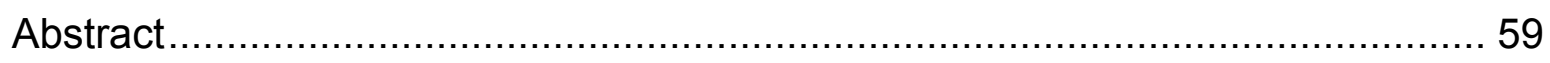

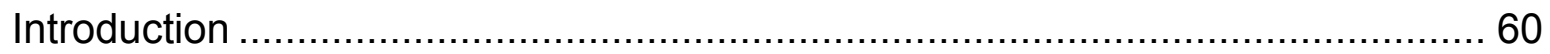

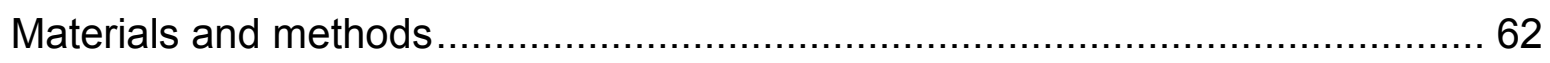

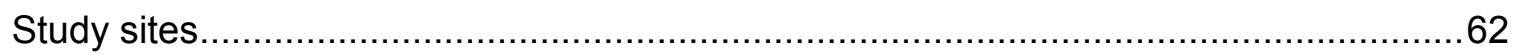

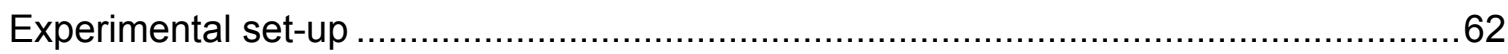

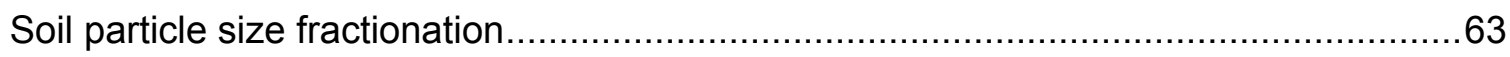

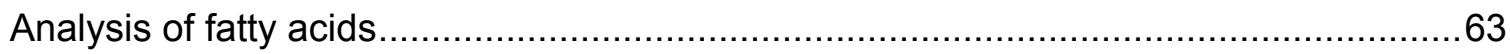

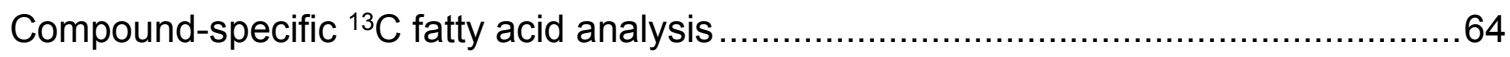

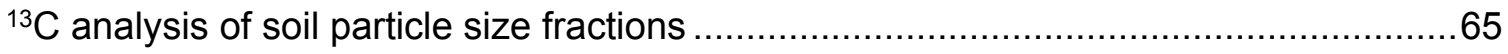

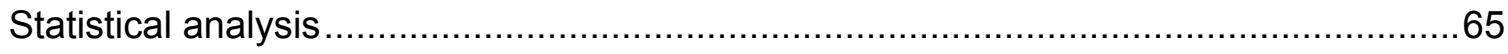

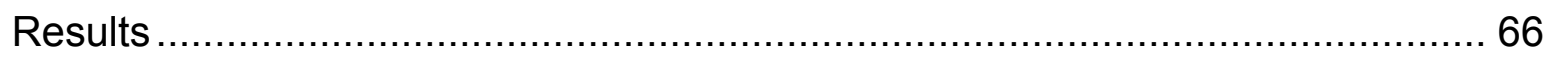

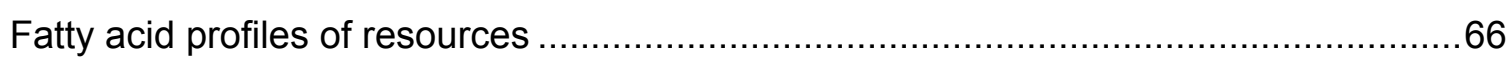

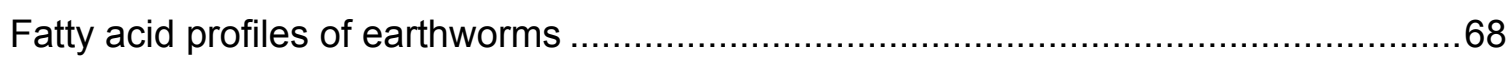

$\delta^{13} \mathrm{C}$ signatures of fatty acids in earthworms and resources ......................................69 
$\delta^{13} \mathrm{C}$ signatures of fatty acids in earthworms and soil particle size fractions. .72

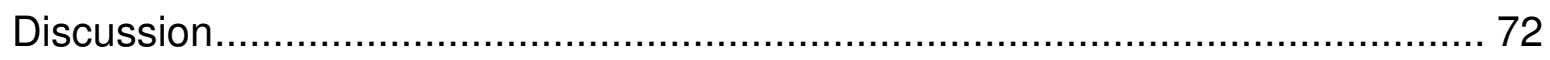

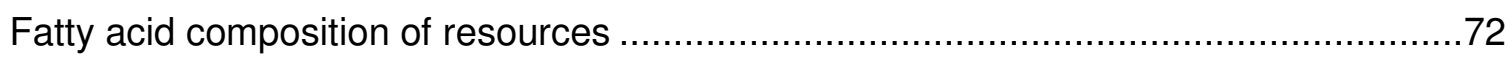

Fatty acid composition of earthworm tissue ....................................................... 74

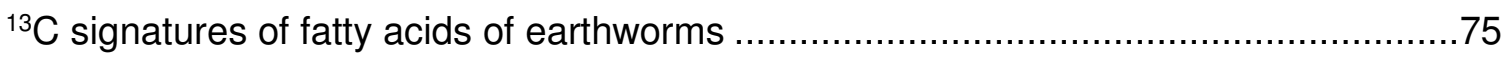

Incorporation of neutral lipid ${ }^{13} \mathrm{C}$ into earthworm fatty acids ....................................

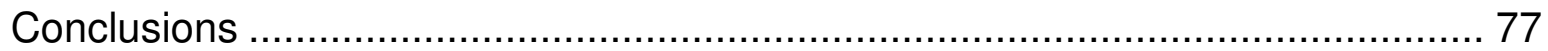

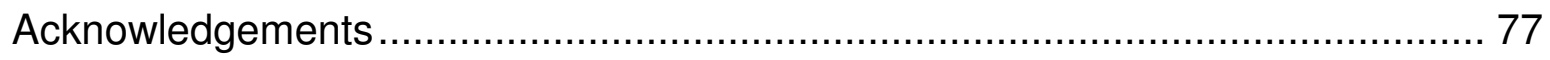

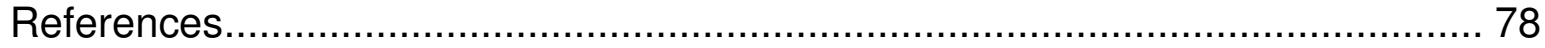

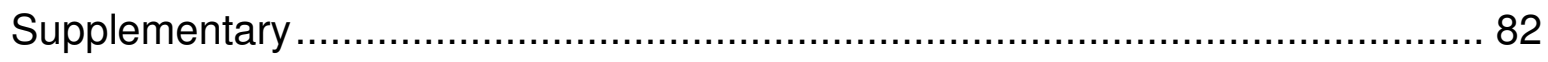

\section{Chapter 5}

Trophic niche differentiation and utilisation of food resources in collembolans based on complementary analyses of fatty acids and stable isotopes

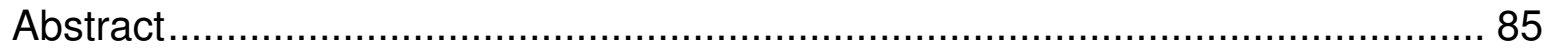

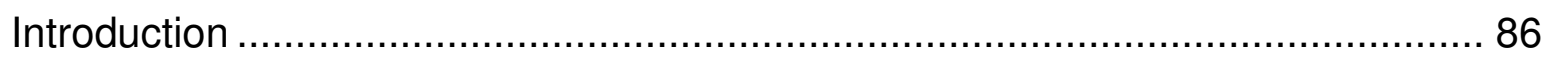

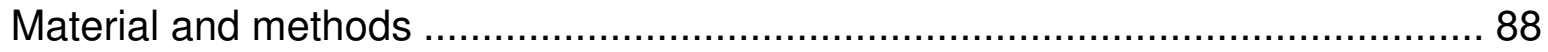

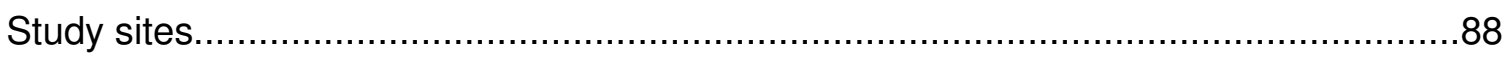

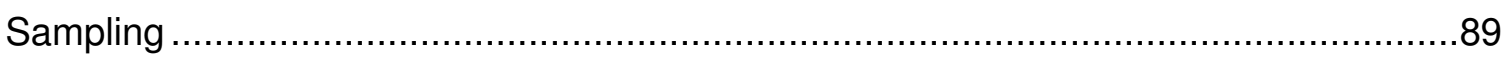

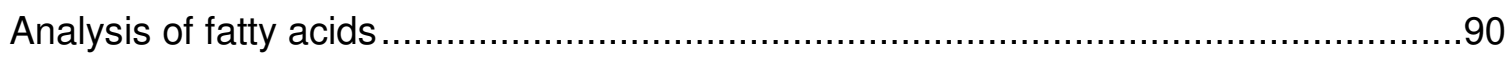

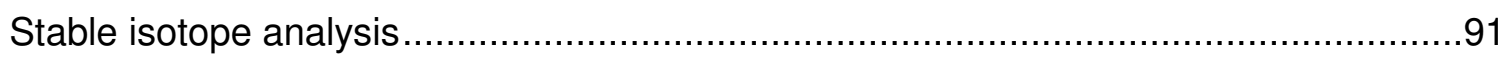

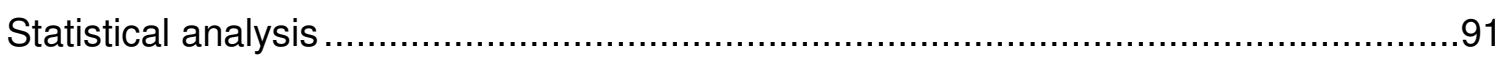

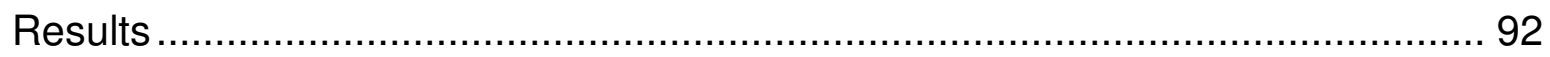

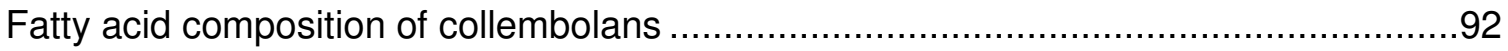

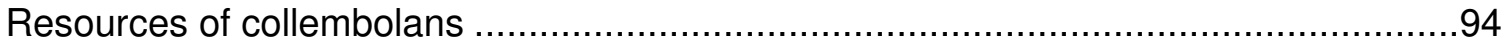

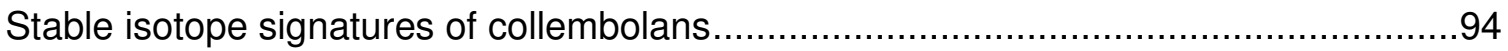

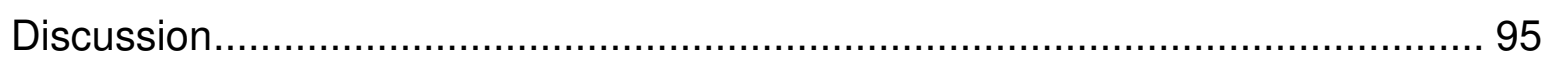

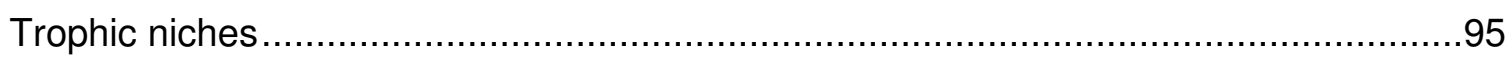

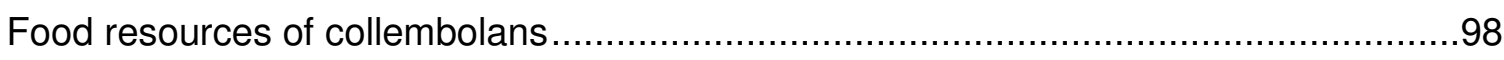

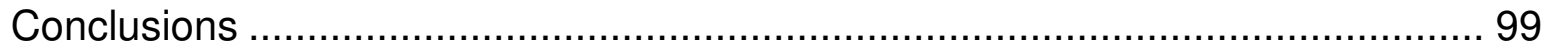

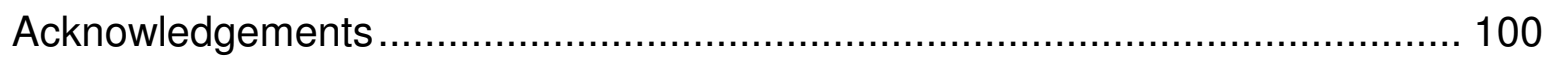


Chapter 6

General Discussion

Acknowledgements

List of Publications 113

Thesis Declaration. 114

Plagiarism Declaration 114

Curriculum vitae 115 


\section{Summary}

The soil system comprises a high diversity of coexisting species interacting in close association. Generally, soil animals are assumed to be trophic generalists feeding on resources of even different trophic levels. The complex structure of soil habitats hampers locating specific resources and this results in feeding on a broad range of resources. It has been assumed that most decomposers rely on labile resources of high nutritional value, such as high quality litter and microorganisms. However, there is increasing evidence that recalcitrant carbon sources being physically and chemically stabilised in soil aggregates are mobilised by certain decomposer groups. However, the soil system with its multitude of trophic interactions and ways of resource utilisation by consumers is still poorly understood. The aim of this thesis was to examine utilisation of food resources and energy channels of important key invertebrate taxa as representatives of different trophic levels in the soil food web. We aimed at identifying trophic niches of closely related species and the driving factors for its variations. Classical techniques, such as microscopic identification of gut contents and feeding experiments, examining trophic interactions and energy flows in soil food webs are increasingly replaced by novel molecular techniques. We used stable isotope, fatty acid and molecular gut content analyses providing reliable time-integrated and indirect methods to unravel trophic linkages between cryptic organisms in opaque soil systems.

In Chapter 2 We investigated feeding strategies of two centipede species to identify their trophic niches and variations therein with forest type. In combination with body size measurements, we conducted stable isotope and fatty acid analyses on centipedes allowing insight into trophic levels and the utilisation of basal resources. The results indicated centipedes to occupy distinct trophic niches with the smaller species relying more on bacterial resources and root-derived carbon as compared to the larger species. Differences in trophic niches were more pronounced in coniferous than in beech forests. The results suggest that habitat structure and body size may act as determinants for variations in trophic niches of soil arthropod predators.

Complementing the study in Chapter 2, in Chapter 3 we investigated centipede gut contents of the same individuals for three prey taxa (collembolans, dipterans and earthworms) applying specific PCR assays. In this approach insight into mechanisms was deepened by including a second region, the Schorfheide-Chorin, and factors, such as prey abundance, litter mass and soil $\mathrm{pH}$ in the analyses. The results indicated that 
forest type did not affect prey choice, but factors representing habitat characteristics, such as litter mass and soil $\mathrm{pH}$, were responsible for differences. Similar to Chapter 2 the results suggest body size and habitat structure to act as important factors in trophic niche differentiation.

In Chapter 4 we investigated the use of carbon resources of ecologically different earthworm species being abundant decomposers in soil and preferred prey of centipedes (Chapters 2 and 3). Using compound-specific ${ }^{13} \mathrm{C}$ stable isotope analysis of fatty acids, we related earthworm ${ }^{13} \mathrm{C}$ signatures to resources of different stability. Endogeic earthworm species, in contrast to epigeic species, were found to predominantly assimilate recalcitrant carbon sources. Results also pointed to the utilisation of stable resources associated with clay attached to soil aggregates. This study revealed specific stable soil carbon pools to essentially contribute to nutrition of endogeic earthworm species.

In Chapter 5 we combined fatty acid and stable isotope analyses to investigate trophic niches of ecologically different collembolan species and their association with litter and root resources. Furthermore, we investigated feeding interactions by relating collembolan fatty acids to that of litter-dwelling microorganisms, which are regarded as major food resource. Results indicate that collembolans occupy several trophic niches acting as decomposers of litter- and root-derived resources as well as as predators. Moreover, we found collembolan fatty acid patterns to not correspond with that of microorganisms suggesting that they feed on specific microsites in soil keeping their trophic niche constant.

This thesis allowed insight into soil animals as generalistic species with distinct trophic niches. The three soil animal taxa occupying different trophic levels were documented to differ in strategies of resource utilisation and variation therein. Furthermore, the studies challenge the view of fixed energy channels with definite associated animal groups in soil food webs. Overall, this thesis considerably contributes to the understanding of soil food web structure and functioning. Using novel techniques it presented insights into trophic interactions on different trophic levels in an elegant way. 


\section{Chapter 1}

\section{General Introduction}

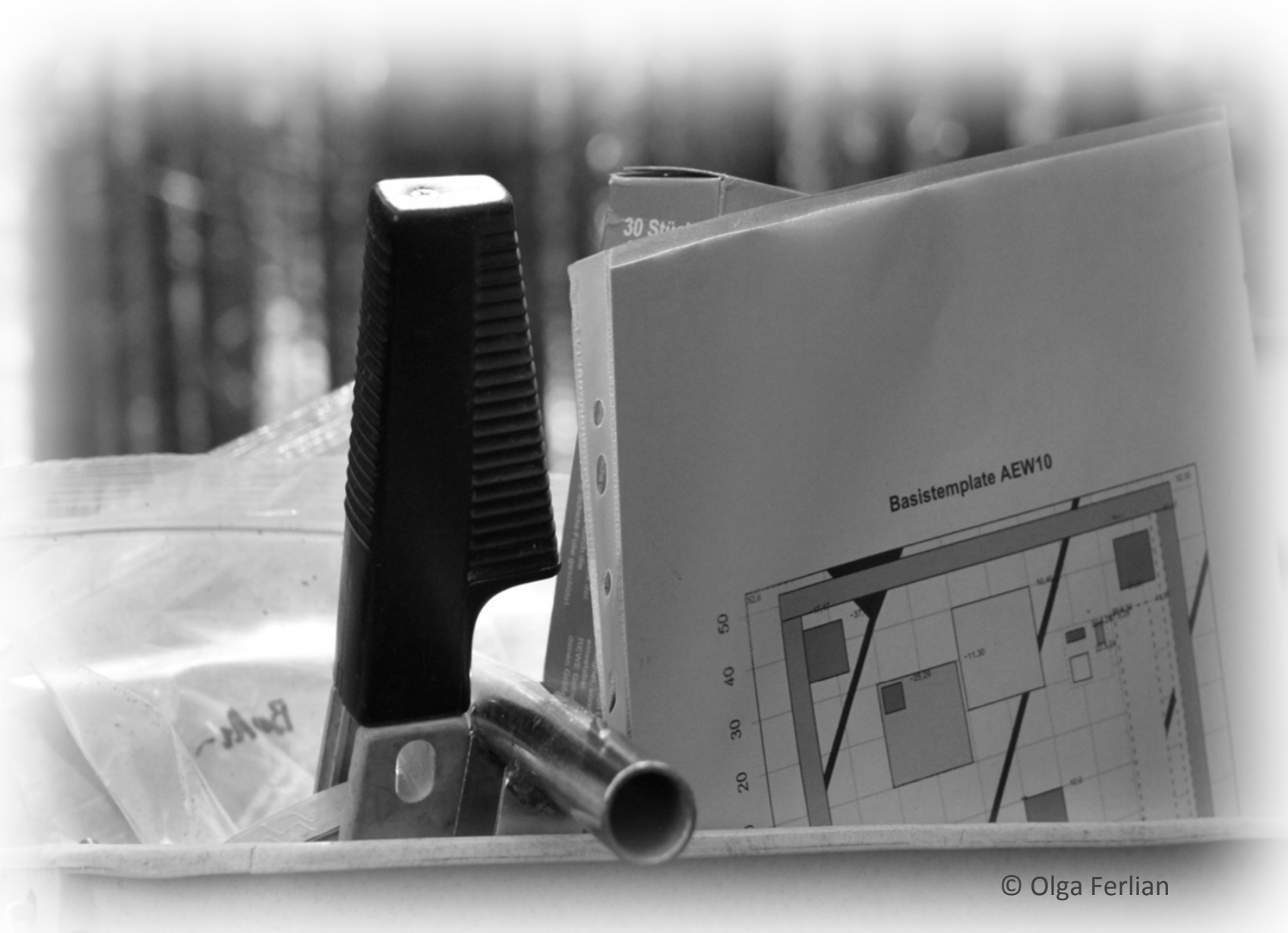


Forest soil food webs

Soil food webs are still poorly understood as they are opaque, complex and, therefore, difficult to disentangle. The soil system comprises a high diversity of coexisting species interacting in minimal space (Bardgett, 2005). However, the key components of soil food webs are not taxonomic species but functional guilds with one taxon possibly occupying multiple functional guilds (Scheu, 2002). The basis of the soil food web is formed by dead organic matter, such as plant litter material, functioning as major carbon source for decomposers. Decomposers comprise primary decomposers digesting plant residues, such as earthworms, and secondary decomposers, such as collembolans and mites, which ingest partly decomposed organic matter and predominantly assimilate litter-colonising microorganisms. Chemistry of litter varying with tree species markedly determines decomposition processes due to concentrations of different nutrients and compounds, such as nitrogen, lignin and indigestible polyphenol compounds (Hättenschwiler and Vitousek, 2000; Reich et al., 2005). Predators feed on different decomposer groups with rove beetles, gamasid mites, centipedes and spiders forming prominent predator groups. Generally, soil animals are assumed to be trophic generalists feeding on resources of even different trophic levels (Scheu and Setälä, 2002). The complex structure of soil habitats hampers locating specific resources and this results in feeding on a broad range of resources. However, within soil animal groups trophic niche differentiation exists with species utilising species-specific mixtures of resources as it was shown for collembolans, mites and centipedes (Chahartaghi et al., 2005; Maraun et al., 2011; Ferlian et al., 2012; Klarner et al., 2013).

It has been assumed that most decomposers rely on labile resources of high nutritional value, such as high quality litter and microorganisms. However, there is increasing evidence that recalcitrant carbon sources being physically and chemically stabilised in soil aggregates are mobilised by certain decomposer groups (Fox et al., 2006). This is well-studied for endogeic earthworms colonising deeper soil layers feeding predominantly on organic matter mixed with mineral soil (Scheu, 1991; Martin et al., 1992; Hyodo et al., 2008). Studying utilisation of recalcitrant carbon resources is essential to understand carbon cycling as these resources comprise the largest proportion of organic carbon in soil (Wolters, 2000).

Generally, plant carbon fuels the soil food web through two pathways: dead organic 
matter, i.e., leaf litter and dead roots, and rhizodeposits. Most studies assumed the litter pathway to be most important, however, recent studies suggest decomposer food webs to essentially rely on carbon resources derived from living roots (Ruf et al., 2006; Paterson et al., 2011; Pollierer et al., 2012). Recently, it has been proposed that the dominance of each of these pathways depends on habitat type, e.g., beech vs. spruce forests, with implications for biota on higher trophic levels (Klarner et al., 2014).

In soil food web studies, energy and nutrient fluxes from plant litter and roots can be tracked to top trophic levels using novel techniques such as fatty acid analysis (Pollierer et al., 2010). The soil food web has been suggested to be arranged in resource compartments which are represented by two main energy pathways, the bacterial and the fungal energy channel, comprising distinct species and different characteristics (Moore and Hunt, 1988). The latter is expected to dominate in forests. However, these channels are not entirely distinct and converge with progressing litter decomposition and at higher predator level. However, the relative contribution of soil biota to the different energy channels is still little understood and needs further research on species scale.

Analysis of trophic interactions in soil

Classical techniques, such as microscopic identification of gut contents and feeding experiments, examining trophic interactions and energy flows in soil food webs are increasingly replaced by novel molecular techniques. Stable isotope, fatty acid and molecular gut content analyses provide reliable time-integrated and indirect methods to unravel trophic linkages between cryptic organisms in opaque soil systems.

Stable isotope analysis is based on the facts that the ${ }^{13} \mathrm{C} /{ }^{12} \mathrm{C}$ ratio changes little between food resources and consumers and that fractionation of nitrogen leads to an enrichment of the heavier isotope $\left({ }^{15} \mathrm{~N}\right)$ from diet to consumer (about $3.4 \%$; Wada et al., 1991; Martinez del Rio et al., 2009). Consequently, by measuring ${ }^{13} \mathrm{C} /{ }^{12} \mathrm{C}$ and ${ }^{15} \mathrm{~N} /{ }^{14} \mathrm{~N}$ ratios of consumers trophic level and carbon sources, e.g., $\mathrm{C}_{3}$ vs. $\mathrm{C}_{4}$ plants and root- vs. litter-derived carbon sources, can be estimated. Variations in stable isotopes can be natural or due to isotopic labelling. However, a number of factors affect fractionation processes and have to be considered for interpreting stable isotope ratios in consumers (Boecklen et al., 2011). Furthermore, measuring basal resources of the 
system for identifying the baseline are indispensible but, especially in soil systems, are not easy to conduct (Traugott et al., 2013).

Fatty acid analysis has been used to estimate microbial community structure in litter and soil as well as to reveal energy channels and feeding strategies of animal consumers (e.g., Ruess and Chamberlain, 2010) even up to the predator level (Pollierer et al., 2010). It is energetically more efficient to incorporate fatty acids from the diet without modification into the consumer tissue and certain fatty acids, i.e., fatty acid biomarkers, cannot be synthesised by the consumer. This allows tracking fatty acids from food resources in consumers (dietary routing; Blem, 1976; Pond, 1981). Fatty acid biomarkers function either as absolute or as relative markers with the former being specific for certain food resources, such as gram-positive and gram-negative bacteria, and the latter being also present in other food resources or being synthesised in small proportions by the consumer (relative fungal and plant marker). Beside measuring fatty acid composition, approaches measuring ${ }^{13} \mathrm{C} /{ }^{12} \mathrm{C}$ ratios of fatty acids in consumers and resources are increasingly used $\left({ }^{13} \mathrm{C}\right.$ compound-specific stable isotope analysis). It provides additional information on the origin of resources that are utilised and, consequently, on the energy pathway the consumer is associated with.

The most recent technique is molecular gut content analysis which allows tracing prey DNA in predator guts even in small animals and predators performing extra-intestinal digestion (e.g., Juen and Traugott, 2007). Prey DNA is amplified using group- and species-specific primers and polymerase chain reaction (PCR) assays and the products are visualised via capillary or gel electrophoresis. As invertebrate predators in soil are assumed to be food generalists, tracing prey organisms in predator guts is costly and is, therefore, increasingly conducted using multiplex PCR assays allowing to screen more than ten prey organisms simultaneously (Harper et al., 2005). In contrast to other methods, molecular gut content analysis has not the advantage of reflecting long-term feeding and provides merely information on the ingested and not the assimilated prey ('snapshot method'). Furthermore, it is a qualitative approach based on presence and absence of prey not assessing quantities of prey ingested. However, compared to other techniques it provides data on trophic links up to species scale.

Overall, the three methods have strengths and weaknesses with each allowing to answer a range of questions. While fatty acid analysis judges channelling of resources 
through food webs, stable isotope analysis complements this method by delineating the trophic structure of the soil food web. Molecular gut content analysis allows fine scale resolution of trophic links between species. Using these three methods in parallel is crucial for understanding the structure and functioning of soil food webs.

\section{Soil fauna}

In the present studies we focussed on three key invertebrate taxa in soil, centipedes, earthworms and collembolans. Centipedes are among the dominating and most important arthropod predators in temperate forest soils but their feeding strategies are still poorly understood. They are known to feed on a variety of prey organisms with different life strategies including earthworms and collembolans. Earthworms and collembolans utilise distinct food resources and represent important links between basal resources and soil predators.

Centipedes are relatively species-poor despite their high abundances and consist of two major groups in Germany, the litter-associated Lithobiomorpha and the soilassociated Geophilomorpha, with both considerably differing in life history, ontogeny and nutrition (Ferlian et al., 2012). Different Lithobiomorpha species typically inhabit litter and soil layers (Poser, 1988) and are sit-and-wait predators feeding on mesofauna, such as mites and collembolans, as well as on macrofauna, such as earthworms and dipteran larvae (Wolters and Ekschmitt, 1997; B. Eitzinger, unpublished data). Recent studies using fatty acid analyses documented distinct trophic niches between species (Ferlian et al., 2012). Moreover, lithobiid species were found to be associated with different energy channels depending on the soil stratum they live in.

Another invertebrate key taxon in soil are earthworms which function as important ecosystem engineers structuring the habitat for other soil biota (Jones et al., 1994; Scheu and Setälä, 2002). Thereby, they affect microbial driven processes such as decomposition of organic matter and nutrient mineralisation via comminution of litter and mixing of litter and mineral soil (Edwards and Fletcher, 1988; Wolters, 2000). Earthworms are typically classified into three ecological groups (Bouché, 1977): epigeic earthworms inhabit the litter layer and consume predominantly litter; anecic earthworms form deep vertical burrows but predominantly feed on litter; endogeic 
earthworms inhabit the upper mineral soil and ingest mixtures of organic and mineral material. Especially endogeic earthworms have low assimilation efficiencies (1-2 \%) which they compensate by high ingestion rates (Scheu, 1991). By mixing organic material with mineral soil, moulding activities and excretion of mucus, earthworms form stable macro-aggregates (Barois, 1992; Marhan et al., 2007) that are not accessible to the majority of biota.

Collembolans are the most widespread decomposers in forest soils reaching densities up to one million individuals per square metre (Peterson and Luxton, 1982). Most of the collembolan species possess a furca that is used to increase mobility by shooting up and thus escaping from potential predators in soil. Species without a furca are assumed to be less palatable to predators. Similar to earthworms collembolan species have often been classified into three functional groups based on occurrence in different soil strata and morphological characteristics (epedaphic, hemiedaphic and euedaphic species; Hopkin, 1997). However, categorisation of collembolan species is often not consistent and functional groups do not reflect feeding strategies. Collembolans are food generalists feeding on a variety of resources, such as detritus, bacteria, fungi, algae and other soil animals (Lee and Widden, 1996; Hopkin, 1997) with fungi regarded as the most important diet (Jørgensen and Hedlund, 2013).

\section{Study site}

The present studies formed part of the ,Biodiversity Exploratories' (DFG priority program 1374), an integrated long-term and large-scale research project investigating land use effects on biodiversity and ecosystem functioning (Fischer et al., 2010). The project is a large interdisciplinary platform for researchers from all over Germany. The Biodiversity Exploratories project consists of three regions ('Exploratories') across Germany: the National Park Hainich and its surroundings in Central Germany (Thuringia), the Biosphere Reserve Schorfheide-Chorin in North-eastern Germany (Brandenburg) and the Biosphere Reserve Schwäbische Alb in South-western Germany (Baden-Württemberg). The Schorfheide-Chorin is on an altitude of $2-139$ $\mathrm{m}$ a.s.l. and the geology is represented by young glacial till. The soil type is predominantly Cambisol; $\mathrm{pH}$ ranges between 3.3 and 6.7; and mean annual temperature is about $8{ }^{\circ} \mathrm{C}$. The Hainich is on an altitude of $330-490 \mathrm{~m}$ a.s.l. with 
Triassic limestone overlain by loess as parent rock. The soil type is predominantly Luvisol; $\mathrm{pH}$ ranges between 4.0 and 5.5; and mean annual temperature is about $7{ }^{\circ} \mathrm{C}$. The Schwäbische Alb is on an altitude of 693 - $817 \mathrm{~m}$ a.s.l. with parent rock being Jurrasic shell limestone with karst phenomena. The soil type is Cambisol and Leptosol; $\mathrm{pH}$ ranges between 4.5 and 5.9; and mean annual temperature is about $6.5^{\circ} \mathrm{C}$.

For descriptive investigations as well as experimental manipulations, 50 forest and 50 grassland plots (each $100 \times 100 \mathrm{~m}$ ) per exploratory were selected out of a pool of 3000 plots representing different land use intensities. The present studies investigated a subset of 16 forest plots per Exploratory with four major land use intensities (referred to as forest types in the following): young beech forests ( $\sim 30$ year old age class stands), old-growth beech forests ( 70 year old age class stands), coniferous forests ( $\sim 70$ year old age class stands) and unmanaged (for at least 60 years) beech forests. The beech forests are dominated by European beech (Fagus sylvatica L.) interspersed with single Common ash (Fraxinus excelsior L.) and Sycamore maple trees (Acer pseudoplatanus L.). The coniferous forest sites are dominated by Norway spruce (Picea abies L.) in Hainich and Schwäbische Alb, whereas they are dominated by Scots pine (Pinus sylvestris L.) in Schorfheide-Chorin. Overall, due to its remarkable regional properties, such as parent rock, soil, humus type and plant species composition, the Schorfheide-Chorin is relatively distinct from the other two Exploratories.

\section{Objectives and chapter outline}

The objectives of this thesis were to examine utilisation of food resources and energy channels of important key invertebrate taxa as representatives of different trophic levels in the soil food web. We aimed at identifying trophic niches of closely related species and the driving factors for its variations. Using three novel techniques for the analysis of feeding interactions in predators, Chapters 2 and 3 aim at understanding structuring forces responsible for trophic niche differentiation in two coexisting closely related centipede species. In Chapter 4 food resources of seven earthworm species were examined with focus on soil aggregates as alternative carbon source for endogeic species. Earthworms are important primary decomposers in soil and are assumed to represent the major prey for centipedes. Thus, they act as important links between 
predators and basal resources in the soil food web. Chapter 5 examines trophic niches of six collembolan species with different life strategies and shifts in utilisation of food resources with habitat type. Similarly, collembolans are typical prey of centipedes but comprise, in contrast to earthworms, predominantly secondary decomposers and markedly different life strategies, such as smaller body size and higher mobility.

The following main hypotheses were tested:

(1) Coexisting and closely related centipede species, occupy distinct trophic niches which vary with forest type due to different habitat structure (Chapters $\mathbf{2}$ and $\mathbf{3}$ ).

(2) In this context, predator body size and prey abundance drive variation in trophic niche (Chapter 3).

(3) Endogeic earthworm species rely on stabilised soil organic matter pools associated with small soil particle fractions, such as clay, being presumably not accessible to other soil biota. In contrast, epigeic and anecic earthworm species rely on recently fixed carbon pools, such as leaf litter (Chapter 4).

(4) As abundant soil microarthropods collembolan species are associated with different energy channels; their trophic niches vary with forest type due to major shifts in microbial community structure (Chapter 5).

In the following a summary of each chapter is given:

Chapter 2. We investigated feeding strategies of the two centipede species Lithobius mutabilis and $L$. crassipes to identify their trophic niches and variations therein with forest type. In combination with body size measurements, we conducted stable isotope and fatty acid analyses on centipedes allowing insight into trophic levels and the utilisation of basal resources. The results indicated centipedes to occupy distinct trophic niches with the smaller species $L$. crassipes relying more on bacterial resources and root-derived carbon as compared to the larger species $L$. mutabilis. Differences in trophic niches were more pronounced in coniferous than in beech forests. Dense needle litter layer in coniferous forests may restrict access of the larger species to litterdwelling prey, whereas the smaller species exploits resources in lower soil layers, which are closely associated with the bacterial energy channel. The results suggest that habitat structure and body size may act as determinants for variations in trophic niches of soil arthropod predators. 
Chapter 3. Complementing the study in Chapter 2, we investigated centipede gut contents for three prey taxa (collembolans, dipterans and earthworms) of the same individuals applying specific PCR assays. In this approach insight into mechanisms was deepened by including a second Exploratory, the Schorfheide-Chorin, and factors, such as prey abundance, litter mass and soil pH in the analyses. The results indicated that forest type did not affect prey choice, but factors representing habitat characteristics, such as litter mass and soil $\mathrm{pH}$, were responsible for differences. Similar to Chapter 2, effects of litter mass on centipedes differed between the two species with the smaller species benefitting from higher litter mass, whereas the larger species took advantage of higher prey abundance. Similar to Chapter 2 the results suggest body size and habitat structure to act as important factors in trophic niche differentiation.

Chapter 4. We investigated the use of carbon resources of ecologically different earthworm species being abundant decomposers in soil and preferred prey of centipedes (Chapters 2 and 3). Using compound-specific ${ }^{13} \mathrm{C}$ stable isotope analysis of fatty acids, we related earthworm ${ }^{13} \mathrm{C}$ signatures to resources of different stability, such as litter, bulk soil and different soil particle size fractions. Endogeic earthworm species, in contrast to epigeic species, were found to predominantly assimilate recalcitrant carbon sources. Results also pointed to the utilisation of stable resources associated with clay attached to soil aggregates. This study revealed specific stable soil carbon pools to essentially contribute to nutrition of endogeic earthworm species.

Chapter 5. Combining fatty acid and stable isotope analyses, we investigated trophic niches of ecologically different collembolan species and their association with litter and root resources. Furthermore, we investigated feeding interactions by relating collembolan fatty acids to that of litter-dwelling microorganisms, which are regarded as major food resource. Results indicate that collembolans occupy several trophic niches acting as decomposers of litter- and root-derived resources as well as as predators. Moreover, we found collembolan fatty acid patterns to not correspond with that of microorganisms over different forest types suggesting that they feed on specific microsites in soil keeping their trophic niche constant. 


\section{References}

Bardgett, R.D., 2005. The biology of soil - A community and ecosystem approach. Oxford University Press, Oxford.

Barois, I., 1992. Mucus production and microbial activity in the gut of two species of Amynthas (Megascolecidae) from cold and warm tropical climates. Soil Biology \& Biochemistry 24, 1507 - 1510.

Blem, C.R., 1976. Patterns of lipid storage and utilization in birds. American Zoologist 16, 671-684.

Boecklen, W.J., Yarnes, C.T., Cook, B.A., James, A.C., 2011. On the Use of Stable Isotopes in Trophic Ecology. Annual Review of Ecology, Evolution and Systematics 42, $411-440$.

Bouché, M.B., 1977. Stratégies lombriciennes. In: Lohm, U., Persson, T. (Eds.), Soil Organisms as Components of Ecosystems. Ecological Bulletins, Stockholm, pp. $122-132$.

Chahartaghi, M., Langel, R., Scheu, S., Ruess, L., 2005. Feeding guilds in Collembola based on nitrogen stable isotope ratios. Soil Biology \& Biochemistry $37,1718-$ 1725.

Edwards, C.A., Fletcher, K.E., 1988. Interactions between earthworms and microorganisms in organic-matter breakdown. Agriculture Ecosystems \& Environment 24, $235-247$.

Ferlian, O., Scheu, S., Pollierer, M.M., 2012. Trophic interactions in centipedes (Chilopoda, Myriapoda) as indicated by fatty acid patterns: Variations with life stage, forest age and season. Soil Biology \& Biochemistry 52, $33-42$.

Fischer, M., Bossdorf, O., Gockel, S., Hänsel, F., Hemp, A., Hessenmöller, D., Korte, G., Nieschulze, J., Pfeiffer, S., Prati, D., Renner, S. et al. 2010. Implementing large-scale and long-term functional biodiversity research: The Biodiversity Exploratories. Basic and Applied Ecology 11, 473 - 485.

Fox, O., Vetter, S., Ekschmitt, K., Wolters, V., 2006. Soil fauna modifies the recalcitrance-persistence relationship of soil carbon pools. Soil Biology \& Biochemistry 38, $1353-1363$.

Harper, G., King, R., Dodd, C., Harwood, J., Glen, D., Bruford, M., Symondson, W.O.C., 2005. Rapid screening of invertebrate predators for multiple prey DNA targets. Molecular Ecology 14, 819 - 827.

Hättenschwiler, S., Vitousek, P.M., 2000. The role of polyphenols in terrestrial ecosystem nutrient cycling. Trends in Ecology and Evolution 15, 238 - 243.

Hopkin, S.P., 1997. Biology of the Springtails (Insecta: Collembola). Oxford University Press, Oxford.

Hyodo, F., Tayasu, I., Konaté, S., Tondoh, J.E., Lavelle, P., Wada, E., 2008. Gradual enrichment of ${ }^{15} \mathrm{~N}$ with humification of diets in a below-ground food web: relationship between ${ }^{15} \mathrm{~N}$ and diet age determined using ${ }^{14} \mathrm{C}$. Functional Ecology $22,516-522$.

Jones, C.G., Lawton, J.H., Shachak, M., 1994. Organisms as Ecosystem Engineers. Oikos 69, $373-386$.

Jørgensen, H.B., Hedlund, K., 2013. Organic amendment and fungal species in 
combination can alter collembolan fitness. Soil Biology \& Biochemistry 65, 316 $-321$.

Juen, A., Traugott, M., 2007. Revealing species-specific trophic links in soil food webs: molecular identification of scarab predators. Molecular Ecology 16, 1545 1557.

Klarner, B., Ehnes, R.B., Erdmann, G., Eitzinger, B., Pollierer, M.M., Maraun, M., Scheu, S., 2014. Trophic shift of soil animal species with forest type as indicated by stable isotope analysis. Oikos, doi: 10.1111/j.1600- 5150706.2013.00939.x.

Klarner, B., Maraun, M., Scheu, S., 2013. Trophic diversity and niche partitioning in a species rich predator guild - natural variations in stable isotope ratios $\left({ }^{13} \mathrm{C} /{ }^{12} \mathrm{C}\right.$, ${ }^{15} \mathrm{~N} /{ }^{14} \mathrm{~N}$ ) of mesostigmatid mites (Acari, Mesostigmata) from central European beech forests. Soil Biology \& Biochemistry 57, 327 - 333.

Lee, Q., Widden, P., 1996. Folsomia candida, a fungivorous collembolan, feeds preferentially on nematodes rather than soil fungi. Soil Biology \& Biochemistry $28,689-690$.

Maraun, M., Erdmann, G., Fischer, B.M., Pollierer, M.M., Norton, R.A., Schneider, K., Scheu, S., 2011. Stable isotopes revisited: Their use and limits for oribatid mite trophic ecology. Soil Biology \& Biochemistry 43, $877-882$.

Marhan, S., Langel, R., Kandeler, E., Scheu, S., 2007. Use of stable isotopes $\left({ }^{13} \mathrm{C}\right)$ for studying the mobilisation of old soil organic carbon by endogeic earthworms (Lumbricidae). European Journal of Soil Biology 43, 201 - 208.

Martin, A., Mariotti, A., Balesdent, J., Lavelle, P., 1992. Soil organic matter assimilation by a geophagous tropical earthworm based on ${ }^{13} \mathrm{C}$ measurements. Ecology 73 , $118-128$.

Martinez del Rio, C., Wolf, N., Carleton, S. A., Gannes, L. Z., 2009. Isotopic ecology ten years after a call for more laboratory experiments. Biological Reviews 84, $91-111$.

Moore, J.C., Hunt, H.W., 1988. Resource compartmentation and the stability of real ecosystems. Nature 333, $261-263$.

Paterson, E., Sim, A., Osborne, S.M., Murray, P.J., 2011. Long-term exclusion of plantinputs to soil reduces the functional capacity of microbial communities to mineralise recalcitrant root-derived carbon sources. Soil Biology \& Biochemistry $43,1873-1880$.

Petersen, H., Luxton, M., 1982. Quantitative ecology of microfungi and animals in soil and litter. Oikos 39, 287-388.

Pollierer, M.M., Dyckmans, J., Scheu, S., Haubert, D., 2012. Carbon flux through fungi and bacteria into the forest soil animal food web as indicated by compoundspecific ${ }^{13} \mathrm{C}$ fatty acid analysis. Functional Ecology 26, $978-990$.

Pollierer, M.M., Scheu, S., Haubert, D., 2010. Taking it to the next level: Trophic transfer of marker fatty acids from basal resource to predators. Soil Biology \& Biochemistry 42, $919-925$.

Pond, C.M., 1981. Storage. In: Townsend, C.R., Calow, P. (Eds.), Physiological Ecology: an Evolutionary Approach to Resource Use. Blackwell, London, pp. $190-219$.

Poser, T., 1988. Chilopoden als Prädatoren in einem Laubwald. Pedobiologia 31, 261 
$-281$.

Reich, P.B., Oleksyn, J., Modrzynski, J., Mrozinski, P., Hobbie, S.E., Eissenstat, D.M., Chorover, J., Chadwick, O.A., Hale, C.M., Tjoelker, M.G., 2005. Linking litter calcium, earthworms and soil properties: a common garden test with 14 tree species. Ecology Letters 8, 811 - 818.

Ruess, L., Chamberlain, P.M., 2010. The fat that matters: Soil food web analysis using fatty acids and their carbon stable isotope signature. Soil Biology \& Biochemistry 42, $1898-1910$.

Ruf, A., Kuzyakov, Y., Lopatovskaya, O., 2006. Carbon fluxes in soil food webs of increasing complexity revealed by ${ }^{14} \mathrm{C}$ labelling and ${ }^{13} \mathrm{C}$ natural abundance. Soil Biology \& Biochemistry 38, $2390-2400$.

Scheu, S., 1991. Mucus excretion and carbon turnover of endogeic earthworms. Biology and Fertility of Soils 12, $217-220$.

Scheu, S., 2002. The soil food web: Structure and perspectives. European Journal of Soil Biology 38, $11-20$.

Scheu, S., Setälä, H., 2002. Multitrophic interactions in decomposer foodwebs. In: Tscharntke, T., Hawkins, B.A. (Eds.), Multitrophic level interactions. Cambridge University Press, Cambridge, pp. 223 - 264.

Traugott, M., Kamenova, S., Ruess, L., Seeber, J., Plantegenest, M., 2013. Empirically characterising trophic networks: what emerging DNA-based methods, stable isotope and fatty acid analyses can offer. Advances in Ecological Research 49, $177-224$.

Wada, E., Mizutani, H., Minagawa, M., 1991. The use of stable isotopes for food web analysis. Critical Reviews in Food Science and Nutrition 30, 361 - 371.

Wolters, V., 2000. Invertebrate control of soil organic matter stability. Biology and Fertility of Soils 31, $1-19$.

Wolters, V., Ekschmitt, K., 1997. Gastropods, isopods, diplopods and chilopods: neglected groups of the decomposer food web. In: Benksier, G. (Ed.), Fauna in Soil Ecosystems: Recycling processes, Nutrient Fluxes and Agricultural Production. Marcel Dekker, New York, USA, pp. 265 - 306. 


\section{Chapter 2}

Shifts in trophic interactions with forest type in soil generalist predators as indicated by complementary analyses of fatty acids and stable isotopes

Olga Ferlian and Stefan Scheu Oikos (2014), published

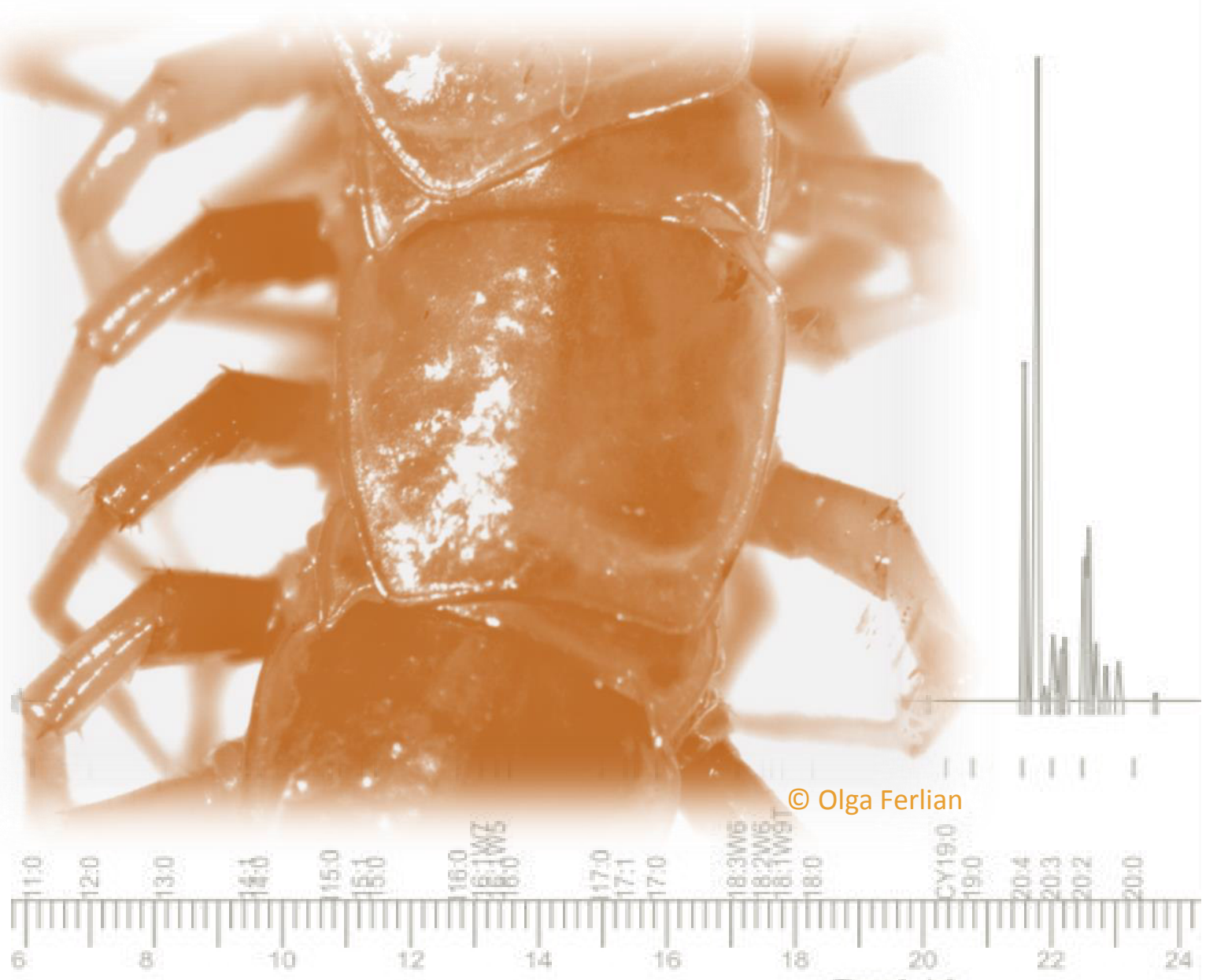




\section{Abstract}

Human impact on structure and functioning of ecosystems is rapidly increasing. Virtually all European forests are managed with major implications for diversity and structure of food webs. Centipedes (Chilopoda: Lithobiidae) are abundant arthropod predators in European temperate forest soils with a generalistic feeding behaviour. However, little is known on the variability in the prey spectrum of centipedes with land use and the responsible factors. Combining fatty acid (FA) analysis, which allows determination of the relative contribution of different prey to predator nutrition, and stable isotope analysis, providing insight into the trophic structure of decomposer food webs, we investigated variations in trophic niches of two dominant centipede species, Lithobius mutabilis and Lithobius crassipes, in differently aged beech and spruce forests. FA composition of the two centipede species differed significantly with bacterial marker FAs being more abundant in L. crassipes as compared to L. mutabilis. Differences were most pronounced in spruce as compared to beech forests. The results suggest that dense needle litter in coniferous forests may restrict prey availability to the larger $L$. mutabilis and confine foraging to the litter surface whereas the smaller $L$. crassipes is able to also exploit prey of deeper litter layers. $L$. crassipes was significantly more enriched in ${ }^{15} \mathrm{~N}$ and ${ }^{13} \mathrm{C}$ compared to $L$. mutabilis suggesting that, compared to $L$. mutabilis, the smaller $L$. crassipes occupies higher trophic levels and relies more on root derived carbon. The results indicate that trophic niches of centipedes vary in a species specific way between forest types with body size and habitat structure being major determinants of the variations in the prey spectrum. Combining techniques for delineating predator - prey interactions allowed insights into variations in trophic interrelationships and their driving forces in temperate forest soil food webs.

Key-words: Beech forest, Habitat structure, Predator-prey interactions, Soil food web, Spruce forest, Trophic niche 


\section{Introduction}

Disentangling trophic interactions in soils posed a challenge for decades due to the complexity of soil food webs - especially in forests - and the difficulty of observing small sized soil organisms in situ (Scheu and Falca 2000, Scheu and Setälä 2002, Bardgett 2005). Soil food webs are based on a variety of basal resources such as bacteria and fungi. Soil animal species are linked to these basal resources either by feeding on them directly or by consuming prey relying on these resources. Thereby, soil food webs are compartmentalised into bacterial and fungal energy channels contributing to food web stability (Moore et al. 2005). Soil food webs are assumed to be typically driven by bottom-up forces, i.e. by the availability of resources, and exploitation competition presumably is of major importance (Hairston et al. 1960, Scheu and Setälä 2002). Therefore, species relying on similar resources are likely to exclude each other ('competitive exclusion principle'; Gause and Witt 1935). According to niche theory, even closely related species need to differ in some niche dimensions to allow coexistence (Hutchinson 1957). In soil, important niche dimensions include vertical distribution and body size. In centipedes, the often coexisting species Lithobius mutabilis (Koch) and Lithobius crassipes (Koch) indeed differ in both depth distribution and body size with the first being larger and colonising litter, and the second being smaller and colonising deeper soil layers (Poser 1988).

Soil food webs typically are constructed by using large taxonomic groups as trophic species neglecting differences in trophic niches between closely related species (Schröter et al. 2003). Ferlian et al. (2012) showed trophic interrelationships and associations of centipede species to differ between species, and to change with life stage and season. However, further research at the level of species is needed to understand variations in trophic interrelationships and niche differentiation of coexisting closely related species within soil food webs, and to uncover the driving forces responsible for these changes.

Abiotic and biotic characteristics differ markedly between forests of different tree species and management (Paquin and Coderre 1997, Scheu et al. 2003). Differences in the chemistry of litter of different tree species determine decomposition processes with pronounced differences between litter of coniferous as compared to deciduous tree species. Due to high concentrations of polyphenol compounds, needle litter decomposes slowly and forms thick organic layers thereby altering the habitat of soil 
animal species (Hättenschwiler and Vitousek 2000, Scheu et al. 2003). Notably, much of the deciduous forest in Europe has been replaced by conifers since the beginning of industrialisation and the associated increase in timber use. Also, microbial communities change with forest management as indicated by increasing fungal-tobacterial phospholipid fatty acid (PLFA) ratios in older stands (Pennanen et al. 1999, Moore-Kucera and Dick 2008). These changes are likely to propagate into higher trophic levels which is supported by decomposer animal communities responding sensitively to forest age and type (Scheu et al. 2003, Cesarz et al. 2013; Digel et al. this issue, Klarner et al. this issue).

Centipedes (Lithobiidae) are among the most important arthropod predators in temperate forest soils (Poser 1988) preying on various soil detritivores. Detritivores comprise primary decomposers living on plant detritus itself and secondary decomposers predominantly feeding on bacteria or fungi (Scheu and Falca 2000, Pollierer et al. 2012). By feeding on detritivores, carbon from bacteria and fungi is channelled to higher trophic levels of the soil food web (Moore et al. 2005, Pollierer et al. 2012). However, little is known on variations in the channeling of bacterial vs. fungal carbon to higher trophic levels and, therefore, for predator nutrition, and to what extent this channelling varies between predator species. Comparing lithobiomorph and geophilomorph centipedes, Ferlian et al. (2012) found lithobiomorphs to more heavily rely on fungal and geophilomorphs to more heavily rely on bacterial feeding prey. These differences are likely to be related to differences in body size and shape of consumers restricting prey capture and driving predator - prey interactions (Rall et al. 2011, Toscano and Griffen 2013, Lang et al. this issue). In soil, the role of body size as driving factor for predator - prey interactions is likely to vary with habitat structure and therefore with forest type as major determinant of soil structure and humus form (Scheu et al. 2003, Ponge 2013).

Advances in methods for investigating food webs have opened new perspectives for tracing feeding strategies of soil arthropods in the field. Fatty acid (FA) analysis, stable isotope analysis and molecular gut content analysis have revolutionised soil food web research. FA analysis allows tracing diets of consumers and, hence, food web links by tracking FAs from one trophic level to another (Ruess and Chamberlain 2010, Thiemann et al. 2011). Assimilated FAs from the diet are incorporated into consumer neutral lipids without change and, therefore, reflect the FA composition of the food 
source ('dietary routing'; Blem 1976, Pond 1981). Certain neutral lipid FAs serve as absolute markers as they exclusively originate from the diet and thereby reflect prey taxa allowing for identification of e.g., feeding on gram-positive and on gram-negative bacteria (Ruess et al. 2005). Further, FAs can serve as relative biomarkers synthesised by consumers but reaching higher concentrations if present in the diet allowing for detection of feeding on plants and fungi (Ruess et al. 2007, Ruess and Chamberlain 2010). Recently, FAs have been tracked over three trophic levels in the field allowing for identification of the contribution of basal resources to predator nutrition in soil food webs (Haubert et al. 2009, Pollierer et al. 2010, Ferlian et al. 2012). Analyses of natural variations in stable isotopes provide insight into trophic levels as well as carbon utilisation of decomposer communities within food webs and may, therefore, complement FA analysis exploring only energy flow from one trophic level to another, i.e. energy channels.

This study aims at analysing variations in trophic niches of two abundant and closely related soil invertebrate predators with forest type and habitat structure. We employed complementary methodologies, i.e. stable isotope $\left({ }^{13} \mathrm{C}\right.$ and $\left.{ }^{15} \mathrm{~N}\right)$ and FA analysis, for analysing variations in the trophic position and association to fungal vs. bacterial energy channels, respectively, in the two differently sized centipede species $L$. mutabilis and $L$. crassipes. Further, in a parallel study employing molecular gut content analysis, links between these two predator species and prey taxa were identified (Günther et al. this issue). We hypothesised that trophic niches of the two centipede species vary with forest type due to differences in habitat structure. Further, we expected the prey spectrum of the two predators to vary with forest type with the fungal energy channel being more pronounced in spruce as compared to beech forests thereby reflecting differences in the dominance of fungi as compared to bacteria between spruce and beech forests.

\section{Materials and methods}

\section{Study sites}

The study was set-up in the Hainich, a mountain range in Thuringia in eastern Germany of an altitude of 330-490 m a.s.l. The study formed part of the "Biodiversity Exploratories", an integrated research project on biodiversity and ecosystem 
functioning. Sedimentary rock is formed by Mesozoic cuesta landscape overlain by limestone and loess. The soil type is mostly luvisol with $\mathrm{pH}$ ranging from 4.0 to 5.5. Mean annual temperature is about $7^{\circ} \mathrm{C}$. Sixteen different forest sites were investigated, four young beech forests of an age of about 30 years, four old beech forests of an age of about 70 years, four unmanaged beech forests of an age of at least 120 years and four coniferous forests (spruce) of an age of about 70 years. The beech forest sites are dominated by European beech (Fagus sylvatica L.) interspersed with single ash (Fraxinus excelsior L.) and maple trees (Acer Pseudoplatanus L.). The herb and shrub layer predominantly consists of Allium ursinum (L.), Anemone nemorosa (L.), Galium odoratum ((L.) Scopoli) and blackberry (Rubus spec.) being mainly present at the unmanaged forest sites. The herb layer of the spruce forests (Picea abies L.) comprises Dryopteris dilatata ((Hoffm.) A. Gray), Impatiens parviflora (DC.) and Oxalis acetosella (L.). The shrub layer comprises mainly Rubus idaeus (L.) and seedlings of European beech.

\section{Sampling of centipedes}

Adult lithobiid centipedes were sampled at each of the sites by sieving litter through 18 $\mathrm{mm}$ mesh and collecting them by hand. Animals were transferred individually into Eppendorf tubes and stored in a cool box to reduce metabolism and avoid regurgitation of prey. In the laboratory, animals were frozen at $-21^{\circ} \mathrm{C}$ until identification and processing. The structure of soil microbial communities was analysed by phospholipid fatty acid (PLFA) analysis. Three soil cores were taken at each site and divided into litter layer and upper soil layer. Samples were transferred to the laboratory and stored at $-21^{\circ} \mathrm{C}$ until analysis.

We focused on the two dominant lithobiid species, $L$. crassipes and $L$. mutabilis. As $L$. mutabilis was more abundant than $L$. crassipes, six individuals per site of the former and five individuals per site of the latter were analysed. Prior to analysis, we measured body length, cleared the animals from attached particles and parasitic mites, and cut the body into three parts. The head capsule including antennae and the hind part were used for stable isotope analysis and FA analysis, respectively. The mid part was used for molecular gut content analysis (see Günther et al. this issue). 


\section{Analysis of fatty acids}

For characterising soil and litter microorganisms PLFAs were analysed as described in Frostegård et al. (1993), whereas for analysing lithobiid diets neutral lipid FAs (NLFAs) were analysed. Lipids in lithobiids were extracted and fractionated into phospholipids and neutral lipids as described in Haubert et al. (2004). PLFAs and NLFAs were dried at $50^{\circ} \mathrm{C}$ in a rotation vacuum concentrator (RVC 2-25, Christ, Osterode am Harz, Germany). Lipid fractions were saponified, methylated and washed following the protocols for the Sherlock Microbial Identification System (MIDI Inc., Newark, USA). The obtained FA methyl esters (FAMEs) of soil, litter and lithobiids were transferred into vials, capped and stored at $-21^{\circ} \mathrm{C}$ until analysis by gas chromatography (Clarus 500, Perkin Elmer, Waltham, USA). The gas chromatograph was equipped with helium as carrier gas and a flame ionisation detector (PE-5 capillary column, Perkin Elmer, Waltham, USA; $30 \mathrm{~m} \times 0.32 \mathrm{~mm}$ i.d.; $0.25 \mu \mathrm{m}$ film thickness). The measurement programme started with a temperature of $60^{\circ} \mathrm{C}$, first increased to $160^{\circ} \mathrm{C}\left(30^{\circ} \mathrm{C}\right.$ per minute) and subsequently to $260^{\circ} \mathrm{C}\left(3^{\circ} \mathrm{C}\right.$ per minute). FAMEs were identified by retention time and comparison with standard mixtures containing unbranched FAMEs ( $\mathrm{C}_{4}-\mathrm{C}_{24}$ chains) and bacterial FAMEs (Sigma-Aldrich, St.Louis, USA). The methylbranched FAs i15:0, a15:0, i16:0 and i17:0 and the cyclic FAs cy 17:0 and cy19:0 served as marker FAs for gram-positive and gram-negative bacteria, respectively. The

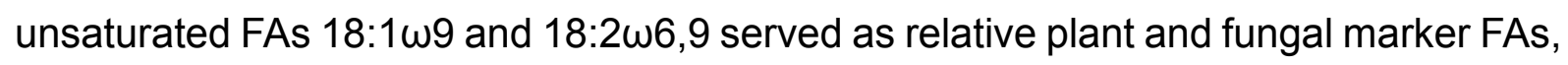
respectively. The ratio between these two marker FAs was used to distinguish between plant and fungal dominated diet (Ruess and Chamberlain 2010).

\section{Stable isotope analysis}

Centipede heads were transferred into tin capsules and dried at $105^{\circ} \mathrm{C}$ for $24 \mathrm{~h}$ before analysing natural variations in ${ }^{13} \mathrm{C} /{ }^{12} \mathrm{C}$ and ${ }^{15} \mathrm{~N} /{ }^{14} \mathrm{~N}$ ratios. In total, 162 samples of $L$. mutabilis and $L$. crassipes were analysed. Additionally, litter samples of the respective forest sites were homogenised, dried at $105^{\circ} \mathrm{C}$ for $24 \mathrm{~h}$, ground with a ball mill (MM200, Retsch, Haan, Germany) and transferred into tin capsules for stable isotope analysis. These measurements were used for calibration of the isotopic signature of the animals from different forests (Klarner et al. this issue). Isotope analyses were performed by an elemental analyser (NA 1500, Carlo Erba, Mailand, Italy) coupled to a mass 
spectrometer (Delta V Plus, Thermo Fisher, Bremen, Germany). Stable isotope signatures are expressed using the $\delta$ notation with $\delta X(\%)=\left(R_{\text {sample }}-R_{\text {standard }}\right) / R_{\text {standard }}$ $\times 1000$, with $X$ being the target isotope and $R$ being the heavy-to-light isotope ratio $\left({ }^{13} \mathrm{C} /{ }^{12} \mathrm{C}\right.$ or $\left.{ }^{15} \mathrm{~N} /{ }^{14} \mathrm{~N}\right)$. PD belemnite and atmospheric nitrogen served as primary standard for ${ }^{13} \mathrm{C}$ and ${ }^{15} \mathrm{~N}$, respectively. For internal calibration Acetanilide (Merck, Darmstadt, Germany) was used.

\section{Statistical analysis}

Percentage values of neutral lipid FAs (NLFAs) and PLFAs were logit-transformed and non-metric multidimensional scaling (NMDS) was used to reduce dimensions of the data. FA profiles were analysed using discriminant function analysis (DFA). If DFA was significant, proportions of individual FAs were inspected by single factor analysis of variance (ANOVA). Means were compared using Tukey's Honestly Significant Difference (HSD) test. Furthermore, variations in FA composition were inspected using multivariate analysis of covariance with body size as covariate (log-transformed) which is represented as proportion of the total variation ( $x \%=$ (sums of squarestreatment $/$ sums of squarestotal) * 100) accounting for by body size. For comparisons of $\delta^{13} \mathrm{C}$ and $\delta^{15} \mathrm{~N}$ signatures two-factorial multivariate analysis of variance (MANOVA) with the factors species and forest type was performed. Further, variances of the signatures within each site were calculated for both species, and forest types were compared using twofactorial ANOVA. Statistical analyses were conducted using STATISTICA 7.1 for Windows (StatSoft Inc, Tulsa, OK, USA).

\section{Results}

\section{FA patterns}

Variations between species

FA composition of $L$. mutabilis and $L$. crassipes differed significantly between each other in both beech and spruce forests (DFA; $F_{84,243}=5.64, P<0.0001$; Fig. 1a). Differences between species were more pronounced in spruce as compared to 


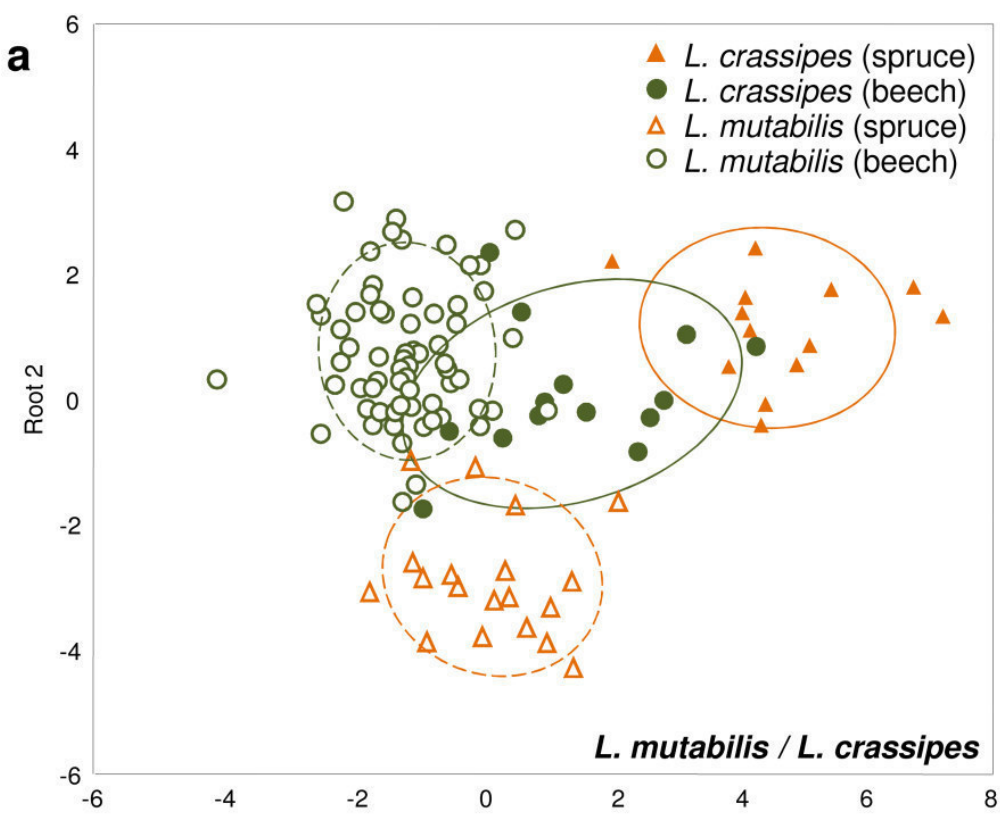

Fig. 1 | Discriminant function analysis of NLFAs of (a) Lithobius mutabilis and Lithobius crassipes in beech and spruce forests, (b) Lithobius mutabilis in young, old and unmanaged beech forests and spruce forests (c) $L$. crassipes in young, old and unmanaged beech forests and spruce forests. Ellipses represent confidence ranges at $P=0.3$.
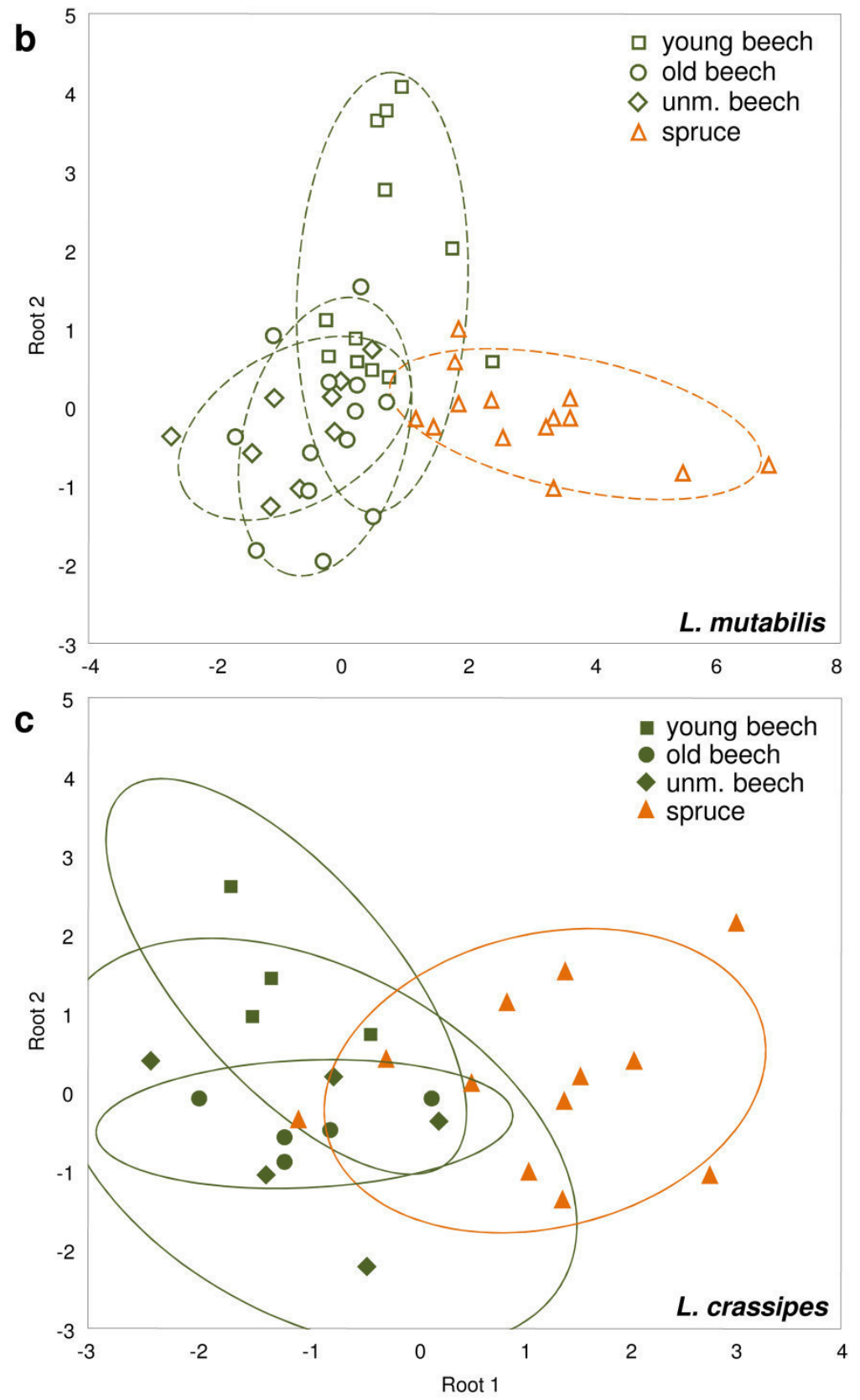


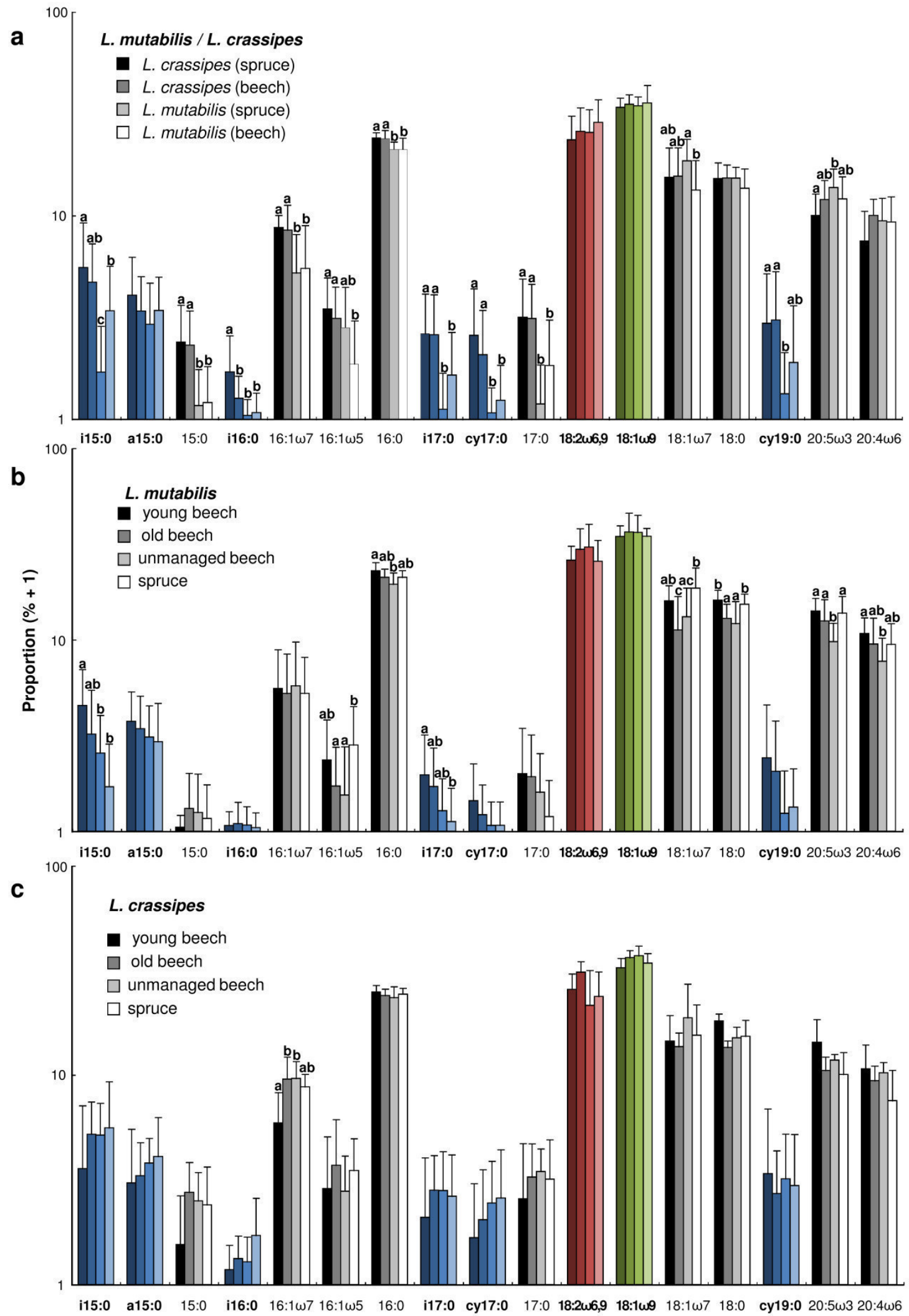

Fig. 2 Concentrations (percentages of total \pm SD; note log scale) of NLFAs of (a) Lithobius mutabilis and Lithobius crassipes in beech and spruce forests, (b) Lithobius mutabilis in young, old and unmanaged beech forests and spruce forests, and (c) L. crassipes in young, old and unmanaged beech forests and spruce forests. Different letters represent significant differences (Tukey's Honestly Significant Difference test; $P<0.05$ ); bacterial marker FAs are given in blue, fungal marker FAs in red and plant marker FAs in green. 
Table 1 | Squared Mahalanobis distances between group centroids and reliability of discrimination for NLFA composition of the centipede species Lithobius mutabilis and Lithobius crassipes in beech and spruce forests, respectively.

\begin{tabular}{llll}
\hline & $\begin{array}{l}\text { L. mutabilis } \\
\text { (beech) }\end{array}$ & $\begin{array}{l}\text { L. mutabilis } \\
\text { (spruce) }\end{array}$ & $\begin{array}{l}\text { L. crassipes } \\
\text { (beech) }\end{array}$ \\
\hline L. mutabilis (spruce) & $13.77^{* * *}$ & - & $18.69^{* * *}$ \\
L. crassipes (beech) & $14.67^{* * *}$ & $18.69^{* * *}$ & - \\
L. crassipes (spruce) & $32.57^{* * *}$ & $34.16^{* * *}$ & $20.63^{* * *}$ \\
\hline
\end{tabular}

*** $P<0.0001$

beech forests $\left(F_{28,81}=6.86, P<0.0001\right.$ and $F_{28,81}=4.54, P<0.0001$, respectively; Table 1). Furthermore, FA composition varied significantly with body size (L. mutabilis: $\varnothing 10.9 \pm 1.5 \mathrm{~cm}$; L. crassipes: $\varnothing 7.5 \pm 0.3 \mathrm{~cm}$ ) and body size accounted for $32.7 \%$ of the total variation in FA composition $\left(F_{29,129}=2.20, P<0.002\right)$. The bacterial marker FAs (i15:0, i16:0, i17:0, cy17:0 and cy19:0) contributed most to separation of the species (Fig. 2a). In both forests they were more abundant in $L$. crassipes than in $L$. mutabilis $\left(F_{3,108}=7.68, P<0.0001, F_{3,108}=10.48, P<0.0001, F_{3,108}=7.54, P<0.0002\right.$, $F_{3,108}=9.94, P<0.0001$ and $F_{3,108}=4.46, P<0.005$ for FAs i15:0, i16:0, i17:0, cy17:0 and cy 19:0, respectively; see Supplementary material, Table S1). Only the amount of FA i16:0 was highest in $L$. mutabilis in spruce forests and at similar low levels in each of the other treatments $\left(F_{3,108}=10.48, P<0.0001\right)$. The ratio between plant and fungal marker FAs was higher in L. crassipes than in L. mutabilis irrespective of the forest type ( $L$. crassipes in spruce and beech: $2.06 \pm 2.36$ and $1.67 \pm 1.22$; L. mutabilis in spruce and beech: $1.34 \pm 0.30$ and $\left.1.27 \pm 0.27 ; F_{3,104}=2.91, P<0.04\right)$.

\section{Variations between forest types}

FA composition of $L$. mutabilis differed significantly between forest types (DFA after NMDS; reduced to six dimensions; $F_{18,110}=5.22, P<0.0001$; Fig. $\left.1 \mathrm{~b}\right)$. Differences in FA composition were most pronounced between the three beech forests and the spruce forest $\left(F_{6,39}=7.55, P<0.0001, F_{6,39}=8.39, P<0.0001\right.$ and $F_{6,39}=8.99, P<$ 0.0001 for young, old and unmanaged beech; Table 2). In single FAs, differences were pronounced in i15:0, i17:0 and cy19:0 (Fig. 2b). Amounts of the bacterial

marker FAs were highest in young, intermediate in old and unmanaged beech forests, 
Table 2 | Mahalanobis distances between group centroids and reliability of discrimination for NLFA composition of the centipede species Lithobius mutabilis and Lithobius crassipes and for PLFA composition of litter and soil in young, old and unmanaged beech forests and spruce forests.

\begin{tabular}{lllll}
\hline & & young beech & old beech & $\begin{array}{l}\text { unmanaged } \\
\text { beech }\end{array}$ \\
\hline \multirow{2}{*}{ L. mutabilis } & old beech & $5.32^{* *}$ & - & 0.91 \\
& unmanaged beech & $5.94^{* *}$ & 0.91 & - \\
& spruce & $7.91^{* * *}$ & $8.42^{* * *}$ & $11.1^{* * *}$ \\
L. crassipes & old beech & 4.05 & - & 0.48 \\
& unmanaged beech & 4.89 & 0.48 & - \\
litter & spruce & $7.91^{*}$ & $5.42^{*}$ & $5.48^{*}$ \\
& old beech & 5.54 & - & $13.46^{*}$ \\
& unmanaged beech & 4.38 & $13.46^{*}$ & - \\
soil & spruce & 2.02 & 1.42 & $7.34^{*}$ \\
& old beech & 4.21 & - & 5.57 \\
& unmanaged beech & 1.92 & 5.57 & - \\
& spruce & 2.76 & 7.68 & 4.85 \\
\hline
\end{tabular}

${ }^{*} P<0.05,{ }^{* *} P<0.0001$

and lowest in spruce forests $\left(F_{3,44}=8.23, P<0.0002, F_{3,44}=3.87, P<0.02\right.$ and $F_{3,44}$ $=2.98, P<0.05$, respectively; see Supplementary material, Table 1$)$. The plant-tofungal marker FA ratio was similar in unmanaged beech forests, old beechforests and spruce forests but higher in young beech forests $(1.17 \pm 0.29,1.29 \pm 0.31,1.35 \pm 0.30$ and $1.36 \pm 0.16$, respectively; $\left.F_{3,82}=2.24, P>0.08\right)$.

In L. crassipes, FA composition differed significantly between forest types (DFA after NMDS; reduced to five dimensions; $F_{15,50}=2.25, P<0.02$; Fig. 1c). Differences were most pronounced between young beech forests and spruce forests $\left(F_{5,18}=3.88, P<\right.$ 0.02; Table 2) and between unmanaged beech forests and spruce forests $\left(F_{5,18}=3.17\right.$, $P<0.04)$. The plant-to-fungal marker ratios did not differ significantly between forest types $\left(F_{3,22}=0.54, P>0.6\right)$.

\section{Basal resources}

The composition of PLFAs extracted from litter differed significantly between forest 


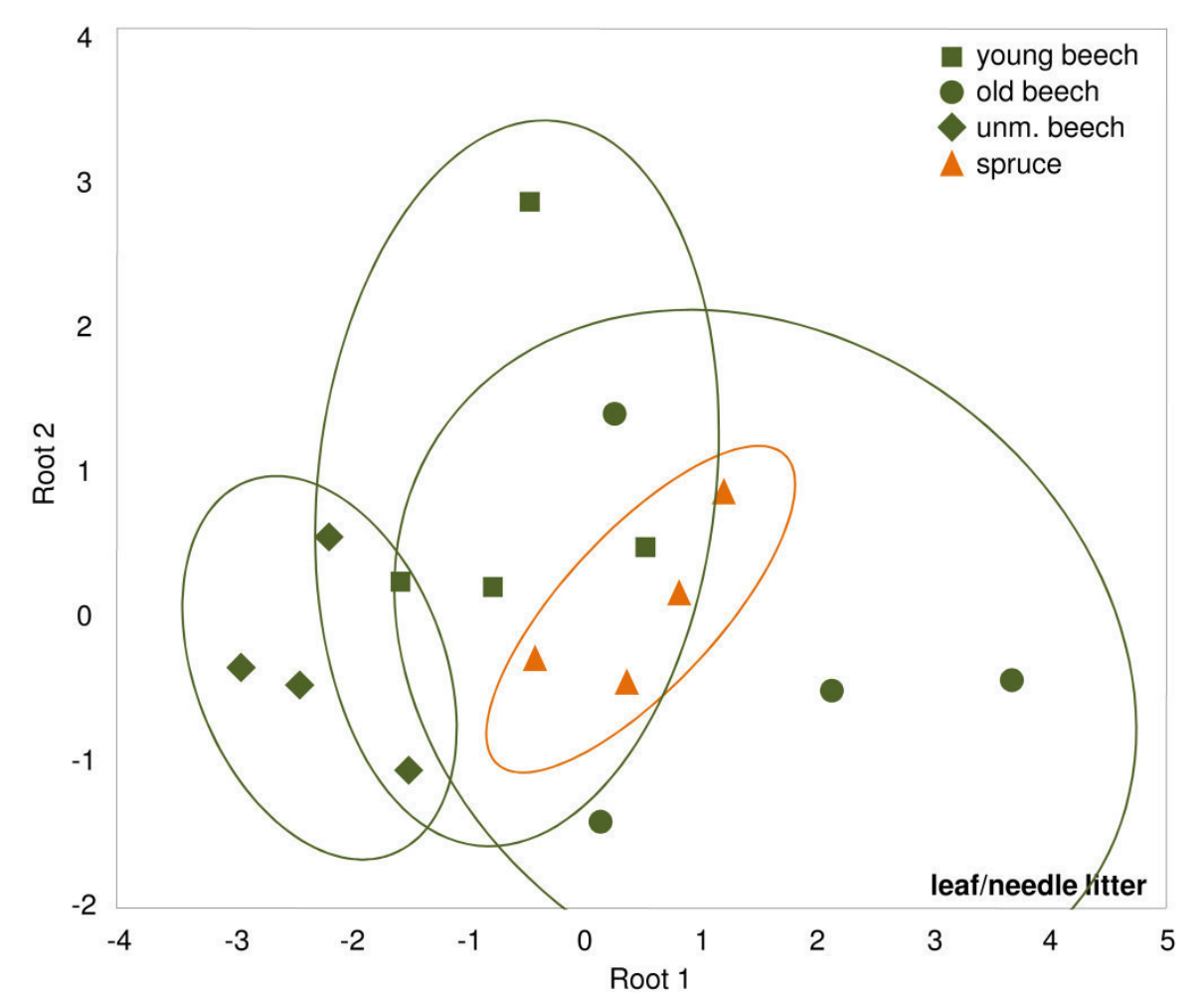

Fig. 3 | Discriminant function analysis of PLFAs in leaf and needle litter of young, old and unmanaged beech forests and spruce forests. Ellipses represent confidence ranges at $P=0.5$.

types (DFA after NMDS, reduced to three dimensions; $F_{9,24}=2.51, P<0.04$; Fig. 3 ). Differences were most pronounced between old and unmanaged beech forests $\left(F_{3,10}\right.$ $=7.48, P<0.01$; Table 2). However, differences were generally small and restricted to few non-marker FAs (see Supplementary material Table S1). In soil, the composition of PLFAs generally did not differ significantly between forest types (DFA after NMDS, reduced to five dimensions; $F_{15,22}=0.99, P>1.15$, data not shown).

\section{Variations in isotopic signatures}

$\delta^{13} \mathrm{C}$ and $\delta^{15} \mathrm{~N}$ values of litter differed little between beech and spruce forests $\left(\delta^{13} \mathrm{C}\right.$ : 28.11 and $-27.37 \%$, respectively; $\delta^{15} \mathrm{~N}$ : -4.21 and $-3.36 \%$, respectively; Fig. $4 \mathrm{a}$ ). Centipedes were enriched in ${ }^{13} \mathrm{C}$ by $2.73-5.44 \%$ and in ${ }^{15} \mathrm{~N}$ by $1.44-5.39 \%$ as compared to leaf litter. $\delta^{13} \mathrm{C}$ and $\delta^{15} \mathrm{~N}$ signatures differed significantly between centipede species $\left(F_{2,148}=59.8, P<0.0001\right)$ and forest types $\left(F_{6,296}=41.1, P<\right.$ $0.0001)$, but differences between species varied between forest types $\left(F_{6,296}=5.1, P\right.$ $<0.0001$ for the interaction between centipede species and forest type). Generally, 

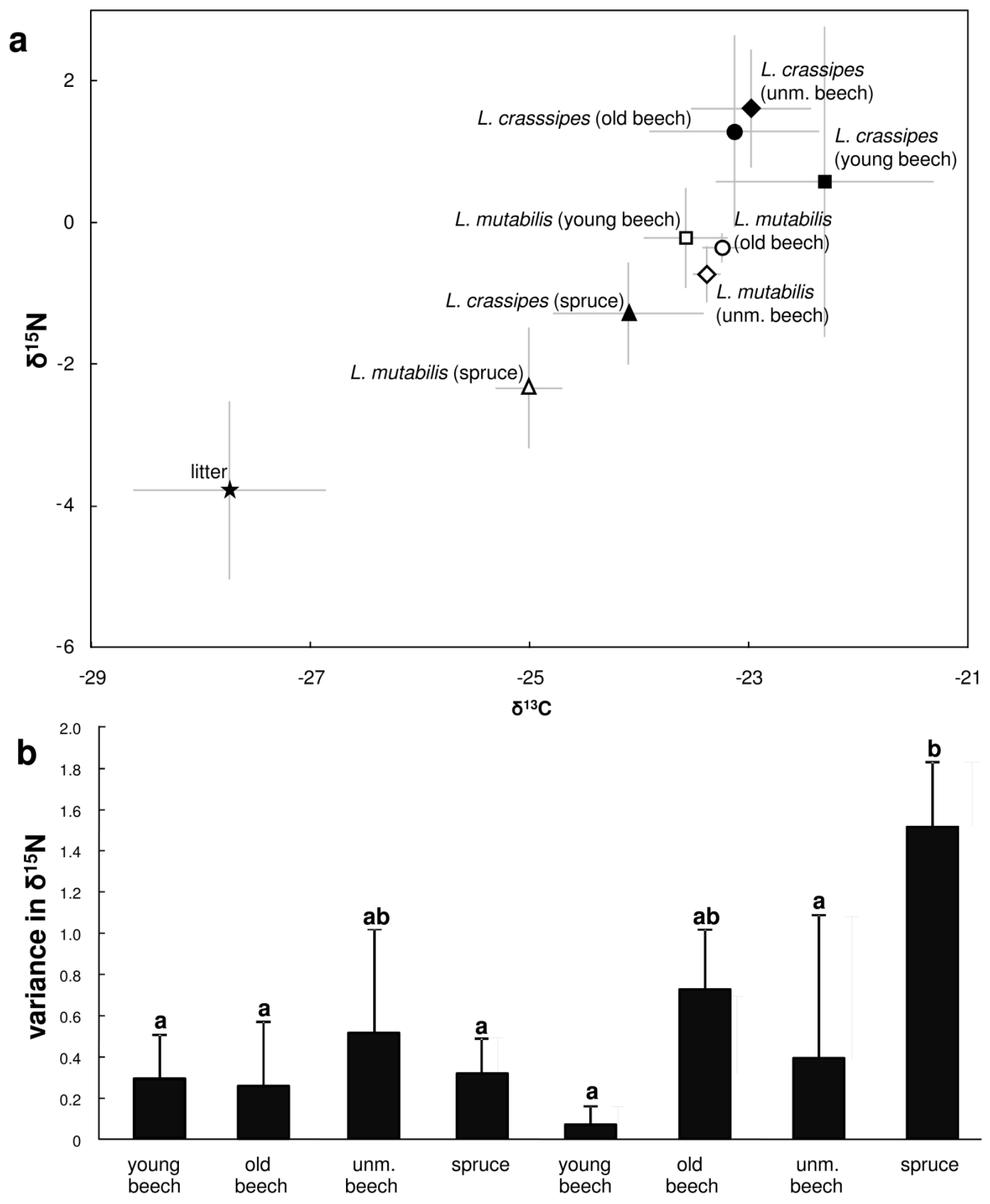

L. mutabilis

L. crassipes

Fig. 4 | (a) Mean stable isotope signatures $\left(\delta^{13} \mathrm{C}\right.$ and $\left.\delta^{15} \mathrm{~N}\right)$ of Lithobius mutabilis, Lithobius crassipes and litter in young, old and unmanaged beech forests and spruce forests. The stable isotope signature of litter represents the mean of the four forest types; (b) variances of $\delta^{15} \mathrm{~N}$ stable isotope signatures of Lithobius mutabilis and Lithobius crassipes in young, old and unmanaged beech forests and spruce forests. Different letters represent significant differences (Tukey's Honestly Significant Difference test; $P<0.05)$. 
both species were least enriched in ${ }^{13} \mathrm{C}$ and ${ }^{15} \mathrm{~N}$ in spruce forests. Further, signatures of both $\delta^{13} \mathrm{C}$ and $\delta^{15} \mathrm{~N}$ were lower in L. mutabilis (-25.01 and $-2.34 \%$, respectively) than in L. crassipes (-24.10 and $-1.28 \%$, respectively). In L. mutabilis, stable isotope signatures of beech forests were similar and averaged -23.95 and $-1.07 \%$ for ${ }^{13} \mathrm{C}$ and ${ }^{15} \mathrm{~N}$, respectively. In L. crassipes, $\delta{ }^{13} \mathrm{C}$ signatures decreased slightly from young to unmanaged to old beech forests $\left(-22.30,-22.98\right.$ and $-23.13 \%$, respectively), and $\delta^{15} \mathrm{~N}$ signatures decreased from unmanaged to old to young beech forests $(1.61,1.29$ and $0.58 \%$, respectively).

Variances in $\delta^{15} \mathrm{~N}$ signatures differed significantly between $L$. mutabilis and $L$. crassipes but the differences depended on forest type $\left(F_{6,46}=2.63, P<0.03\right.$ for the interaction between centipede species and forest type; Fig. 4b). They were highest in $L$. crassipes in spruce forests exceeding those of $L$. crassipes in beech forests and those of $L$. mutabilis in each of the forests. Variances in $\delta^{13} \mathrm{C}$ signatures generally did not differ significantly between centipede species nor between forest types $\left(F_{1,24}=\right.$ 1.01, $P>0.32$ and $F_{3,24}=2.12, P>0.12$, respectively).

\section{Discussion}

\section{Trophic niches}

Significant differences in the FA composition of the two lithobiid species between beech and spruce forests support our hypothesis that trophic niches of the two species vary with forest type. However, differences were more pronounced in spruce forests as compared to beech forests, suggesting that trophic niches of the two species are more distinct in spruce than in beech forests. Consistent with niche theory (Hutchinson 1957), closely related soil invertebrate species have been reported to occupy distinct trophic niches before. Based on stable isotope signatures $\left({ }^{13} \mathrm{C}\right.$ and $\left.{ }^{15} \mathrm{~N}\right)$, Klarner et al. (2013) found gamasid mite species of the same genus to occupy markedly different trophic niches. Similarly, closely related species of lithobiids and geophilomorphs have been found to be trophically distinct with trophic niches in lithobiid species even varying between life stages presumably due to the ability of larger individuals to catch large mobile prey (Ferlian et al. 2012). Using molecular gut content analysis, Günther et al. 
(this issue) also found that $L$. mutabilis and $L$. crassipes differ in the frequency of feeding on lumbricid prey with the differences being associated with differences in body size. In the present study, the trophic separation of these two species was mainly due to bacterial marker FAs being high in L. crassipes and low in L. mutabilis, suggesting that $L$. crassipes is more strongly associated with the bacterial energy channel as compared to L. mutabilis. Significant variation in trophic niches with centipede body size suggests that the smaller $L$. crassipes exploits deeper soil layers than the larger L. mutabilis where bacteria and bacterial grazers, such as lumbricids, certain mite and euedaphic collembolan species, are more abundant thereby increasingly contributing to the diet of $L$. crassipes (Poser 1988, White et al. 1996, Günther et al. this issue).

In L. mutabilis, concentrations of the bacterial marker FAs were generally low and decreased in the order young, old and unmanaged beech and spruce forests, suggesting that $L$. mutabilis is restricted to feeding on fungivorous microarthropods especially in spruce forests, which corresponds to the dominance of fungi in spruce litter (Frostegård and Baath 1996, Scheu et al. 2003, Salamon et al. 2008). Fatty acid analysis therefore suggests $L$. crassipes and $L$. mutabilis to be integrated to a different degree into different energy channels of the food web. ${ }^{15} \mathrm{~N}$ isotope signatures complement this information by providing evidence that the two species also differ in the trophic level they occupy, with $L$. crassipes being higher up in the food chain than L. mutabilis. The two methods therefore complement each other in allowing to judge channelling of resources through food webs horizontally and vertically. ${ }^{13} \mathrm{C}$ analysis further supports the conclusion that the smaller $L$. crassipes relies more on root derived carbon as root exudates are less depleted in ${ }^{13} \mathrm{C}$ as compared to leaf litter (Bowling et al. 2008, Hobbie et al. 2012, Pollierer et al. 2012) with both forming important resources for the decomposer system (Cesarz et al. 2013). Supporting the stronger association with the bacterial channel in $L$. crassipes as compared to $L$. mutabilis, root exudates are assumed to be used predominantly by bacteria (Moore et al. 2005). Generally, the results suggest that lithobiid centipedes form part of more than one energy channel depending on predator size and, thus, accessibility to resources.

\section{Variations with forest type}

Our hypothesis that variations in trophic niches of the two lithobiid species differ 
between forest types with the fungal energy channel being more pronounced in spruce as compared to beech forests also was supported by our data. FA composition of the two lithobiid species differed significantly between the four forest types studied suggesting that trophic niches of lithobiids varied with habitat conditions in the different forests. Differences in FA composition were most pronounced between beech and spruce forests suggesting that tree species more than forest age affect trophic niches of lithobiids.

Trophic niche variation with forest type was more pronounced in $L$. mutabilis than in $L$. crassipes presumably due to variations in the effect of habitat structure with lithobiid body size. Thickness of the litter layer of beech forests is known to vary with forest age but is generally lower as compared to spruce forests where litter decomposes slowly (Swift et al. 1979, Scheu et al. 2003, Klarner et al. this issue). This also affects decomposer animals feeding on litter (primary decomposers) or grazing on litter inhabiting microorganisms (secondary decomposers). Furthermore, litter also affects soil animals via non-trophic effects, e.g. by altering habitat structure thereby also affecting predator - prey interactions (Langellotto and Denno 2006, Kalinkat et al. in press). Rich structured habitats were found to reduce predation by providing hiding space for prey of arthropod soil predators (Vucic-Pestic et al. 2010b, Kalinkat et al. in press) and, thereby, controlling access of predators to prey in deeper litter layers. This is in line with our findings that compared to beech forests dense needle litter in coniferous forests affects feeding of the larger lithobiid species.

FA composition of microorganisms in litter and soil corresponded poorly with FA patterns of lithobiids suggesting selective flux of microbial carbon to higher trophic levels. By contrast, Ruess et al. (2007) found FA composition of microorganisms to correspond well with collembolan FA profiles in different forests. Due to smaller body size compared to lithobiids, collembolans are less restricted by habitat structure (Hågvar 1982, Salamon and Alphei 2009).

Lithobiids in beech forests were more enriched in stable isotope signatures $\left({ }^{13} \mathrm{C}\right.$ and ${ }^{15} \mathrm{~N}$ ) as compared to spruce forests coinciding with the study of Klarner et al. (this issue) who investigated stable isotope signatures of a variety of soil animal species at the study sites. Presumably, in beech forests, lithobiids more heavily rely on root derived carbon resources thereby being more closely integrated into the bacterial energy channel (Bowling et al. 2008, Cesarz et al. 2013) and, furthermore, differ in the trophic 
level they occupy in these forests. Klarner et al. (this issue) suggested the thick and dense needle litter layer in spruce forests to restrict access of larger species to root derived resources and bacterial grazers, thereby fostering the role of litter derived resources for soil animal food webs.

As indicated by molecular gut content analysis, lithobiids mainly prey on collembolans, lumbricids and Diptera larvae (Günther et al. this issue). As indicated by FA composition, the former two predominantly feed on fungi/bacteria (Ruess et al. 2007) and the latter on bacteria (O. Ferlian, unpublished data). Diptera larvae are trophically diverse and difficult to ascribe to certain prey groups (Healey and Russell-Smith 1971). Mixed diet comprising these three prey groups therefore results in incorporation of both bacterial and fungal carbon suggesting that lithobiids form part of both the fungal and bacterial energy channel, and this is well supported by the FA composition of lithobiids in this study.

Ascribing soil animal species to energy channels has been based mainly on laboratory studies and therefore may be of limited value for reflecting predator - prey interactions in the field. Indeed, stable isotope analyses indicate that decomposer animals are trophically more diverse as previously assumed with even closely related species occupying very different trophic niches (Scheu and Falca 2000, Schneider et al. 2004, Maraun et al. 2011, Klarner et al. 2013). In line with niche theory, differences in FA composition between the two investigated lithobiid species in the present study support the view that even closely related predator species occupy different trophic niches and that these niches vary in a species specific way with habitat structure. Notably, the species-specific changes in trophic niches with habitat structure suggest that ascribing predators to energy channels is equivocal and depends on structural habitat characteristics. Overall, energy channels of top predators, such as centipedes, cannot be clearly separated as they converge towards top predators (Moore and Hunt 1988, Digel et al. this issue), though it is possible to trace the predominating energy channel contributing to predator nutrition and its variability with habitat characteristics.

\section{Conclusions}

The results suggest that trophic niche differentiation in lithobiid species varies with body size and these variations depend on habitat structure. Depending on habitat 
structure, body size may determine access to prey relying predominantly on root derived resources and thereby the relative contribution of bacterial carbon to higher trophic levels. The study challenges the view of fixed energy channels in soil food webs by documenting that the relative contribution of bacterial and fungal carbon to predator nutrition varies between habitats. Local variations in habitat structure presumably contribute to the coexistence of closely related predator species.

The study documents that techniques allow understanding of complex trophic interactions and energy channels and their variations with forest type and habitat structure. Analysing the same individuals with different methods maximised the complementary power of these methods. FA analysis allows following the channelling of carbon from different basal resources to higher trophic levels and, therefore, allows differentiating the niche of consumers of similar trophic level, i.e. the channelling of energy through the food web horizontally. Analyses of natural variations in stable isotope ratios in consumers complement the method by allowing to delineate trophic positions of consumers, i.e. the vertical structure of soil food webs. Combining stable isotope, FA and, furthermore, molecular gut content analysis promises to ultimately open the 'black box' of soil food webs and to understand the factors responsible for its variation in space and time.

\section{Acknowledgements}

The work has been funded by the DFG Priority Program 1374 "InfrastructureBiodiversity-Exploratories". Field work permits were given by state environmental office of Thuringia according to $\S 72$ BbgNatSchG. We thank the managers of the three exploratories, Swen Renner, Sonja Gockel, Kerstin Wiesner, and Martin Gorke for their work in maintaining the plot and project infrastructure; Simone Pfeiffer and Christiane Fischer giving support through the central office, Michael Owonibi for managing the central data base, and Markus Fischer, Eduard Linsenmair, Dominik Hessenmöller, Jens Nieschulze, Daniel Prati, Ingo Schöning, François Buscot, Ernst-Detlef Schulze, Wolfgang W. Weisser and the late Elisabeth Kalko for their role in setting up the Biodiversity Exploratories project. We thank Bernhard Eitzinger, Mark Maraun, Babett Günther, Andrea Gräbe-Treger, Christian Bluhm and Simone Cesarz for support during field work, lab work, statistics and the writing process. Sincere thanks to Martin 
Blumenberg for GC-MS measurements.

\section{References}

Bardgett, R.D. 2005. The biology of soil. -Oxford Univ. Press.

Blem, C.R. 1976. Patterns of lipid storage and utilization in birds. - Am Zool 16 : 671684.

Bowling, D.R. et al. 2008. Carbon isotopes in terrestrial ecosystem pools and $\mathrm{CO}_{2}$ fluxes. - New Phytol 178 : 24-40.

Cesarz, S. et al. 2013. Tree species diversity versus tree species identity: driving forces in structuring forest food webs as indicated by soil nematodes. - Soil Biol Biochem 62 : 36-45.

Digel, C. et al. Unraveling the complex structure of forest soil food webs: High omnivory and more trophic levels (this issue).

Ferlian, O. et al. 2012. Trophic interactions in centipedes (Chilopoda, Myriapoda) as indicated by fatty acid patterns: Variations with life stage, forest age and season. - Soil Biol Biochem 52 : 33-42.

Frostegård, A. and Bååth, E. 1996. The use of phospholipid fatty acid analysis to estimate bacterial and fungal biomass in soil. - Biol Fert Soils 22 : 59-65.

Frostegård, A. et al. 1993. Shifts in structure of soil microbial communities in limed forests as revealed by phospholipid fatty acid analysis. - Soil Biol Biochem 25 : 723-730.

Gause, G.F. and Witt, A.A. 1935. Behavior of mixed populations and the problem of natural selection. - Amer Nat 69 : 596-609.

Günther, B. et al. Which factors affect prey choice of invertebrate forest soil predators? Examining variance in trophic interactions using molecular gut content analysis (this issue).

Hågvar, S. 1982. Collembola in Norwegian coniferous forests soils, I. Relations to plant communities and soil fertility. - Pedobiologia 24 : 255-296.

Hairston, N.G. et al. 1960. Community structure, population control, and competition. - Amer Nat $94:$ 421-425.

Hättenschwiler, S. and Vitousek, P.M. 2000. The role of polyphenols in terrestrial ecosystem nutrient cycling. - Trends Ecology Evol 15 : 238-243.

Haubert, D. et al. 2004. Effects of fungal food quality and starvation on the fatty acid composition of Protaphorura fimata (Collembola). - Comp Biochem Phys B 138 : 41-52.

Haubert, D. et al. 2009. Trophic structure and major trophic links in conventional versus organic farming systems as indicated by carbon stable isotope ratios of fatty acids. - Oikos $118:$ 1579-1589.

Healey, I.N. and Russell-Smith, A. 1971. Abundance and feeding preferences of fly larvae in two woodland soils. - Ann Zool Ecol Anim (Hors Ser) : 177-191.

Hobbie, E.A. et al. 2012. Controls of isotopic patterns in saprotrophic and 
ectomycorrhizal fungi. - Soil Biol Biochem 48 : 60-68.

Hutchinson, G.E. 1957. Population studies - Animal ecology and demograghy Concluding remarks. - Cold Spring Harbor Symposia on Quantitative Biology $22: 415-427$.

Kalinkat, G. et al. Habitat structure alters top-down control in litter communities. Oecologia (in press), doi:10.1007/s00442-012-2530-6.

Klarner, B. et al. 2013. Trophic diversity and niche partitioning in a species rich predator guild - Natural variations in stable isotope ratios $\left({ }^{13} \mathrm{C} /{ }^{12} \mathrm{C},{ }^{15} \mathrm{~N} /{ }^{14} \mathrm{~N}\right)$ of mesostigmatid mites (Acari, Mesostigmata) from Central European beech forests. - Soil Biol Biochem 57 : 327-333.

Klarner, B. et al. Trophic shift of soil animal species with forest type as indicated by stable isotope analysis (this issue).

Lang, B. et al. Effects of environmental warming and drought on size-structured soil food webs (this issue).

Langellotto, G.A. and Denno, R.F. 2006. Refuge from cannibalism in complexstructured habitats: implications for the accumulation of invertebrate predators. - Ecol Entomol 31 : 575-581.

Maraun, M. et al. 2011. Stable isotopes revisited: their use and limits for oribatid mite trophic ecology. - Soil Biol Biochem $43: 877-882$.

Moore, J.C. and Hunt, H.W. 1988. Resource compartmentation and the stability of real ecosystems. - Nature $333:$ 261-263.

Moore, J.C. et al. 2005. Modeling trophic pathways, nutrient cycling, and dynamic stability in soils. - Pedobiologia 49 : 499-510.

Moore-Kucera, J. and Dick, R.P. 2008. PLFA profiling of microbial community structure and seasonal shifts in soils of a Douglas-fir chronosequence. - Microb Ecol 55 : 500-511.

Paquin, P. and Coderre, D. 1997. Changes in soil macroarthropod communities in relation to forest maturation through three successional stages in the Canadian boreal forest. - Oecologia 112 : 104-111.

Pennanen, T. et al. 1999. Structure of the microbial communities in coniferous forest soils in relation to site fertility and stand development stage. - Microb Ecol 38 : 168-179.

Pollierer, M.M. et al. 2010. Taking it to the next level: trophic transfer of marker fatty acids from basal resource to predators. - Soil Biol Biochem 42 : 919-925.

Pollierer, M.M. et al. 2012. Carbon flux through fungi and bacteria into the forest soil animal food web as indicated by compound-specific ${ }^{13} \mathrm{C}$ fatty acid analysis. Funct Ecol 26 : 978-990.

Pond, C.M. 1981. Storage. - In: Townsend, C.R. and Calow, P. (eds.), Physiological Ecology: an Evolutionary Approach to Resource Use. Blackwell, pp. 190-219.

Ponge, J.-F. 2013. Plant-soil feedbacks mediated by humus forms: A review. - Soil Biol Biochem 57 : 1048-1060.

Poser, T. 1988. Chilopoden als Prädatoren in einem Laubwald. - Pedobiologia 31 : 261281.

Rall, B.C. et al. 2011. Taxonomic versus allometric constraints on nonlinear interaction strengths. - Oikos $120: 483-492$. 
Ruess, L. and Chamberlain, P.M. 2010. The fat that matters: soil food web analysis using fatty acids and their carbon stable isotope signature. - Soil Biol Biochem 42 : 1898-1910.

Ruess, L. et al. 2005. Application of lipid analysis to understand trophic interactions in soil. - Ecology 86 : 2075-2082.

Ruess, L. et al. 2007. Lipid composition of Collembola and their food resources in deciduous forest stands - implications for feeding strategies. - Soil Biol Biochem 39 : 1990-2000.

Salamon, J.-A. and Alphei, J. 2009. The Collembola community of a Central European forest: Influence of tree species composition. - Eur J Soil Biol 45 : 199-206.

Salamon, J.-A. et al. 2008. The Collembola community of pure and mixed stands of beech (Fagus sylvatica) and spruce (Picea abies) of different age. Pedobiologia 51 : 385-396.

Scheu, S. and Falca, M. 2000. The soil food web of two beech forests (Fagus sylvatica) of contrasting humus type: stable isotope analysis of a macro- and a mesofauna-dominated community. - Oecologia 123 : 285-296.

Scheu, S. and Setälä, H. 2002. Multitrophic interactions in decomposer food webs. In: Hawkins, B.A. and Tscharntke, T. (eds.), Multitrophic level interactions. Cambridge Univ. Press, pp. 223-264.

Scheu, S. et al. 2003. The soil fauna community in pure and mixed stands of beech and spruce of different age: trophic structure and structuring forces. - Oikos $101: 225-238$.

Schneider, K. et al. 2004. Trophic niche differentiation in soil microarthropods (Oribatida, Acari): evidence from stable isotope ratios $\left({ }^{15} \mathrm{~N} /{ }^{14} \mathrm{~N}\right)$. - Soil Biol Biochem 36 : 1769-1774.

Schröter, D. et al. 2003. C and $\mathrm{N}$ mineralisation in the decomposer food webs of a European forest transect. - Oikos 102 : 294-308.

Swift, M.J. et al. 1979. Decomposition in terrestrial ecosystems. - Univ. California Press.

Thiemann, G.W. et al. 2011. Individual patterns of prey selection and dietary specialization in an Arctic marine carnivore. - Oikos $120: 1469-1478$.

Toscano, B.J. and Griffen, B.D. 2013. Predator size interacts with habitat structure to determine the allometric scaling of the functional response. - Oikos $122: 454$ 462.

Vucic-Pestic, O. et al. 2010b. Habitat structure and prey aggregation determine the functional response in a soil predator-prey interaction. - Pedobiologia $53: 307$ 312.

White, D.C. et al. 1996. Quantitative comparisons of in situ microbial biodiversity by signature biomarker analysis. - J Ind Microbiol 17 : 185-196. 


\section{Supplementary}

Table S1 | ANOVA table of $F$ - and $P$-values (with degrees of freedom) on the effects of forest type (young, old-growth and unmanaged beech forests and spruce forests) on the amount of individual PLFAs in litter and soil, and the amount of NLFAsin the lithobiid species Lithobius mutabilis and Lithobius crassipes, as well as the interaction between lithobiid species and forest type. Significant effects are given in bold $(P<0.05)$.

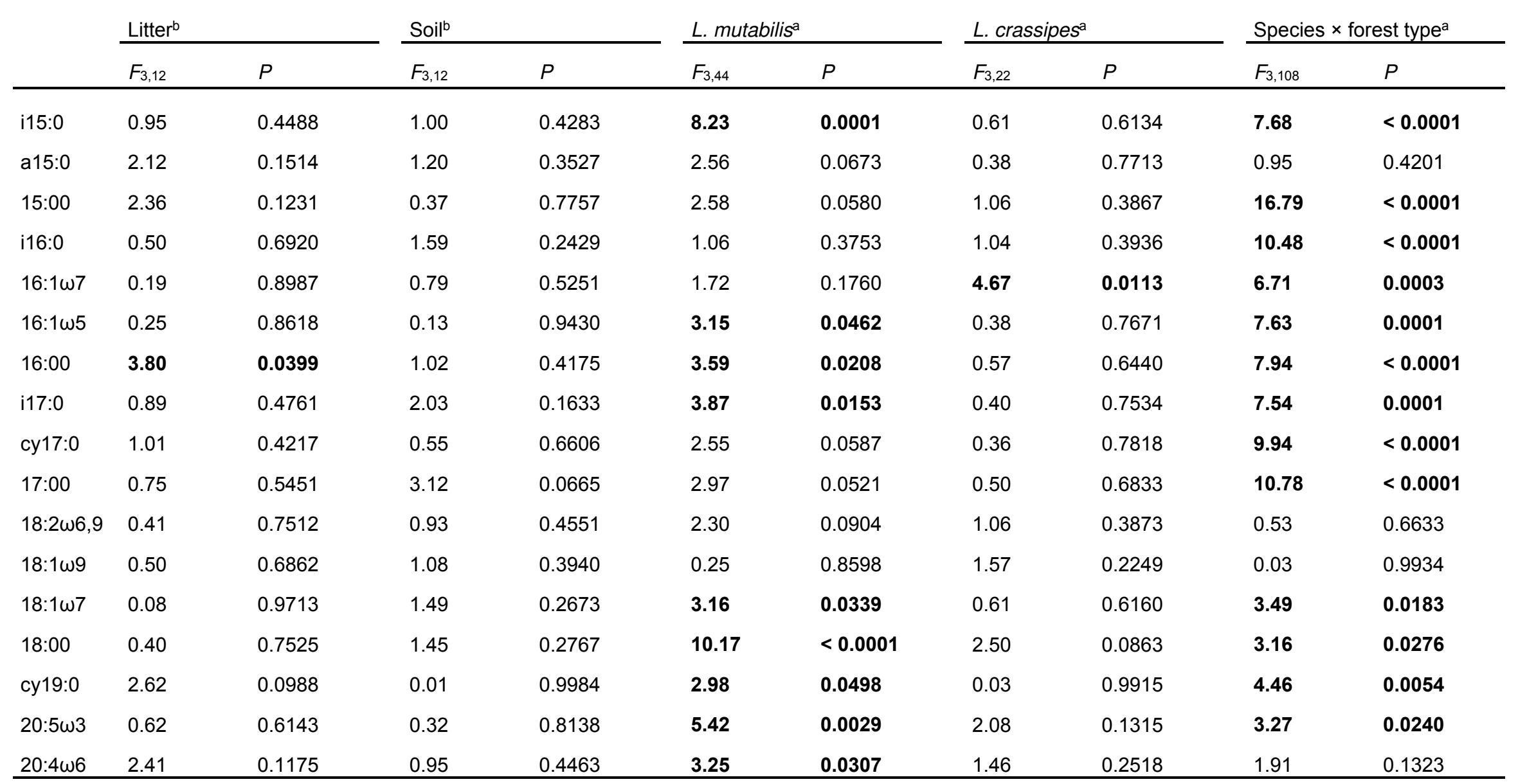

aNLFA data ${ }^{b} P L F A$ data 


\section{Chapter 3}

Variations in prey consumption of centipede predators in forest soils as indicated by molecular gut content analysis

Babett Günther, Björn C. Rall, Olga Ferlian, Stefan Scheu, Bernhard Eitzinger Oikos (2014), published 


\begin{abstract}
Predation is an important ecological factor driving animal population structures, community assemblages and consequently ecosystem stability and biodiversity. Many environmental factors influence direction and intensity of predation, suggesting that trophic linkages between animals vary between different habitats. This in consequence has particular relevance in anthropogenically altered habitats such as managed forests, where disturbance regime, tree composition and stand age may change the natural food web structure. We investigated how prey consumption of three common centipede predators (Lithobius spp., Chilopoda), representing two body sizes varies between four differently managed forest types in two regions across Germany. We hypothesized that prey preference of these generalist predators is independent of forest type but rather driven by habitat structure, prey abundance and predator body size. Applying specific PCR assays to test for DNA of three abundant prey groups, i.e. Collembola, Diptera and Lumbricidae, in the predators' guts, we tracked trophic interactions. The results showed that management type indeed has no influence on centipede prey consumption but depth of litter layer and soil $\mathrm{pH}$. Trophic interactions varied between the two sampled forests regions mainly due to changes in the detection of Lumbricidae and Diptera. Also, effect of litter layer and prey abundance significantly differed between the smaller $L$. crassipes and the larger $L$. mutabilis, indicating a body size effect. The results complement food web analyses using fatty acids and stable isotopes by elucidating trophic interactions in soil in unprecedented detail.
\end{abstract}

Key-words: Beech forest, Body size, Coniferous forest, Forest management, Habitat structure, Lithobiidae, Prey abundance, Predator-prey interactions, Soil food web 


\section{Introduction}

Analyzing trophic interactions is essential to understand the dynamics and functioning of ecosystems. Trophic interactions in soil food webs are of particular interest as most predators feed on a wide range of prey organisms and are thought to exert top-downpressure on prey communities, thus shaping soil animal communities (Scheu and Setälä 2002). Environmental characteristics, e.g. habitat structure, however may influence predation impact and prey choice of generalist species, suggesting that effects on prey communities vary between habitats. This also applies to managed forests as the structure of food webs and the relative importance of bottom-up and top-down forces can vary with tree species and timber harvest practices (Scheu et al. 2003, Salmon et al. 2008). Generalist predators are supposed to adapt quickly to new environmental conditions, allowing them to switch between different prey and to exploit new resources (Halaj and Wise 2002). Yet, recent studies investigating centipede prey choice using fatty acid analysis indicated only little variation between forests of different age and management practice (Ferlian et al. 2012). Rather, single environmental factors which are not exclusive for specific forest management types may play an important role.

Habitat structure, i.e. texture and thickness of the litter layer, provides structural niches serving as microhabitats and food resource for a variety of soil invertebrates (Poser 1990, Jabin 2008). Increasing resource availability not only supports larger populations, but allows coexistence of many species, such as decomposer animals and their predators (Ferlian and Scheu this issue). As indicated by semi-natural laboratory experiments (Vucic-Pestic et al. 2010a, Kalinkat et al. 2011), higher prey densities in soils lead to higher encounter probabilities resulting in higher predation rates. This effect however, may be compensated by the increased provision of hiding places. In laboratory experiments Kalinkat et al. (2012) demonstrated that search time of centipede predators increases with amount of litter resulting in a decline in predation frequency. This has particular effects on survival of small prey populations, whereas large populations are confronted with high encounter and predation rates even in structure-rich habitats (Vucic-Pestic et al. 2010b). Habitat structure therefore, acts as an important driver of predator-prey interactions (Langellotto and Denno 2004, Vucic-Pestic et al. 2010b).

In the present study we investigated trophic interactions of centipede predators in the litter layer of four differently managed forest types, including stands of different age and tree composition. We focused on three species Lithobius mutabilis L. Koch, 1862, Lithobius 
crassipes L. Koch, 1862 and L. curtipes Koch, C.L. 1847 (Chilopoda, Lithobiidae) representing two size classes. Each of these species feeds on a wide spectrum of invertebrate prey including collembolans and earthworms, performing a sit-and-wait feeding strategy to capture prey (Poser 1988, Dennis and Sotherton 1994). The larger L. mutabilis colonizes the litter layer, but also occurs near tree trunks and in tree stumps (Fründ 1987, Poser 1990). In contrast, the smaller $L$. crassipes and L. curtipes predominate in the $F$ and $\mathrm{H}$ horizon of the litter layer as well as in dead wood. Due to their specific body sizes and preferred habitat these species are expected to show specific prey preferences (Ferlian et al. 2012). Optimal body size ratios suggest that small centipedes prefer feeding on small prey, such as collembolans, while large $L$. mutabilis feeds on a wider range of prey body sizes (Cohen et al. 1993, Brose et al. 2006).

To test for feeding interactions we applied PCR-based molecular gut content analysis, which in recent years has proved to be the most sensitive and specific method to study soil food webs (Juen and Traugott 2007, King et al. 2008). This method is particularly advantageous when studying fluid-feeding predators or predators that consume soft-tissued prey organisms, as in both cases no microscopically discernable prey remains are available. Using group- and species-specific PCR assays even small remnants of prey DNA in the predators gut can be detected, allowing identification of prey species up to several days post-feeding (Waldner and Traugott 2012).

Here, by applying molecular gut content analysis, we studied effects of management type and specific environmental and biological factors on the prey spectrum and prey consumption of lithobiid predators in forests of two regions in central and northeast Germany. We hypothesized that (1) lithobiid predators display similar prey preferences across differently managed forest types, (2) mass of the litter layer reduces prey encounter rate leading to lower detection frequency in centipedes, (3) prey DNA detection increases with prey abundance and (4) small lithobiid species preferably feed on smaller prey than do large L. mutabilis.

\section{Materials and methods}

\section{Study sites}

The study was carried out in forest sites of the two regions, Schorfheide-Chorin 
(Brandenburg, Germany) and the Hainich in the western part of Thuringia, Germany. This study formed part of the interdisciplinary project "Biodiversity Exploratories" investigating effects of forest management and land use on biodiversity and ecosystem functioning (Fischer et al. 2010). Altitude at the Schorfheide is between 2-139 m a.s.l.; soils are sandy with $\mathrm{pH}$ ranging between 3.30 and 6.65 with a leaf litter mass between 0.21 and $0.58 \mathrm{~g} / \mathrm{cm}^{2}$. Mean annual temperature is $6.5-8{ }^{\circ} \mathrm{C}$ and average precipitation is $520-580 \mathrm{~mm}$ with a sub continental climate characterized by hot summers and cold winters. The climate at the Hainich (altitude 330-490 m a.s.I.) is sub-oceanic with precipitation ranging between 630$800 \mathrm{~mm}$, soil $\mathrm{pH}$ between 5.64 and 7.23 , leaf litter mass between 0.14 and $0.37 \mathrm{~g} / \mathrm{cm}^{2}$ and the annual average temperature is $7.0^{\circ} \mathrm{C}$ (Fischer et al. 2010).

In each of the two exploratory regions, Hainich and Schorfheide, sixteen different forest sites were selected which represent four different forest types: (1) managed coniferous forests with Norway spruce (Picea abies H. Karst.) in the Hainich ("spruce") and Scots pine (Pinus silvestris L.) in the Schorfheide ("pine"), (2) 30 years old managed beech forests ("young beech"), (3) 70 years old managed beech forests ("old beech") and (4) unmanaged natural beech forests ("unmanaged beech"). All plots were randomly arranged and minimum distance between two sites was $500 \mathrm{~m}$. Beech forests were dominated by Fagus sylvatica L., interspersed with ash (Fraxinus excelsior L.) and sycamore (Acer pseudoplatanus L.).

\section{Sampling and DNA extraction}

Adult specimens of the centipedes $L$. mutabilis and L. crassipes were collected by sieving litter through $18 \mathrm{~mm}$ mesh in an area of c. $20 \times 20 \mathrm{~m}$ at all 32 sites in April 2012. In the Schorfheide we additionally collected Lithobius curtipes Koch, 1847, a close relative of $L$. crassipes with similar distribution, body size and prey spectrum, for a useful amount of individuals for statistical analyses. The animals were immediately transferred individually in cooled microcentrifuge tubes and stored at $-21^{\circ} \mathrm{C}$ upon further processing. For gut content analysis we predominantly used the mid body part of the lithobiids from the Hainich; the head capsule and the hind part were used for stable isotope and fatty acid analysis, respectively (see Ferlian and Scheu this issue). To avoid carry-over contamination, dissection was performed under sterile conditions using heat-sterilized instruments. Lithobiids from Schorfheide were processed using the whole body. 
(cetyltrimethylammonium bromide) protocol (Juen and Traugott 2005) and subsequently purified using Geneclean Turbo Kit (MP Biomedicals, Solon, OH, USA). Every batch of 47 samples contained one blank sample (PCR-water replacing DNA) to check for carry-over contamination. None was found when testing all extracts for false negatives and false positives, using the universal invertebrate primer pair LCO1490/HCO2198 (Folmer et al. 1994); for PCR conditions see Eitzinger et al. (2013).

For detection of collembolan, dipteran and lumbricid prey in the predators we took a twostep approach: First, we developed a multiplex PCR assay with primers 185F/14233R (Harper et al. 2005) and Col3F/Col5R (Kuusk and Agusti 2007) targeting 12S rDNA of earthworms and 18S rDNA of collembolans, respectively. Following extensive cross reactivity tests against up to 119 non-target organism (Eitzinger et al. 2013), sensitivity of primer mixes were evaluated on a series of prey DNA solutions in gradient PCR resulting in the following PCR protocol: Each $10 \mu$ multiplex PCR contained $1 \mu \mathrm{l} \mathrm{PCR}$ water, $1 \mu \mathrm{l}$ primer mix (final concentration of $4 \mu \mathrm{M}$ for Col3F/Col5R and $2 \mu \mathrm{M}$ for 185F/14233R), $5 \mu \mathrm{l}$ multiplex PCR reaction mix (Qiagen, Hilden, Germany) and $3 \mu$ of DNA extract. PCR cycling conditions were $95^{\circ} \mathrm{C}$ for 15 min followed by 35 cycles of $95^{\circ} \mathrm{C}$ for $30 \mathrm{~s}, 65^{\circ} \mathrm{C}$ for $90 \mathrm{~s}, 72$ ${ }^{\circ} \mathrm{C}$ for $45 \mathrm{~s}$ and a final elongation at $72{ }^{\circ} \mathrm{C}$ for $3 \mathrm{~min}$. For detection of dipteran prey we used a singleplex PCR assay with dipteran primer DIP S16/DIP A17 (final concentration of $10 \mu \mathrm{M}$ ) and thermocycling conditions given in Eitzinger et al. (2013). All PCR products were analyzed using the capillary electrophoresis system QIAxcel and software ScreenGel (both Qiagen). Fragments of expected length and a relative fluorescent value (RFU) $\geq 0.08$ were scored as positives. Samples showing negative results were tested twice in order to exclude possible false negatives.

\section{Statistical analysis}

We investigated 318 centipede individuals from two regions with each 16 sample sites. For the statistical analysis of the data we measured centipede body length and converted it into predator body mass using a log-linear equation (B. Eitzinger, unpubl. data). Consumption data was coded binary (prey DNA present or absent). We used a generalized linear model (GLM) with the family set to "binomial" in R 2.12.2 (R Development Core Team 2011, allowing analyses of presence/absence data by using a Bernoulli distribution and a logitlinearization (see Crawley 2007) to analyze the relationships between the dependent 
variable "DNA presence" and the explanatory variables exploratory region (factorial), forest type (factorial), predator body mass (mg, continuous, $\log _{10}$ transformed), prey abundance (ind $/ \mathrm{m}^{2}$, continuous, $\log _{10}$ transformed), soil $\mathrm{pH}$ (continuous) and litter mass $\left(\mathrm{g} / \mathrm{cm}^{2}\right.$, continuous, $\log _{10}$ transformed). For each of the three prey species we calculated separate GLMs to avoid pseudoreplication. Data on prey abundance were taken from Klarner et al. (this issue), values of environmental factors are from Birkhofer et al. (2012) and Klarner et al. (this issue). We used the automated step-function (AIC based method in R) for model selection. We created two basic models, (1) the full model, including all explanatory variables and their interactions with predator species and (3) the "null" model that describes the data only by its average (in case of presence/absence data the average means the average probability of the presence of prey DNA). From those models we applied the step function, allowing for both forward and backward selection. Subsequently, two models, one beginning from the "full"-model (2) and one beginning from the "null"-model (4) where created. For each prey species we compared all four resulting models and choose the one with the lowest AIC according to the generally accepted how models should be selected via this information criterion (Burnham and Anderson 2004).

\section{Results}

\section{Detection of prey DNA in field-caught predators}

DNA of 318 individuals was successfully extracted and subsequently tested for prey DNA. 136 of 192 L. mutabilis were tested positive for collembolans ( $43.8 \%$ ) followed by lumbricids $(n=70 ; 36.5 \%)$ and dipterans $(79 ; 25.5 \%)$, (Supplementary material Table S1). Of the individuals tested positive $23.4 \%(n=65)$ contained DNA of two different prey groups, $5.7 \%$ $(n=21)$ of all three groups. Of the 126 individuals of L. crassipes $(n=94)$ and L. curtipes $(n$ = 32) 112 were tested prey-positive. Detection frequency was highest for collembolans $(n=51 ; 45.5 \%)$ followed by dipterans $(n=30 ; 26.8 \%)$ and lumbricids $(28 ; 22.2 \%)$. Of the individuals tested positive, $31.7 \%(n=20)$ had fed on two and $10.2 \%(n=10)$ on three prey groups.

Also, prey consumption differed between the two exploratory regions. The main prey detected in centipedes in the Hainich $(n=193)$ were collembolans $(n=79 ; 40.9 \%)$, while in the Schorfheide $(n=125)$ DNA of earthworms was most often detected $(n=69 ; 55.2 \%)$ 
Table 1 | Selection of the most parsimonious model using the Akaike Information Criterion (AIC) following the automated step-function in R. For details please refer to the respective section in Material \& Methods.

\begin{tabular}{|c|c|c|c|c|c|c|c|c|c|c|}
\hline & \multirow[t]{2}{*}{ Region } & \multirow[t]{2}{*}{ Prey type } & \multicolumn{2}{|c|}{ GLM 1} & \multicolumn{2}{|c|}{ GLM 2} & \multicolumn{2}{|c|}{ GLM 3} & \multicolumn{2}{|c|}{ GLM 4} \\
\hline & & & DF & $\Delta \delta A I C$ & DF & $\Delta \delta A I C$ & DF & $\Delta \delta \mathrm{AIC}$ & DF & $\Delta \delta \mathrm{AIC}$ \\
\hline S3 & Hainich & Dipteran & 12 & 7.742 & 7 & 0 & 1 & 13.537 & 5 & 2.712 \\
\hline S4 & Hainich & Collembolan & 12 & 2.537 & 10 & 0 & 1 & 20.245 & 2 & 1.696 \\
\hline S5 & Hainich & Lumbricid & 12 & 17.206 & 2 & 0 & 1 & 5.803 & 2 & 1.347 \\
\hline S6 & Schorfheide & Lumbricid & 12 & 11.655 & 4 & 0 & 1 & 25.014 & 2 & 12.494 \\
\hline
\end{tabular}

considerably exceeding detection frequency in the Hainich ( $n=29 ; 15.0 \%$ ) (Supplementary material Table S1). Dipteran prey DNA was detected in $46.4 \%(n=58)$ of the Schorfheide samples but only in $10.9 \%$ of the tested individuals from the Hainich.

Forest type did not significantly affect prey consumption in any model, which is why it was excluded from following calculations (Supplementary material Table S2). Additionally, overall prey detection frequency differed significantly between Hainich and Schorfheide $(p<0.0001$; Supplementary material Table S2). We consequently calculated region-specific models for Hainich and Schorfheide (Table 1). For both regions a negative correlation between litter mass and soil pH is given, while all other variables did not show any correlation. In the exploratory Hainich the variables predator body mass, soil $\mathrm{pH}$ and prey species significantly affected prey consumption. Feeding frequency in large as compared to the small centipedes species increased significantly with the density of dipteran prey by a slope of $20.4(p<0.05$; Fig. 1a; Supplementary material Table S3). Further, consumption of dipteran prey correlated negatively with a slope of -14 with litter mass $(p<0.05)$ in $L$. mutabilis but positively with a slope of 7.8 in L. crassipes (Fig. 1b). Feeding frequency increased significantly for collembolan prey abundance with a slope of 5.8 in L. mutabilis $(p<0.01)$ but decreased with a slope of -3.4 in $L$. crassipes ( $<0.05$; Fig. $1 c$; Supplementary material Table S4). Additionally, higher litter mass corresponded with higher detection frequency with a slope of 6.6 in L. crassipes, but lower frequency in L. mutabilis with a slope of $-8.2(p<0.05$, Fig. 1d). For $L$. mutabilis, feeding frequency decreased with increasing $\mathrm{pH}$ values with a slope of $-3.1(p<0.01)$. Predator body mass strongly affected consumption of lumbricid prey $(p<$ 0.0001; Fig. 2a; Supplementary 


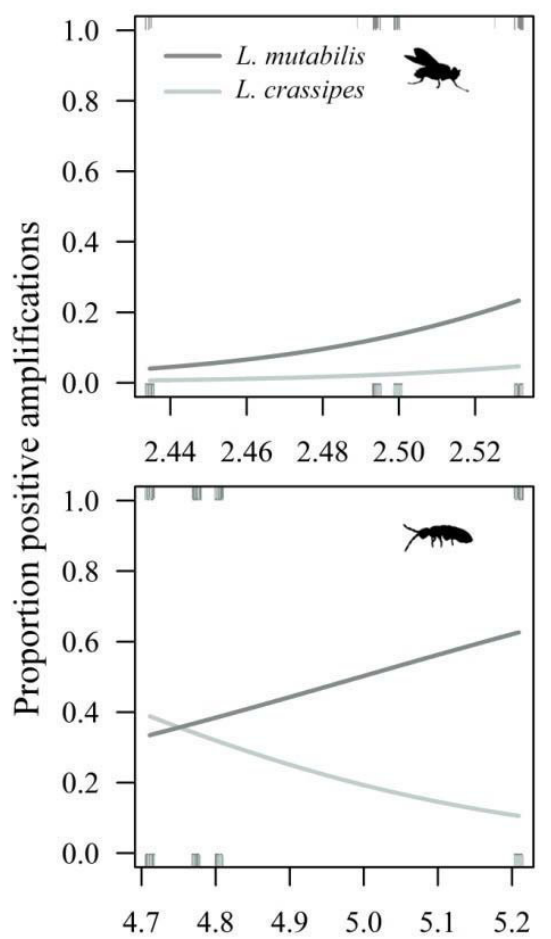

Log 10 abundance prey (Ind/ $\mathrm{m}^{2}$ )

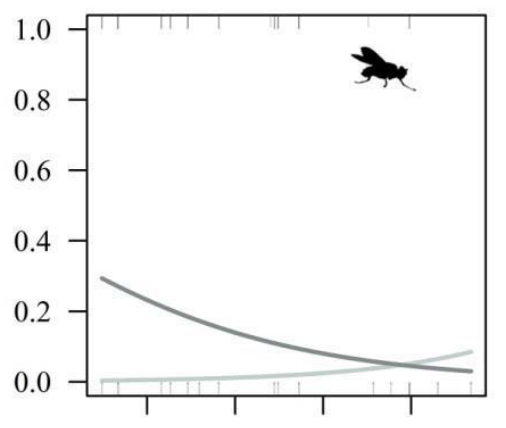

$\begin{array}{llll}-0.8 & -0.7 & -0.6 & -0.5\end{array}$

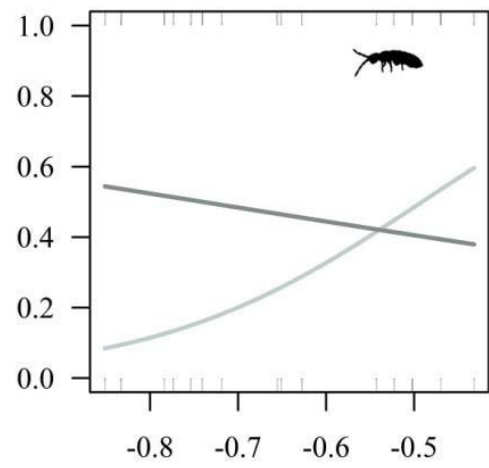

Log 10 litter mass $\left(\mathrm{g} / \mathrm{cm}^{2}\right)$

Fig. 1 | Changes in the frequency of detection given by GLM models of dipteran $(a, b)$ and collembolan prey DNA $(c, d)$ in the Hainich with prey abundance $(a, c)$ and amount of litter in the litter layer $(b, d)$. Rugs along the $x$-axis indicate the measured data points with a positive (upper horizontal-axis) and negative (lower X-axis) prey detection according to the binary characteristics of the statistics color coded as the centipede species.

material Table S5); starting with predators of about $10 \mathrm{mg}$ (equivalent to about $10 \mathrm{~mm}$ body length) detection of lumbricids increased exponentially. The probability of finding a feeding event increases with the log body mass with a slope of -6.3 , and of 4.1 with the squaretransformed log-body mass.

In the Schorfheide only predator body mass and prey species significantly affected prey consumption. Body mass significantly affected consumption of lumbricids by a slope of -23.3 and of 12.0 with the square-transformed body mass $(p<0.001$; Supplementary material Table S6) in both lithobiid species (Fig 2b). Similar to the Hainich, small (2.5-4 mg) and large centipedes (25-40 mg) were tested positive for lumbricid DNA whereas detection in mediumsized lithobiids (6-16 $\mathrm{mg})$ was low. 

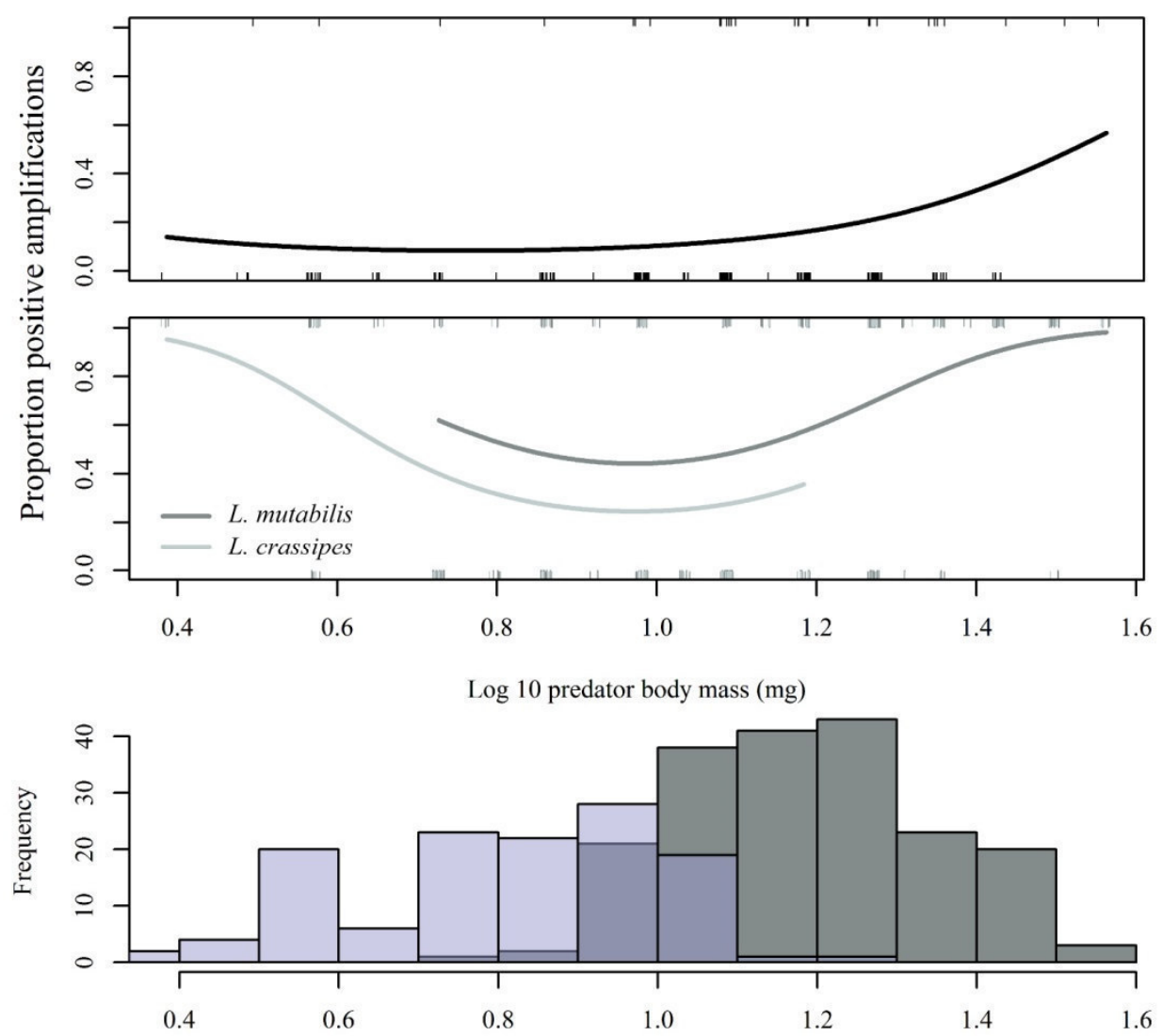

Log 10 predator body mass (mg)

Fig. 2 | Detection frequency of lumbricid prey DNA in the Schorfheide (a) and the Hainich (b) as affected by body mass of predators, and distribution of body mass of the measured centipedes (c). Rugs along the $\mathrm{x}$-axis indicate the measured data points with a positive (upper horizontal-axis) and negative (lower $\mathrm{X}$-axis) prey detection according to the binary characteristics of the statistics color coded as the centipede species.

\section{Discussion}

We hypothesized that feeding of soil predators is positively affected by low litter mass and high prey abundance while prey preference is driven by predator body size rather than forest type. Results of the present study suggest that the validity of these hypotheses depends on lithobiid centipede species.

Consumption frequency of collembolan and dipteran prey decreased significantly with the amount of litter in L. mutabilis while the opposite was true for $L$. crassipes. Our results corroborate findings from laboratory experiments by Kalinkat et al. (2012) that detection frequency for collembolan prey in $L$. mutabilis decreases with increasing habitat structure. 
Thick organic layers increase the search time for prey resulting in predators spending more energy for catching prey and eventually to switch to other prey. Additionally, large $L$. mutabilis preferably dwell in upper litter layers, whereas they are found only occasionally in lower horizons (Fründ 1987). This suggests that prey dilution reduces predation rates for large centipede predators, lessening top-down control of decomposer prey. Our field-derived results correspond well with other laboratory-based work, in which spiders feeding on collembolans (Vucic-Pestic et al. 2010b) and tardigrades preying on nematodes (Hohberg and Traunspurger 2005) showed to be significantly affected by habitat structure as a regulating factor of predator-prey interactions in soil systems.

Increase of predation rates for smaller centipedes however, may be driven by various factors: First, L. crassipes (and L. curtipes), which only show a low resistance against desiccation therefore dwelling predominantly in deeper litter layers (Fründ 1987, Jabin 2008), took advantage from an extension of their foraging range. Due to their small body size they are adapted to hunt in small crevices and burrows, which is why additional litter facilitates prey capture and consumption. Moreover, the absence of larger (lithobiid) predators, which can compete for same prey or even interact as intraguild predators, allows a better exploitation of its prey resources (Finke and Denno 2002). Fatty acid analysis of $L$. crassipes from the same lithobiid predators corroborate our findings, showing small $L$. crassipes being more effective in exploiting prey in deeper organic layers than the large $L$. mutabilis (Ferlian and Scheu this issue).

While negative correlation between litter mass and soil $\mathrm{pH}$ indicates decreased decomposition rate in acidic soils (Guckland et al. 2009, Trap et al. 2011) both factors are not associated with forest management type. The inconsistency of litter mass along the management gradient may be the reason why there were no significant interactions between prey detection rates and the four forest types, confirming our hypothesis. On the contrary, Ferlian and Scheu (this issue) found the diet of centipedes to differ between spruce and beech forests when using fatty acid analysis (FA). Despite we used in part the same individuals we could not confirm these results with molecular gut content analysis. However, the two methods target different aspects of predator - prey interactions with FA analysis providing information on the association of predators to different food web channels, such as the bacterial and fungal channel, whereas molecular gut content analysis providing information on links between predators and prey. In our study we used general prey primers neglecting that different collembolan species may feed on very different resources ranging 
from leaf litter to fungi to nematodes (Chahartaghi et al. 2005, Heidemann et al. this issue). The two methods therefore are complementary rather than redundant providing insight into different food web characteristics.

Based on functional response models of soil predators (Vucic-Pestic et al. 2010a, Rall et al. 2011) we expected the frequencies of detection of predators on prey to increase with increasing prey density. This could be demonstrated for $L$. mutabilis feeding on collembolan and dipteran prey, while consumption of $L$. crassipes did not change for dipteran prey or even decreased with increasing collembolan abundance. Similar to Brose (2010) our findings show that the capture frequency of predators varies with predator body size as smaller predators reach maximum feeding at lower prey density than larger predators. A higher abundance of collembolans prey might also form a kind of defense ("swarming") preventing predators from attacking (Vucic-Pestic et al. 2010b), therefore explaining a negative correlation between predation rate and prey abundance. In contrast to collembolan and dipteran prey, feeding on lumbricids in Schorfheide was high despite low prey densities. This discrepancy however, may be explained by predators in the Schorfheide feeding on small lumbricids, which typically are underrepresented in mustard and heat extracted samples (Eisenhauer et al. 2008).

This phenomenon could also explain the obvious rejection of our last hypothesis, stating that small predators preferably feed on small prey. Following an optimal body size ratio between predator and prey (Cohen et al. 1993, Brose 2010) we expected individuals of small species $L$. crassipes and $L$. curtipes predominantly feeding on small collembolan prey and only $L$. mutabilis to include large lumbricid prey in its diet. Indeed, only large $L$. mutabilis were tested positive for earthworms in the Hainich, while in the Schorfheide also the small $L$. crassipes fed on lumbricids. Poser (1988) showed $L$. crassipes and $L$. mutabilis to be able to subdue and kill earthworms if not longer than 1.5 and $3.0 \mathrm{~cm}$, respectively, suggesting that mostly juvenile or small individuals are attacked. Epigeic lumbricids living in the litter layer typically are of that size and are present in high numbers in the litter layer of temperate forests (Scheu and Poser 1996). Earthworms constitute a protein-rich food source (Sun et al. 1997) which is digested more easily than collembolans or dipterans due to missing chitin cuticle (Karasov et al. 2011). Therefore, large predators may switch to lumbricid prey for saving costs for digestion. Furthermore, prey preferences increase significantly with the predator-prey body-mass ratio (Kalinkat et al. 2011). In Schorfheide the frequency of detection on dipteran prey by L. mutabilis exponentially increased with predator body mass, 
peaked at $25 \mathrm{mg}$ and then decreased. Passive preference, as indicated by the allometric model (Kalinkat et al. 2011), can explain prey switching in predators exceeding 6-16 mg body mass from lumbricid towards dipteran prey.

Results of this study indicate that consumption rates of centipedes on collembolan, dipteran and lumbricid prey depend on a number of factors. Forest type does not control centipede feeding, as driving factors are not associated with forest management. Habitat structure, indicated as litter mass, provides refuges for prey thereby impeding predation by the large $L$. mutabilis but increasing predation by the small $L$. crassipes. In contrast, the large $L$. mutabilis takes advantage from higher prey abundance. Overall, results suggest that direction of feeding differs markedly between the two lithobiid species dominantly as a result of their different body size, confirming results of laboratory based studies on the dominant role of predator-prey body-size ratios for trophic interactions in soil systems (Kalinkat et al. 2011, Schneider et al. 2012). We conclude that when studying feeding interactions not only taxonomic affiliation, but also trans-species allometry to be considered.

\section{Acknowledgments}

We thank the managers of the Biodiversity Exploratories, Swen Renner, Sonja Gockel, Kerstin Wiesner, and Martin Gorke for their work in maintaining the plot and project infrastructure; Simone Pfeiffer and Christiane Fischer giving support through the central office, Michael Owonibi for managing the central data base, and Markus Fischer, Eduard Linsenmair, Dominik Hessenmöller, Jens Nieschulze, Daniel Prati, Ingo Schöning, François Buscot, Ernst-Detlef Schulze, Wolfgang W. Weisser and the late Elisabeth Kalko for their role in setting up the Biodiversity Exploratories project. In addition, we are grateful for the field work permits of the state environmental office of Thuringia and Brandenburg according to $\S 72$ BbgNatSchG. Special thanks to Mark Maraun, Christian Bluhm, David Ott, Emily Solly, Kerstin Heidemann, Guido Humpert and Amrei Binzer for support during field work, lab work, help with statistical analyses and the writing process.

\section{References}

Birkhofer, K. et al. 2012. General relationships between abiotic soil properties and soil biota 
across spatial scales and different land-use types. PloS one, 7, e43292.

Brose, U. et al. 2006. Allometric scaling enhances stability in complex food webs. - Ecol. Lett. 9: 1228-1236.

Brose, U. 2010. Body-mass constraints on foraging behavior determine population and foodweb dynamics. - Funct. Ecol. 24: 28-34.

Burnham, K.P. and Anderson, D.R. 2004. Multimodel inference - understanding AIC and BIC in model selection. - Sociol. Method. Res. 33: 261-304.

Chahartaghi, M. et al. 2005. Feeding guilds in Collembola based on nitrogen stable isotope ratios. - Soil. Biol. Biochem. 37: 1718-1725.

Cohen, J.E. et al. 1993. Body sizes of animal predators and animal prey in food webs. $-\mathrm{J}$. Anim. Ecol. 62: 67-68.

Crawley, M. J. 2007. The R Book. - John Wiley and Sons.

Dennis, P. and Sotherton, N.W. 1994. Behavioural aspects of staphylinid beetles that limit their aphid feeding potential in cereal crops. - Pedobiologia 38: 222-237.

Eisenhauer, N. et al. 2008. Efficiency of two widespread non- destructive extraction methods under dry soil conditions for different ecological earthworm groups. - Eur. J. Soil. Sci. 44: 141-145.

Eitzinger, B. et al. 2013. Unveiling soil food web links: New PCR assays for detection of prey DNA in the gut of soil arthropod predators. - Soil. Biol. Biochem. 57: 943-945.

Ferlian, O. and Scheu, S. (this issue). Shifts in trophic interactions with forest type in soil generalist predators as indicated by complementary analyses of fatty acids and stable isotopes. - Oikos.

Finke, D.L. and Denno, R.F. 2002. Intraguild predation diminished in complex-structured vegetation: implications for prey suppression. - Ecology 83: 643-652.

Fischer, M. et al. 2010. Implementing large-scale and long-term functional biodiversity research: The Biodiversity Exploratories. - Basic. Appl. Ecol. 11: 473-485.

Folmer, O. et al. 1994. DNA primers for amplification of mitochondrial cytochrome c oxidase subunit I from diverse metazoan invertebrates. - Mol. Mar. Biol. Biotech. 3: 294-299.

Fründ, H.C. 1987. Räumliche Verteilung und Koexistenz der Chilopoden in einem Buchen Altbestand. - Pedobiologia 30: 19-29.

Guckland, A. et al. 2009. Acidity, nutrient stocks, and organic-matter content in soils of a temperate deciduous forest with different abundance of European beech (Fagus sylvatica L.). - J. Plant. Nutr. Soil. Sc. 172: 500-511.

Halaj, J. and Wise, D.H. 2002. Impact of a Detrital Subsidy on Trophic Cascades in a Terrestrial Grazing Food Web. - Ecology 83: 3141-3151.

Harper, G.L. et al. 2005. Rapid screening of invertebrate predators for multiple prey DNA targets. - Mol. Ecol. 14: 819-827.

Heidemann, K. et al. (this issue). Free-living nematodes as prey for higher trophic levels of forest soil food webs. - Oikos.

Hohberg, K. and Traunspurger, W. 2005. Predator-prey interaction in soil food web: functional response, size-dependent foraging efficiency, and the influence of soil texture. - Biol. Fert. Soils. 41: 419-427. 
Jabin, M. 2008. Influence of environmental factors on the distribution pattern of centipedes (Chilopoda) and other soil arthropods in temperature deciduous forest. - Cuvillier Verlag, Göttingen, Germany.

Juen, A. and Traugott, M. 2005. Detecting predation and scavenging by DNA gut-content analysis: a case study using a soil insect predator-prey system. - Oecologia 142: 34452.

Juen, A. and Traugott, M. 2007. Revealing species-specific trophic links in soil food webs: molecular identification of scarab predators. - Mol. Ecol. 16: 1545-57.

Kalinkat, G. et al. 2011. The allometry of prey preferences. - PloS one 6: e25937.

Kalinkat, G. et al. 2012. Habitat structure alters top-down control in litter communities. Oecologia DOI 10.1007/s00442-012-2530-6.

Karasov, W.H. et al. 2011. Ecological Physiology of Diet and Digestive Systems. - Annu. Rev. Physiol. 73: 69-93.

King, R. A. et al. 2008. Molecular analysis of predation: a review of best practice for DNAbased approaches. - Mol. Ecol. 17: 947-63.

Klarner, B. et al. (this issue). Trophic shift of soil animal species with forest type as indicated by stable isotope analysis. - Oikos.

Kuusk, A. K. and Agustí, N. 2007. Group-specific primers for DNA-based detection of springtails (Hexapoda: Collembola) within predator gut contents. - Mol. Ecol. Resour. 8: 678-681.

Langellotto, G. A. and Denno, R.F. 2004. Responses of invertebrate natural enemies to complex-structured habitats: a meta-analytical synthesis. - Oecologia 139: 1-10.

Poser, T. 1988. Chilopoden als Prädatoren in einem Laubwald. - Pedobiologia 31: 261-281.

Poser, T. 1990. Die Hunderfüßer (Myriapoda, Chilopoda) eines Kalkbuchenwaldes: Populationsökologie, Nahrungsbiologie und Gemeinschaftsstrucktur. - Dissertation, University of Goettingen.

Post, D.M. 2002. Using stable isotopes to estimate trophic position: models, methods, and assumptions. - Ecology 83: 703-718.

R Development Core Team 2010. R: A Language and Environment for Statistical Computing. Vienna, Austria.

Rall, B.C. et al. 2011. Taxonomic versus allometric constraints on non-linear interaction strengths. -Oikos 120: 483-492.

Salmon, S. et al. 2008. Linking forest dynamics to richness and assemblage of soil zoological groups and to soil mineralization processes. - Forest Ecol. Manag. 256: 1612-1623.

Scheu, S. and Poser, G. 1996. The soil macrofauna (Diplopoda, Isopoda, Lumbricidae and Chilopoda) near tree trunks in a beechwood on limestone: indications for stemflow induced changes in community structure. - Appl. Soil Ecol. 3: 115-125.

Scheu, S. and Setälä, H. 2002. Multitrophic interactions in decomposer foodwebs. In: Tscharntke, T. and Hawkins, B.A. (eds.), Multitrophic level interactions. Cambridge University Press, pp. 223-264.

Scheu, S. et al. 2003. The soil fauna community in pure and mixed stands of beech and spruce of different age: trophic structure and structuring forces. - Oikos 101: 225-238. 
Schneider, F.D. et al. 2012. Body mass constraints on feeding rates determine the consequences of predator loss. - Ecol. Lett. 15: 436-443.

Sun, Z. J. et al. 1997. Earthworm as a potential protein resource. - Ecol. Food Nutr. 36: 221236.

Trap, J. et al. 2011. Does moder development along a pure beech (Fagus sylvatica L.) chronosequence result from changes in litter production or in decomposition rates? Soil Biol. Biochem. 43: 1490-1497.

Vucic-Pestic, O. et al. 2010a. Allometric functional response model: body masses constrain interaction strengths. - J. Anim. Ecol. 79: 249-256.

Vucic-Pestic, O. et al. 2010b. Habitat structure and prey aggregation determine the functional response in a soil predator-prey interaction. - Pedobiologia 53: 307-312.

Waldner, T. and Traugott, M. 2012. DNA-based analysis of regurgitates: a noninvasive approach to examine the diet of invertebrate consumers. - Mol. Ecol. Resour. 12: 669-675. 


\section{Supplementary}

Table S1 | Number and percentage of Lithobius sp. tested positive for prey DNA in exploratories Hainich (HEW) and Schorfheide (SEW). Columns marked with a star $\left(^{*}\right)$ are percentages in relation to the number of tested predators. Number of predators tested positive for 1, 2 or 3 prey groups are presented in the last column. Individuals of $L$. curtipes (SEW only) were included in number of $L$. crassipes for statistical analyses.

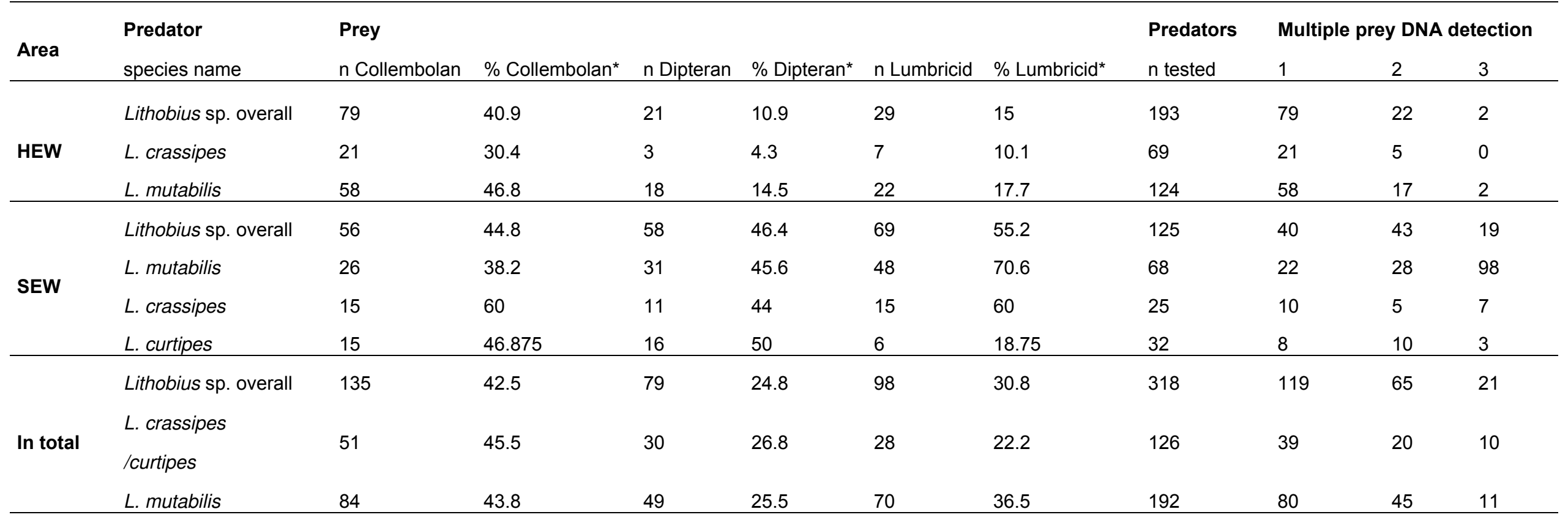


Table S2 | Selection of most parsimonious model by comparison of Akaike Information Criterion (AIC). Asterisk $\left(^{*}\right)$ denote factor being significant, plus $(+)$ denote factor being in a significant interaction.

\begin{tabular}{|c|c|c|c|c|c|}
\hline & \multicolumn{5}{|c|}{ Prey type } \\
\hline & & & Dipteran & Collembolan & Lumbricid \\
\hline \multirow{9}{*}{ GLM 1} & \multirow{2}{*}{ Results } & DF & 20 & 20 & 20 \\
\hline & & $\Delta \delta \mathrm{AIC}$ & 16.968 & 11.1524 & 16.7522 \\
\hline & \multirow{7}{*}{ Factors } & Exploratory region & yes* & yes+ & yes $^{*}$ \\
\hline & & Forest type & yes & yes & yes+ \\
\hline & & Predator species & yes+ & yes+ & yes* \\
\hline & & Body mass predator & yes $^{*}$ & yes & yes $^{*}$ \\
\hline & & Abundance prey & yes & yes & yes \\
\hline & & Litter mass & yes+ & yes* & yes \\
\hline & & Soil pH & yes & yes+ & yes \\
\hline \multirow{9}{*}{$\begin{array}{l}\text { GLM } 2 \text { (step } \\
\text { model of } \\
\text { GLM 1) }\end{array}$} & \multirow[b]{2}{*}{ Results } & DF & 6 & 10 & 11 \\
\hline & & $\Delta \delta \mathrm{AIC}$ & 0 & 0 & 2.2172 \\
\hline & \multirow{7}{*}{ Factors } & Exploratory region & yes* & yes & yes $^{*}$ \\
\hline & & Forest type & no & no & yes+ \\
\hline & & Predator species & yes+ & yes+ & yes* \\
\hline & & Body mass predator & yes $^{*}$ & no & yes $^{*}$ \\
\hline & & Abundance prey & no & yes $^{*}$ & no \\
\hline & & Litter mass & yes+ & yes* & no \\
\hline & & Soil pH & no & yes+ & no \\
\hline \multirow{9}{*}{ GLM 3} & \multirow{2}{*}{ Results } & DF & 1 & 1 & 1 \\
\hline & & $\Delta \delta \mathrm{AIC}$ & 66.3476 & 10.3145 & 84.1549 \\
\hline & \multirow{7}{*}{ Factors } & Exploratory region & no & no & no \\
\hline & & Forest type & no & no & no \\
\hline & & Predator species & no & no & no \\
\hline & & Body mass predator & no & no & no \\
\hline & & Abundance prey & no & no & no \\
\hline & & Litter mass & no & no & no \\
\hline & & Soil pH & no & no & no \\
\hline \multirow{9}{*}{$\begin{array}{l}\text { GLM } 4 \text { (step } \\
\text { model of } \\
\text { GLM 3) }\end{array}$} & \multirow{2}{*}{ Results } & DF & 5 & 3 & 5 \\
\hline & & $\Delta \delta \mathrm{AIC}$ & 3.6721 & 2.8112 & 0 \\
\hline & \multirow{7}{*}{ Factors } & Exploratory region & yes $^{*}$ & no & yes $^{*}$ \\
\hline & & Forest type & no & no & no \\
\hline & & Predator species & yes+ & no & yes \\
\hline & & Body mass predator & yes $^{*}$ & no & yes $^{*}$ \\
\hline & & Abundance prey & no & yes $^{*}$ & no \\
\hline & & Litter mass & no & no & no \\
\hline & & Soil pH & No & Yes* & no \\
\hline
\end{tabular}


Table S3 | Table of Estimates of generalized linear model (GLM 2) on the effect of predator species, predator body mass, prey abundance, litter mass and soil $\mathrm{pH}$ for presence of dipteran prey DNA in the Hainich exploratory. SE represents the standard error of the estimated coefficient of the model The AICs defining the best fitting model are provided in Table 1.

\begin{tabular}{lllll}
\hline & Estimate & Std. Error & Z value & P value \\
\hline & & & & \\
L. crassipes & -68.779 & 26.953 & -2.552 & 0.0107 \\
L. mutabilis & -78.007 & 27.438 & -2.843 & 0.0045 \\
Predator body mass & 33.402 & 25.063 & 1.333 & 0.1826 \\
Predator body mass ${ }^{2}$ & -13.157 & 10.575 & -1.244 & 0.2135 \\
Prey abundance & 20.434 & 8.860 & 2.306 & 0.0211 \\
Litter mass & 7.754 & 5.493 & 1.412 & 0.1581 \\
L. mutabilis $x$ Litter mass & -13.966 & 6.025 & -2.318 & 0.0204 \\
\hline
\end{tabular}

Table S4 | Table of Estimates of generalized linear model (GLM 2) on the effect of predator species, predator body mass, prey abundance, litter mass and soil pH for presence of collembolan prey DNA in the Hainich exploratory. Std. Error represents the standard error of the estimated coefficient of the model. The AICs defining the best fitting model are provided in Table 1.

\begin{tabular}{lllll}
\hline & Estimate & Std. Error & Z value & P value \\
\hline & & & & \\
L. crassipes & 19.8531 & 7.4969 & 2.648 & 0.00809 \\
L. mutabilis & 6.4564 & 5.7424 & 1.124 & 0.26086 \\
Predator body mass & -8.4593 & 4.6798 & -1.808 & 0.07066 \\
Predator body mass ${ }^{2}$ & 4.1918 & 2.2958 & 1.826 & 0.06788 \\
Prey abundance & -3.3777 & 1.6220 & -2.082 & 0.03730 \\
Litter mass & 6.6102 & 2.8597 & 2.312 & 0.02080 \\
Soil pH & 0.6688 & 0.8798 & 0.760 & 0.44718 \\
L. mutabilis $\times$ Prey abundance & 5.7919 & 2.0353 & 2.846 & 0.00443 \\
L. mutabilis $\times$ Litter mass & -8.2022 & 3.3140 & -2.475 & 0.01332 \\
L. mutabilis $\times$ Soil $\mathrm{pH}$ & -3.0617 & 1.0766 & -2.844 & 0.00446 \\
\hline
\end{tabular}


Table S5 | Table of Estimates of generalized linear model (GLM 2) on the effect of predator species, predator body mass, prey abundance, litter mass and soil $\mathrm{pH}$ for presence of lumbricid prey DNA in the Hainich exploratory. Std. Error represents the standard error of the estimated coefficient of the model. The AICs defining the best fitting model are provided in Table 1

\begin{tabular}{lllll}
\hline & Estimate & Std. Error & Z value & $P$ value \\
\hline & & & & \\
Predator body mass & -6.3055 & 1.1824 & -5.3330 & 0.0000 \\
Predator body mass $^{2}$ & 4.1453 & 0.9724 & 4.2630 & 0.0000 \\
\hline
\end{tabular}

Table S6 | Table of Estimates of generalized linear model (GLM 2) on the effect of predator species, predator body mass, prey abundance, litter mass and soil $\mathrm{pH}$ for presence of lumbricid prey DNA in the Schorfheide exploratory. Std. Error represents the standard error of the estimated coefficient of the model. The AICs defining the best fitting model are provided in Table 1

\begin{tabular}{lllll}
\hline & Estimate & Std. Error & Z value & P value \\
\hline & & & & \\
L. crassipes & 10.2051 & 3.2518 & 3.138 & 0.001699 \\
L. mutabilis & 11.098 & 3.322 & 3.341 & 0.000835 \\
& - & & & \\
Body mass & 23.3028 & 6.764 & -3.445 & 0.000571 \\
Body mass $^{2}$ & 11.9783 & 3.4403 & 3.482 & 0.000498 \\
\hline
\end{tabular}




\section{Chapter 4}

Carbon food resources of earthworms of different ecological groups as indicated by ${ }^{13} \mathrm{C}$ compound-specific stable isotope analysis

Olga Ferlian, Simone Cesarz, Sven Marhan, Stefan Scheu Soil Biology \& Biochemistry (2014), published 


\begin{abstract}
One of the challenges in soil ecology has been to unravel which organisms utilise stable carbon in soil. Recent studies indicated that endogeic earthworms are able to mobilise stable carbon compounds. However, it remains unclear which compounds of stabilised carbon in soil is utilised. Furthermore, current knowledge on ecological groups and food resources of earthworms mainly is based on direct observations only reflecting what is ingested but not what actually is assimilated. We analysed seven earthworm species of beech and spruce forests and the respective litter, earthworm middens and soils and employed compoundspecific ${ }^{13} \mathrm{C}$ stable isotope analysis of fatty acids (FAs) to identify carbon resources of earthworms. To relate food resources to carbon compounds of different stability we analysed ${ }^{13} \mathrm{C}$ signatures of FAs of different particle size fractions. FA $\delta^{13} \mathrm{C}$ profiles of epigeic and endogeic earthworm species indicated assimilation of recently fixed and recalcitrant carbon resources, respectively, whereas anecic earthworms assimilated a mixture of resources of different stability. Utilisation of carbon resources did not differ between beech and spruce forests. Endogeic species were associated with neutral lipids of soil particle size fractions with $\delta^{13} \mathrm{C}$ signatures of the bacterial marker a15:0 in earthworms resembling those of the clay fraction. This suggests that they preferentially assimilated carbon associated with small particle size fractions attached to clay-humus complexes. The results showed that earthworms of different ecological groups utilise carbon pools of different origin and stability. As indicated by neutral lipids of bacterial origin physically stabilised organic matter contributes to the nutrition of endogeic earthworms.
\end{abstract}

Keywords: Clay, Endogeic, Fatty acids, Soil organic matter, Soil particle size fractions, Stable carbon pools 


\section{Introduction}

Earthworms function as important ecosystem engineers structuring the habitat for other soil biota (Jones et al., 1994). By comminution of litter and mixing of litter and mineral soil they accelerate microbial processes such as decomposition of organic matter and nutrient mineralisation (Edwards and Fletcher, 1988; Wolters, 2000). However, incorporation of organic particles into soil aggregates may also reduce decomposition of organic matter (Gunina and Kuzyakov, 2014). Earthworm activity is known to vary with soil pH but also depends on forest type, e.g., spruce forests are characterised by low bioturbation activity and low incorporation of organic matter into soil aggregates. Importantly, the stability of organo-mineral complexes depends on soil texture with small particles, such as clay, fostering cohesion between particles into aggregates due to large surface-to-volume ratio (Balabane, 1997; Denef and Six, 2005). Carbon in such clay-humus complexes may be conserved for hundreds or even thousands of years (Skjemstad et al. 1993, Collins et al., 2000). One of the challenges in soil ecology has been to unravel which organisms utilise stable carbon in soil.

Earthworms are classified into three ecological groups: epigeic, anecic and endogeic species (Bouché, 1977). However, ecological categories and feeding strategies of earthworms have been shown to change during ontogeny (Briones and Schmidt, 2004) and are mainly based on the material the animals ingest rather than what they assimilate. In contrast to epigeic and anecic species, endogeic earthworms have low assimilation efficiencies (1-2 \%) which they compensate by high ingestion rates (Scheu, 1991). Supporting the trophic distinctness of endogeic species, Schmidt et al. (1997) found ${ }^{15} \mathrm{~N}$ signatures of endogeic earthworms to be less depleted as compared to those of epigeic and anecic earthworms. ${ }^{13} \mathrm{C}$ and ${ }^{14} \mathrm{C}$ isotope signatures of endogeic earthworm species suggest that these resources comprise of carbon of an average age of several years (Briones et al., 2005; Hyodo et al., 2008) supporting suggestions that endogeic earthworms are able to utilise stable carbon compounds in soil (Scheu, 1991; Martin et al., 1992; Briones and Schmidt, 2004; Fox et al., 2006; Marhan et al., 2007a; Fonte et al., 2007). However, it remains unclear which compounds of stabilised carbon in soil are utilised. Further, earthworms also have been shown to utilise easily accessible food resources, such as glucose (Tiunov and Scheu, 2004), and living soil organisms including fungi (Wolters, 2000), bacteria (Dungait et al., 2008), protozoa (Bonkowski and Schaefer, 1997) and nematodes (Monroy et al., 2008). Therefore, the extent labile and stable carbon pools contribute to 
endogeic earthworm nutrition remains unclear.

Organic matter associated with stable carbon pools comprises a multitude of complex recalcitrant compounds including cellulose, lignin and humic acids, but also simple and easily degradable compounds such as sugars, amino acids and lipids (Gleixner et al., 2002; Liu et al., 2013). The latter may account for $4-8 \%$ of the organic matter in aggregates and comprises different types of lipids (Gleixner et al., 2002; Rethemeyer et al., 2004). Due to stronger microbial processing and thereby more pronounced ${ }^{13} \mathrm{C}$ fractionation, these lipids are characterised by higher ${ }^{13} \mathrm{C}$ signatures as compared to lipids not being associated with aggregates (Gunina and Kuzyakov, 2014; Marschner et al., 2008). ${ }^{13} \mathrm{C}$ signatures of lipids, therefore, may allow tracing the origin of carbon pools used by earthworms.

As shown for collembolans, oribatid mites and soil macrofauna, stable isotope signatures of lipids, i.e. ${ }^{13} \mathrm{C}$ compound-specific stable isotope analysis in fatty acid (FA) biomarkers, are a powerful tool for tracing the diet of consumers and its origin (Chamberlain et al., 2004; Pollierer et al., 2012). Dietary lipids are incorporated into consumer tissue without or with only minor changes ("dietary routing"; Blem, 1976; Pond, 1981). Neutral lipids form part of the deposit fat of eukaryotes and also occur in the soil matrix, whereas phospholipids form part of membranes of bacteria, fungi and other biota. Feeding on soil earthworms ingest and incorporate lipids of different origin which may be identified by using its stable isotope signatures. Earlier studies used FA analysis to trace food resources of earthworms (Sampedro et al., 2006), but studies using ${ }^{13} \mathrm{C}$ compound-specific stable isotope analysis are lacking. Current knowledge on food resources in earthworms mainly is based on direct observation of the gut content only reflecting what is ingested but not what actually is assimilated (Briones and Schmidt, 2004) contrasting approaches using stable isotope and FA analysis allowing insight into resources which actually are assimilated. Moreover, most studies have been conducted in the laboratory, field studies are scarce (Curry and Schmidt, 2007).

We analysed seven earthworm species of beech and spruce forests and employed compound-specific ${ }^{13} \mathrm{C}$ stable isotope analysis of FAs to identify carbon resources of earthworms. To relate food resources to carbon compounds of different stability we analysed ${ }^{13} \mathrm{C}$ signatures of FAs of different particle size fractions. We hypothesised that (1) the combined compound-specific ${ }^{13} \mathrm{C}$ stable isotope analysis of FAs in earthworm ecological groups and in soil carbon pools of different stability allows tracing the origin of food resources 
of earthworms, and that (2) in particular endogeic earthworms incorporate lipids from stabilised soil organic matter pools associated with clay fractions.

\section{Materials and methods}

\section{Study sites}

The study formed part of the 'Biodiversity Exploratories', an integrated research project on biodiversity and ecosystem functioning in three regions of Germany (Fischer et al., 2010), and was set-up in the Hainich, a mountain range in Thuringia being one of the largest forestcovered regions in Germany of an altitude of 330 - 490 m a.s.I. Mesozoic cuesta landscape as sedimentary rock is overlain by limestone and loess. Soil pH ranged from 4.0 to 5.5; mean annual temperature is about $7^{\circ} \mathrm{C}$. Due to different rates of bioturbation of organic with mineral layers and expected distinct degrees of recalcitrance between different forest types, four beech and four coniferous (spruce) forest sites with a tree age of about 70 years were investigated. Mean distance between sites was between 1.5 and $17 \mathrm{~km}$. Soils of five of the sites were characterised as Luvisols independent of forest type, soils of all other sites as Stagnosols. The beech forest sites are dominated by European beech (Fagus sylvatica L.) interspersed with single common ash (Fraxinus excelsior L.) and sycamore maple trees (Acer pseudoplatanus L.). The herb and shrub layer predominantly consists of Allium ursinum (L.), Anemone nemorosa (L.) and Galium odoratum ((L.) Scopoli). Soil texture of beech stands is approximately $0.4 \%$ medium and coarse sand, $5.8 \%$ fine sand, $69.0 \%$ silt and 24.8 \% clay (I. Schöning, unpublished data). In the spruce (Picea abies L.) forests, the herb layer comprises Dryopteris dilatata ((Hoffm.) A. Gray), Impatiens parviflora (DC.) and Oxalis acetosella (L.). The shrub layer comprises mainly Rubus idaeus (L.) and seedlings of European beech. Soil texture is approximately $1.4 \%$ medium and coarse sand, $4.9 \%$ fine sand, $58.2 \%$ silt and $35.5 \%$ clay.

\section{Experimental set-up}

Adult earthworms were sampled by a combination of modified mustard extraction (Gunn, 1992) and hand-sorting. Animals were stored individually in plastic tubes placed on ice to reduce metabolism and avoid break down of earthworm FAs. At each of the sites in beech 
and spruce forests, one litter, upper soil $\left(0-10 \mathrm{~cm}, A_{h}\right.$ horizon) and lower soil $(10-20 \mathrm{~cm}$, $A_{h}$ horizon) sample was randomly taken as well as middens of the anecic earthworm $L$. terrestris were collected for phospholipid FA (PLFA) analysis, ${ }^{13} \mathrm{C}$ compound-specific stable isotope analysis in FAs of microbial communities, neutral lipid FA (NLFA) analysis of soil particle size fractions and bulk stable isotope analysis of soil particle size fractions. All samples were frozen at $-21^{\circ} \mathrm{C}$ until further processing.

The following seven earthworm species common at all study sites were selected for the analyses: L. terrestris, Lumbricus rubellus (Hoffmeister), Lumbricus castaneus (Savigny), Dendrobaena octaedra (Savigny), Octolasion tyrtaeum (Savigny), Aporrectodea caliginosa (Savigny) and Aporrectodea rosea (Savigny). Three or more replicates per forest type were analysed except for rare species. Prior to analysis animals were cleared from attached material and washed with deionised water; gut contents were removed by dissection and rinsing.

\section{Soil particle size fractionation}

Part of each soil sample (upper and lower soil merged) was sieved (4 $\mathrm{mm}$ mesh) to remove plant roots and stones and for homogenisation. Samples were physically disaggregated by low-energy sonication (Stemmer et al., 1998). Particle sizes of medium and coarse sand (> $250 \mu \mathrm{m})$, fine sand $(250-63 \mu \mathrm{m}$, referred to as $>63 \mu \mathrm{m})$, silt $(63-2 \mu \mathrm{m}$, referred to as $>2$ $\mu \mathrm{m})$ and clay $(2-0.1 \mu \mathrm{m}$, referred to as $>0.1 \mu \mathrm{m})$ were fractionated by several steps of wetsieving and centrifugation as described in Marhan et al. (2007b). Despite containing appreciable amounts of organic matter, the former two fractions are referred to as sand fractions.

\section{Analysis of fatty acids}

Earthworm lipids were extracted and fractionated as described in Haubert et al. (2004). Neutral lipids were dried $\left(50^{\circ} \mathrm{C}\right)$ using a rotation vacuum concentrator (RVC 2-25, Christ, Osterode am Harz, Germany). Then, lipids were saponified, methylated and washed using the protocol for the Sherlock Microbial Identification System (MIDI Inc., Newark, USA). To gain comparable PLFA methyl esters of the same molecular structure as NLFA methyl 
esters of earthworms, lipids extracted from litter, soil and earthworm middens (PLFAs) and part of the soil particle size fractions (NLFAs) were processed as described in Frostegård et al. (1993). The obtained FA methyl esters were transferred into vials, capped and analysed via gas chromatography (Clarus 500, Perkin Elmer, Waltham, USA). Helium was used as carrier gas and FAs were identified by a flame ionisation detector (capillary column: $30 \mathrm{~m} \mathrm{x}$ $0.32 \mathrm{~mm}$ i.d., $0.25 \mu \mathrm{m}$ film thickness; PE-5, Perkin Elmer, Waltham, USA). The temperature programme started with a temperature of $60^{\circ} \mathrm{C}$ and increased to $160^{\circ} \mathrm{C}$ in steps of $30^{\circ} \mathrm{C}$ per minute and afterwards to $260^{\circ} \mathrm{C}$ in steps of $3^{\circ} \mathrm{C}$ per minute. On the basis of retention time and comparison with standard mixtures, FA methyl esters were identified (FAMEs and BAMEs, Sigma-Aldrich, St. Louis, USA). The following FAs served as biomarkers: i15:0, a15:0, i16:0 and i17:0 (methyl-branched FAs, for gram-positive bacteria); cy 17:0 and cy19:0

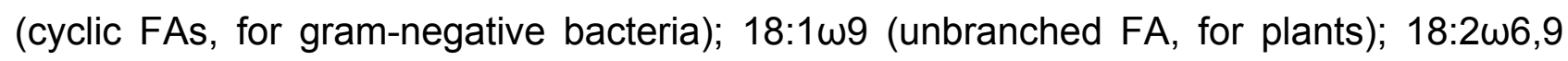
(unbranched FA, for fungi). The ratio of $18: 1 \omega 9$ and $18: 2 \omega 6,9$ was used to distinguish between plant and fungal dominated FA composition as both were only relative marker FAs. Data were randomly verified using GC-MS (GC: Varian CP-3800, Walnut Creek, USA) with a fused silica column (30 m x $0.32 \mathrm{~mm}$ i.d., $0.25 \mu \mathrm{m}$ film thickness; ZB-5MS, Phenomenex Zebron, Torrance, CA, USA) coupled to a $1200 \mathrm{~L}$ mass spectrometer.

\section{Compound-specific ${ }^{13} \mathrm{C}$ fatty acid analysis}

For the analysis of $\delta^{13} \mathrm{C}$ in FAs the obtained FA methyl esters of earthworms, middens, litter, upper soil, lower soil and soil particle size fractions were analysed using a trace gas chromatograph coupled to a Delta Plus mass spectrometer via GC combustion interface using helium as carrier gas (Thermo Finnigan, Bremen, Germany). The temperature programme started with $60^{\circ} \mathrm{C}$ and increased to a temperature of $310^{\circ} \mathrm{C}$ in steps of $6^{\circ} \mathrm{C}$ per minute and held at $310^{\circ} \mathrm{C}$ for $15 \mathrm{~min}$. Samples were injected at $250^{\circ} \mathrm{C}$. FA methyl esters were identified on the basis of retention time and comparison with standard mixtures. Vienna Pee Dee belemnite served as primary standard. Stable isotope ratios are reported using the $\delta$ notation as $\delta^{13} \mathrm{C}(\%)=\left[\left({ }^{13} \mathrm{C} /{ }^{12} \mathrm{C}\right)\right.$ sample $/\left({ }^{13} \mathrm{C} /{ }^{12} \mathrm{C}\right)$ standard -1$]{ }^{*} 1000$. FA isotope ratios were corrected for isotope ratios of the methyl moiety as described in Pollierer et al. (2012). 


\section{${ }^{13} \mathrm{C}$ analysis of soil particle size fractions}

The remaining soil particle size fraction material of beech and spruce forest sites was dried at $105^{\circ} \mathrm{C}$ for $24 \mathrm{~h}$ before analysing natural variations in $\delta^{13} \mathrm{C}$. Isotope analyses were conducted using an elemental analyser (NA 1500, Carlo Erba, Mailand, Italy) coupled to a mass spectrometer (Delta V Plus, Thermo Fisher, Bremen, Germany). Stable isotope signatures are expressed using the $\delta$ notation as described above. PD belemnite served as primary standard; for internal calibration acetanilide (Merck, Darmstadt, Germany) was used.

\section{Statistical analysis}

Absolute amounts of NLFAs and PLFAs were converted into percentage values and logittransformed. NLFA profiles of earthworm species and PLFA profiles of litter, upper soil, lower soil and middens of beech and spruce forest sites were analysed by discriminant function analysis (DFA). Due to the high number of different FAs gained, for PLFA data nonmetric multidimensional scaling (NMDS) was used prior to DFA. In case of significant DFA, proportions of individual FAs were analysed by single factor analysis of variance (ANOVA). Means were compared by Tukey's honestly significant difference (HSD) test. Compoundspecific $\delta^{13} \mathrm{C}$ signature profiles of all FAs were analysed using DFA (earthworm species, midden, litter and upper and lower soil) and General Linear Model (GLM, endogeic earthworm species and soil particle size fractions). As forest type did not affect $\delta^{13} \mathrm{C}$ signature profiles of FAs, samples of beech and spruce forests were pooled in all further analyses. Furthermore, $\delta^{13} \mathrm{C}$ signature profiles in FAs of prokaryotic and eukaryotic origin

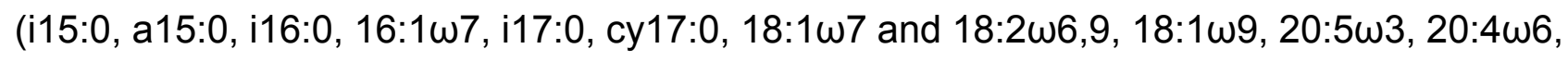
20:1 $\omega 9$, respectively) were compared between the Aporrectodea species and the two soil

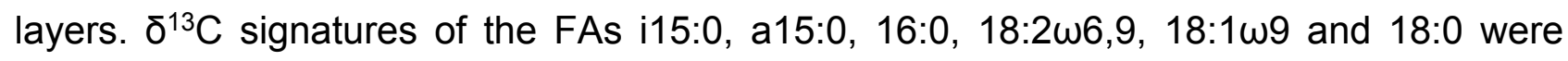
chosen as target FAs for analysis of individual FAs via single factor ANOVA. Means were compared by Tukey's HSD test. All statistical analyses were performed using STATISTICA 10 for Windows (StatSoft Inc, Tulsa, OK, USA). 


\section{Results}

\section{Fatty acid profiles of resources}

PLFA composition of resources (earthworm middens, litter, upper soil and lower soil) differed significantly between beech and spruce forests (DFA after NMDS; reduced to four dimensions; $\left.F_{24,5}=5.71, P=0.03\right)$. In beech forests, PLFA composition differed significantly between resources (DFA; $F_{12,24}=4.24, P<0.01$; Fig. 1a; see Supplementary material Table S3) with earthworm middens and litter differing significantly from upper soil as well as from lower soil. Differences were pronounced in the bacterial marker FAs i15:0, a15:0, i16:0, i17:0

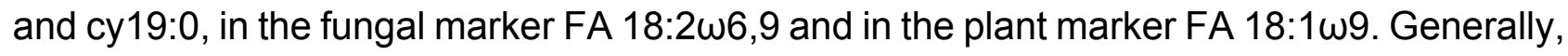
amounts of bacterial marker FAs were high in both soil horizons and low in middens and litter (Fig. 2, Table 1). Amounts of the fungal marker 18:2w6,9 decreased from middens and litter to upper and lower soil; amounts of the plant marker decreased in the order litter > midden > upper > lower soil. As plant and fungal markers individually represent only relative biomarkers, ratios of both were used to detect dominant basal resources. Plant-to-fungal marker ratios indicated that middens and litter were more intensively colonised by fungi as compared to upper and lower soil $(0.92 \pm 0.27,0.97 \pm 0.11,2.72 \pm 1.02$ and $2.65 \pm 0.56$ for middens, litter, upper soil and lower soil, respectively).

In spruce forests FA composition also differed significantly between resources, but differences were less pronounced than in beech forests (DFA after NMDS; reduced to four dimensions; $F_{15,16}=2.33, P<0.05$; Supplementary material Table S3) and only FA composition of litter differed from that of the upper and lower soil layer. For concentrations of individual FAs (percentages of total), differences were pronounced in the bacterial markers $\mathrm{i} 15: 0$ and a15:0 being high in the two soil layers and low in litter (Table 1). Furthermore, concentrations of the marker FA 18:1 $\omega 9$ differed between resources being highest in litter, intermediate in middens and upper soil, and lowest in lower soil. The plantto-fungal marker ratio indicated higher fungal colonisation of middens and litter as compared to the lower soil layer $(1.21 \pm 0.17,1.01 \pm 0.16$ and $3.98 \pm 1.13$, respectively) 
(a)
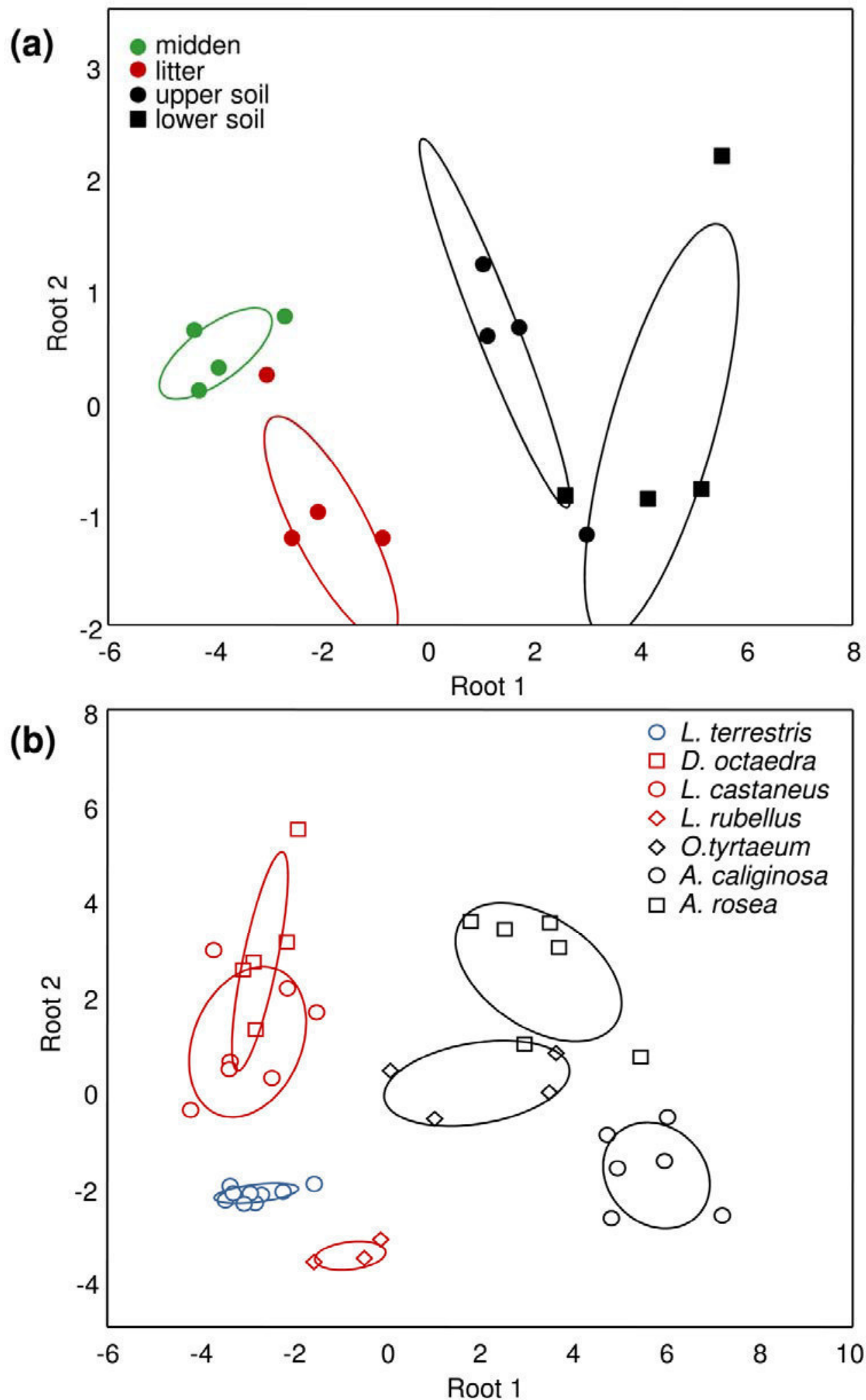

Fig. 1 | Discriminant function analysis of (a) PLFA composition in litter, earthworm middens, upper soil and lower soil in beech forests, and (b) NLFA composition of earthworm species pooled for forest type. Ellipses represent confidence ranges of the data at $P=0.05$. 


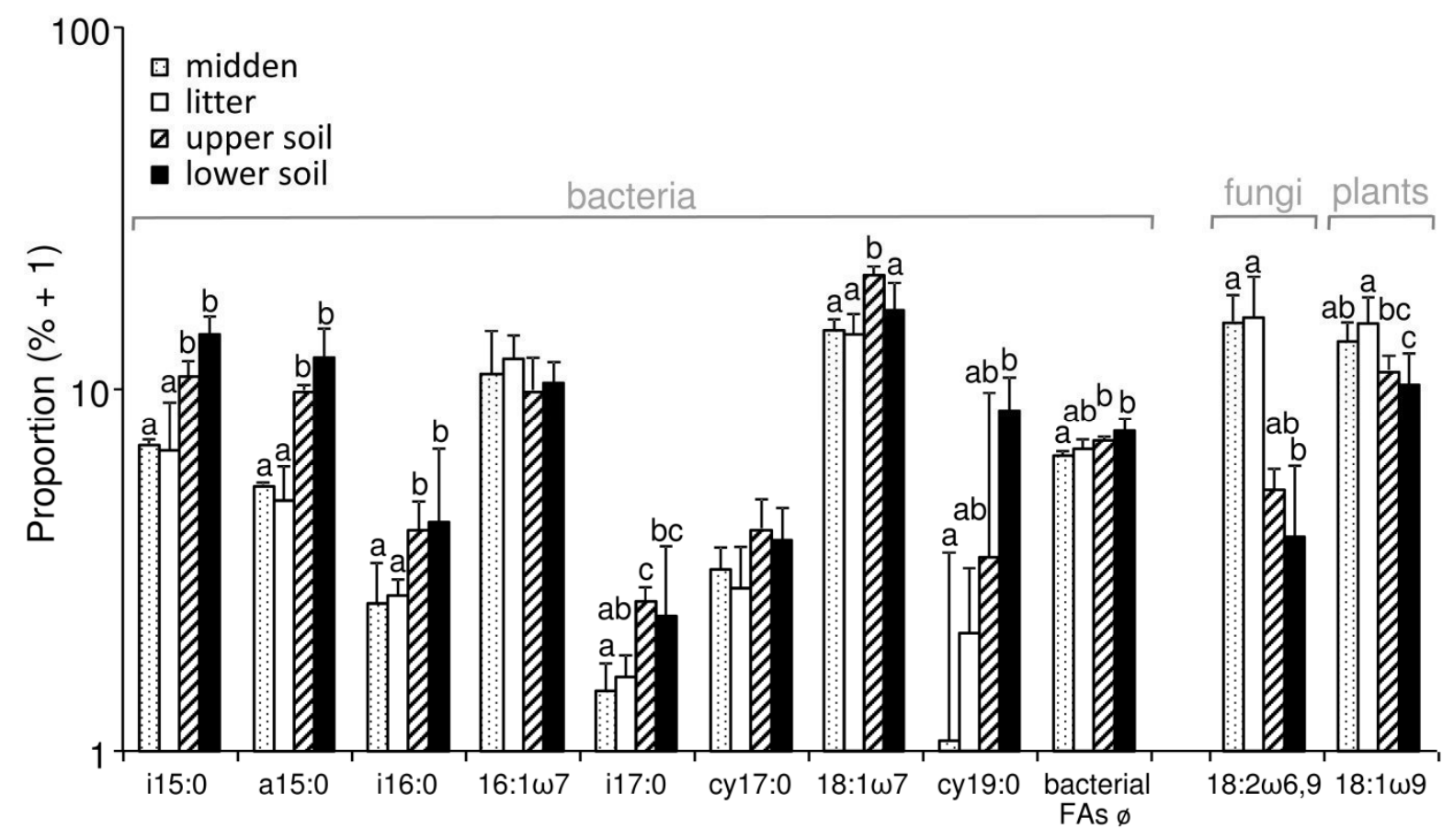

Fig. 2 | Concentrations (percentages of total \pm SD; note log scale) of bacterial, fungal and plant PLFAs of litter, earthworm middens, upper soil and lower soil in beech forests. Different letters represent significant differences (Tukey's HSD test; $P<0.05$ ).

\section{Fatty acid profiles of earthworms}

NLFA profiles did not differ between forest types (DFA; $F_{4,35}=0.78, P=0.54$ ), but between earthworm species (DFA; $F_{90,113}=2.92, P<0.001$; Fig. $1 \mathrm{~b}$; see Supplementary material Table S3; therefore data pooled for forest type). Differences were significant between almost all species except between $L$. terrestris and $L$. rubellus, between $O$. tyrtaeum and the two Aporrectodea species, and between L. castaneus and D. octaedra. The plant marker 18:1 $\mathrm{W9}$ contributed to the differences with concentrations (percentages of total) being high in $D$. octaedra and L. castaneus and low in the two Aporrectodea species (Table 1). Further, the bacterial marker i16:0 contributed to the differences with concentrations being high in $L$. terrestris, low in $O$. tyrtaeum and intermediate in the other species. The plant-to-fungal marker ratio indicated that the contribution of plant material to diet decreased in the order D. octaedra $(2.99 \pm 1.54)>L$. castaneus $(2.89 \pm 1.08)>0$. tyrtaeum $(1.56 \pm 0.68)>L$. rubellus $(1.43 \pm 0.53)>L$. terrestris $(1.26 \pm 0.35)>A$. rosea $(1.05 \pm 0.22)>A$. caliginosa $(0.67 \pm 0.21)$. 
Table 1 | ANOVA table of $F$-values for the effects of resources (litter, earthworm middens, upper soil, lower soil) of beech and spruce forests, and earthworm species on the amounts of bacterial, fungal and plant fatty acids. Significant effects are in bold.

\begin{tabular}{|c|c|c|c|c|}
\hline & \multicolumn{2}{|c|}{$\begin{array}{l}\text { resources } \\
\text { beech }\end{array}$} & $\begin{array}{l}\text { resources } \\
\text { spruce }\end{array}$ & \multirow{2}{*}{$\begin{array}{l}\text { earthworm } \\
\text { species } \\
F_{6,33} \\
\end{array}$} \\
\hline & $F_{3,12}$ & & $F_{2,9}$ & \\
\hline i15:0 & 20.47 & $* * *$ & $9.31 * *$ & 1.05 \\
\hline a15:0 & 32.03 & $* * *$ & $24.21 * * *$ & 0.41 \\
\hline i16:0 & 7.65 & $* *$ & 0.64 & $2.78 *$ \\
\hline $16: 1 \omega 7$ & 0.42 & & 1.23 & 0.92 \\
\hline i17:0 & 7.80 & $* *$ & 0.73 & 1.98 \\
\hline cy17:0 & 2.08 & & 4.08 & 0.72 \\
\hline $18: 1 \omega 7$ & 19.86 & $* * *$ & 4.23 & 0.76 \\
\hline cy19:0 & 4.23 & * & 0.00 & 0.89 \\
\hline$\varnothing$ bacterial FAs & 9.14 & $* *$ & 4.20 & 0.50 \\
\hline $18: 2 \omega 6,9$ & 8.28 & $* *$ & 3.48 & 2.04 \\
\hline $18: 1 \omega 9$ & 7.59 & ** & $5.69 *$ & 4.17 ** \\
\hline
\end{tabular}

${ }^{*} P<0.05,{ }^{* *} P<0.01,{ }^{* * *} P<0.001$

\section{$\delta^{13} \mathrm{C}$ signatures of fatty acids in earthworms and resources}

To relate feeding strategies of different earthworm species to resources (litter, midden, upper soil, lower soil), $\delta^{13} \mathrm{C}$ signatures of marker FAs in earthworm species were compared to the respective signatures of resources. $\delta^{13} \mathrm{C}$ profiles of FAs did not differ between forest types (DFA; $F_{22,44}=1.65, P=0.07$; pooled for forest types in the following), but between earthworm species, middens, litter and upper and lower soil (DFA; $F_{220,343}=1.94, P<0.001$; Fig. 3a, Table 2). Differences were most pronounced between the two Aporrectodea species and most other earthworm species and resources. $\delta^{13} \mathrm{C}$ profiles of the two soil layers differed from each of the other resources and also from each of the earthworm species; FA $\delta^{13} \mathrm{C}$ profiles of $L$. terrestris, $L$. rubellus, $L$. castaneus and $D$. octaedra resembled that of middens and litter. $\delta^{13} \mathrm{C}$ signatures of individual FAs differed significantly between earthworm species and resources in each of the six target FAs (see Supplementary material Fig S1), e.g. FA $\delta^{13} \mathrm{C}$ signatures of the Aporrectodea species and $\mathrm{O}$. tytraeum were depleted by about 3.94 $\pm 1.63 \%$ compared to upper as well as to lower soil. 

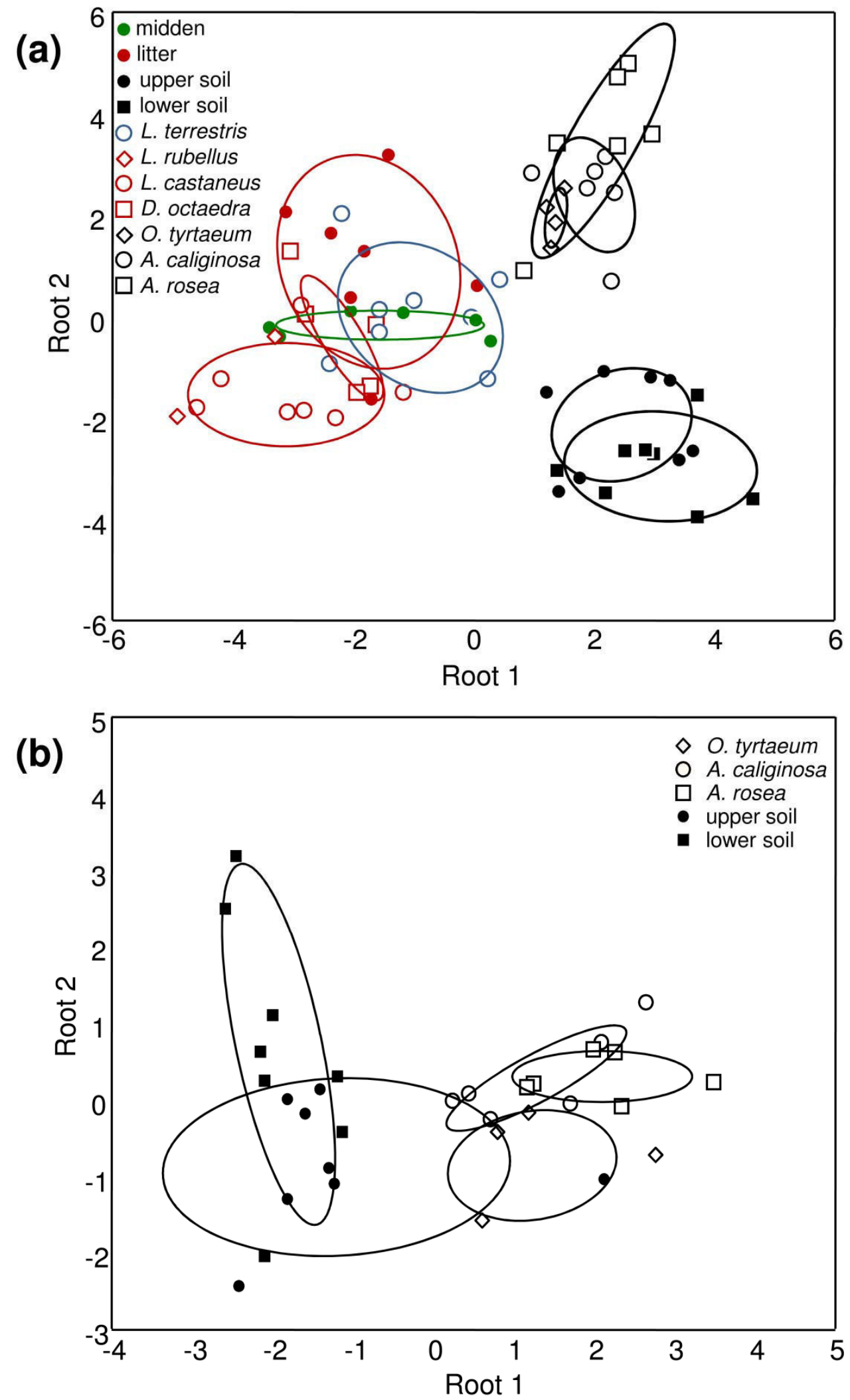

Fig. 3. Discriminant function analysis of (a) PLFA $\delta^{13} \mathrm{C}$ profiles in litter, earthworm middens, upper soil and lower soil, and NLFA $\delta^{13} \mathrm{C}$ profiles of earthworm species (pooled for forest type), and (b) PLFA $\delta^{13} \mathrm{C}$ profiles in upper and lower soil, and NLFA $\delta^{13} \mathrm{C}$ profiles in endogeic earthworm species of prokaryotic markers (pooled for forest type). Ellipses represent confidence ranges of the data at $P=0.05$. 

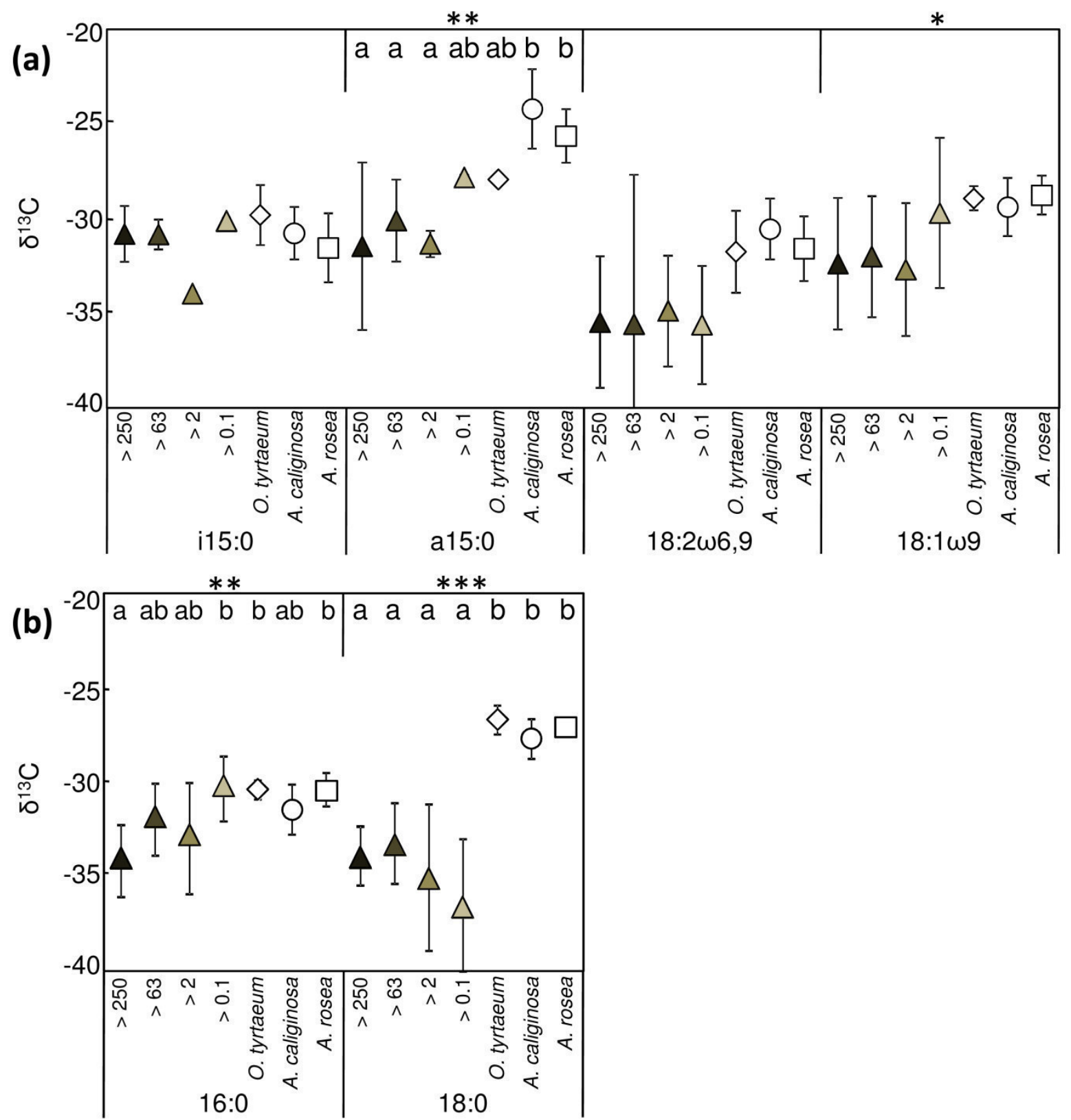

Fig. $4 \mid$ Mean $\delta^{13} \mathrm{C}$ stable isotope signatures $( \pm$ SD) of (a) NLFA marker FAs in soil particle size fractions and endogeic earthworm species, and (b) NLFAs in soil particle size fractions and endogeic earthworm species (both pooled for forest type). Asterisks (GLM) and different letters (Tukey's HSD test; $P<0.05$ ) represent significant differences.

Individual FAs uniformly followed this pattern. Prokaryotic FA $\delta^{13} \mathrm{C}$ profiles of the two Aporrectodea species, $O$. tytraeum differed significantly from those of the two soil layers (DFA; $F_{28,77}=2.17, P<0.01$; Fig. $3 \mathrm{~b}$, Table 3 ) with the marker FAs i15:0 and cy17:0 significantly contributing to this separation $\left(F_{4,27}=15.08, P<0.001\right.$ and $F_{4,27}=6.19, P<$ 
0.01 , respectively). In contrast, eukaryotic $\mathrm{FA} \delta^{13} \mathrm{C}$ profiles of the respective earthworm species and resources did not differ significantly $\left(\mathrm{DFA} ; F_{20,77}=1.25, P=0.24\right.$, data not shown).

\section{$\delta^{13} \mathrm{C}$ signatures of fatty acids in earthworms and soil particle size fractions}

$\delta^{13} \mathrm{C}$ bulk signatures of the four soil particle size fractions differed significantly and increased from the $>250$ to the $>63$ to the $>2$ and to the $>0.1 \mu \mathrm{m}$ fraction (mean values pooled for forest type: $-28.29 \pm 0.38 \%$ \% $-27.39 \pm 0.48 \%$, $-27.32 \pm 0.47 \%$ o and $25.83 \pm 0.74 \%$,

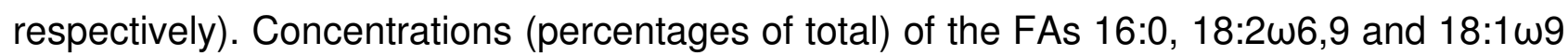
increased, whereas those of a15:0 and 18:0 decreased with particle size fractions (see Supplementary materialTable S1). FA $\delta^{13} \mathrm{C}$ profiles differed significantly between the four soil particle size fractions, $A$. caliginosa, $A$. rosea and $O$. tytraeum (GLM; F $36,51=2.14, \mathrm{P}<$ $0.05)$, but not between forest types. Among the six target $\mathrm{FAs}, \delta^{13} \mathrm{C}$ signatures of the marker FA a15:0 and 18:1 $\omega 9\left(F_{6,21}=5.22, P<0.01\right.$ and $F_{6,36}=2.56, P<0.05$, respectively $)$ as well as the two non-specific FAs 16:0 and 18:0 $\left(F_{6,36}=3.85, P<0.01\right.$ and $F_{6,33}=17.66, P<$ 0.001 , respectively) differed significantly between the three earthworm species and the four soil particle size fractions (Fig. $4 a$ ). $\delta^{13} \mathrm{C}$ signatures of the bacterial marker FA a15:0 were most depleted in the fractions $>250,>63$ and $>2 \mu \mathrm{m}$ and most enriched in the two Aporrectodea species. $\delta^{13} \mathrm{C}$ signatures of FA a15:0 of the $>0.1 \mu \mathrm{m}$ fraction and those of $O$. tyrtaeum were intermediate. $\delta^{13} \mathrm{C}$ signatures of the FA 16:0, were most depleted in the $>$ $250 \mu \mathrm{m}$ fraction and most enriched in the $>0.1 \mu \mathrm{m}$ fraction, in $O$. tyrtaeum and in $A$. rosea. Respective signatures in the $>63$ and $>2 \mu \mathrm{m}$ fractions and in $A$. caliginosa were intermediate. $\delta^{13} \mathrm{C}$ signature of the FA 18:0 was significantly depleted in each of the soil particle size fractions as compared to each of the three earthworm species (Fig. 4b).

\section{Discussion}

\section{Fatty acid composition of resources}

FA composition of resources differed significantly between soil layers and middens 
Table 2 | Squared Mahalanobis distances between group centroids and reliability of discrimination for PLFA $\delta^{13} \mathrm{C}$ profiles of resources (litter, earthworm middens, upper soil, lower soil) and NLFA $\delta^{13} \mathrm{C}$ profiles of earthworm species (pooled for forest type). Significant effects are in bold.

\begin{tabular}{|c|c|c|c|c|c|c|c|c|c|c|c|c|c|c|c|c|c|c|c|}
\hline \multirow[b]{2}{*}{ midden } & \multirow{2}{*}{$\begin{array}{c}\text { litter } \\
11.6\end{array}$} & \multicolumn{2}{|c|}{ upper soil } & \multicolumn{2}{|c|}{ lower soil } & \multicolumn{2}{|c|}{$\begin{array}{l}\text { L. } \\
\text { terrestris }\end{array}$} & \multicolumn{2}{|c|}{$\begin{array}{l}O . \\
\text { tyrtaeum }\end{array}$} & \multicolumn{2}{|c|}{$\begin{array}{l}A . \\
\text { caliginosa }\end{array}$} & \multicolumn{2}{|c|}{$\begin{array}{l}A . \\
\text { rosea }\end{array}$} & \multicolumn{2}{|c|}{$\begin{array}{l}\text { L. } \\
\text { castaneus }\end{array}$} & \multicolumn{2}{|c|}{$\begin{array}{l}\text { D. } \\
\text { octaedra }\end{array}$} & \multicolumn{2}{|c|}{$\begin{array}{l}\text { L. } \\
\text { rubellus }\end{array}$} \\
\hline & & 27.8 & $* * *$ & 42.9 & $* * *$ & 14 & & 26.1 & & 34 & ** & 36.6 & ** & 18.9 & & 16 & & 34 & \\
\hline litter & - & 37.9 & ** & 44.9 & $* * *$ & 7.3 & & 20.9 & & 25.7 & * & 28.8 & $* *$ & 19 & * & 15.1 & & 33.2 & \\
\hline upper soil & & - & & 16 & & 24.2 & $* *$ & 29.4 & * & 27.3 & ** & 41.2 & $* * *$ & 41.2 & $* * *$ & 35.8 & $* *$ & 60.6 & *** \\
\hline lower soil & & & & - & & 31.1 & $* * *$ & 35.6 & ** & 38.3 & $* * *$ & 46.1 & $* * *$ & 44.5 & $* * *$ & 43.6 & $* * *$ & 68 & *** \\
\hline L. terrestris & & & & & & - & & 20.3 & & 18.6 & & 27.8 & ** & 15.9 & & 9.4 & & 23 & \\
\hline O. tyrtaeum & & & & & & & & - & & 9.6 & & 13.5 & & 36.2 & $* *$ & 33.5 & * & 55.8 & * \\
\hline A. caliginosa & & & & & & & & & & - & & 9.3 & & 44 & $* * *$ & 35.1 & $* *$ & 58.4 & ** \\
\hline A. rosea & & & & & & & & & & & & - & & 55.6 & $* * *$ & 40.1 & $* *$ & 72.5 & ** \\
\hline L. castaneus & & & & & & & & & & & & & & - & & 15.8 & & 13.7 & \\
\hline D. octaedra & & & & & & & & & & & & & & & & - & & 23 & \\
\hline
\end{tabular}

${ }^{*} P<0.05,{ }^{* *} P<0.01,{ }^{* * *} P<0.001$

Table 3 | Squared Mahalanobis distances between group centroids and reliability of discrimination for PLFA $\delta^{13} \mathrm{C}$ profiles of prokaryotic markers of upper and lower soil and NLFA $\delta^{13} \mathrm{C}$ of prokaryotic markers of endogeic earthworm species (pooled for forest type). Significant effects are in bold.

\begin{tabular}{lcccc}
\hline & A. caliginosa & A. rosea & upper soil & lower soil \\
\hline O. tyrtaeum & 3.49 & 3.01 & 8.39 & $\mathbf{1 3 . 4 3}$ \\
A. caliginosa & - & 1.02 & $\mathbf{7 . 5 5 *}$ & $\mathbf{1 1 . 3 6}{ }^{* *}$ \\
A. rosea & & - & $\mathbf{1 1 . 9 7 * *}$ & $\mathbf{1 6 . 4 6}{ }^{* * *}$ \\
upper soil & & & - & 3.49 \\
\hline
\end{tabular}

${ }^{*} P<0.05,{ }^{* *} P<0.01,{ }^{* * *} P<0.001$ 
as well as between soil layers and litter, with higher proportions of bacterial markers in soils and higher proportions of fungal markers in middens and litter. This suggests distinct bacteria-dominated microbial communities in soil and fungi-dominated microbial communities in middens and litter which is consistent with earlier observations (White et al., 1996; Ruess et al., 2007). However, differences between soil and litter varied between forest types with microbial communities in soil and litter of spruce forests being more similar than those in beech forests. This indicates that vertical stratification of resources is less pronounced in spruce as compared to beech forests, presumably due to the overriding importance of the chemical composition of spruce needles and associated lower bioturbation (Swift et al., 1979; Thoms and Gleixner, 2013). Similarity of the FA composition in earthworm middens and litter reflects the dominant role of litter in middens.

\section{Fatty acid composition of earthworm tissue}

FA compositions of the two epigeic earthworm species, D. octaedra and $L$. castaneus, and the three endogeic species, $O$. tyrtaeum, $A$. caliginosa and $A$. rosea, were distinct suggesting utilisation of different food resources. Epigeic earthworm species are known to predominantly assimilate litter material, whereas endogeic species assimilate material associated with mineral soil (Curry and Schmidt, 2007), and this difference was reflected in the FA composition of their body tissue. Surprisingly, in O. tyrtaeum the plant-to-fungal marker ratio resembled that of epigeic species suggesting plant material to be of importance for this species despite $O$. tyrtaeum being an endogeic species. FA composition of the anecic species $L$. terrestris was significantly different from that of epigeic species (lower proportions of plant markers) despite both having been shown to predominantly feed on litter (Bouché, 1977; Curry and Schmidt, 2007). Based on ${ }^{14} \mathrm{C}$ analysis Briones et al. (2005) found anecic earthworm species to have distinct radiocarbon signatures compared to epigeic species indicating assimilation of different food material, which is in line with our findings. In L. terrestris ingestion of sand for grinding of food materials in the gizzard promotes fragmentation of litter material (Schulmann and Tiunov, 1999) and, as a consequence, access to litter resources (Suzuki et al., 2003). Furthermore, FA composition in the epiendogeic species $L$. rubellus differed significantly from the two epigeic species with lower proportions of plant markers in $L$. rubellus suggesting that, similar to $L$. terrestris, this species also relies on other food resources than litter. In a greenhouse experiment Eisenhauer et al. 
(2008) found $L$. rubellus to behave similar to $L$. terrestris burying seeds and incorporating litter into mineral soil. The FA composition of the latter two species significantly differed from that of endogeic species as indicated by DFA, confirming that solely endogeic species live on alternative carbon resources.

\section{${ }^{13} \mathrm{C}$ signatures of fatty acids of earthworms}

$\delta^{13} \mathrm{C}$ profiles of neutral and phospholipid marker FAs differed significantly between earthworm species, litter and soil, but not between spruce and beech forests suggesting that assimilation of specific carbon resources of earthworms and, hence, feeding strategies are similar across these different forest ecosystems. Gunina and Kuzyakov (2014) postulated that the formation of carbon pools of different recalcitrance is independent of forest type which may explain the similarity in earthworm food resources. In contrast, Neilson et al. (2000) found stable isotope signatures of earthworms to differ between deciduous and coniferous forests of different locations. In our study biotic and abiotic properties of the deciduous and spruce forests were similar, especially in lower soil layers, as both were growing on similar parent rock and this likely contributed to the similarity of deciduous and spruce forests. $\delta^{13} \mathrm{C}$ profiles of PLFAs did not differ between the two soil layers suggesting that the carbon resources used by microorganisms change little with soil depth (at least to a soil depth of $20 \mathrm{~cm}$ ).

$\delta^{13} \mathrm{C}$ profiles of marker NLFAs of epigeic and anecic earthworm species resembled those of PLFA $\delta^{13} \mathrm{C}$ profiles of middens and litter suggesting that, as documented earlier, earthworms of these ecological groups predominantly assimilate litter and associated microorganisms recently fixed carbon in the labile carbon pool (Rethemeyer et al., 2004; Briones et al., 2005). FA $\delta^{13} \mathrm{C}$ profiles of $L$. terrestris were similar to that in most of the endogeic as well as the epigeic species studied suggesting that $L$. terrestris fed on a mixture of resources of different stability. Further, the results support earlier studies using FAs that epigeic and anecic earthworms heavily rely on litter bacteria (Sampedro et al., 2006; Dungait et al., 2008). Bacteria are assumed to preferentially digest labile carbon compounds, such as simple sugars and amino acids (Wolters, 2000; Moore et al., 2003), which is in line with the assumption of epigeic and anecic earthworms assimilating recent carbon.

$\delta^{13} \mathrm{C}$ profiles of NLFAs of each of the endogeic species studied differed from that of epigeic species, and from $\delta^{13} \mathrm{C}$ profiles of PLFAs of litter and soil, suggesting that endogeic earthworm species utilise other, more recalcitrant carbon resources than those of plant or 
microbial origin. $\delta^{13} \mathrm{C}$ signatures of recalcitrant resources differ from those based on recently assimilated carbon (Martin et al., 1992; Briones et al., 2005; Curry and Schmidt, 2007; Marhan et al., 2007a; Hyodo et al., 2008; present study). Interestingly, FA $\delta^{13} \mathrm{C}$ profiles of endogeic earthworms were more closely associated with those of fungi than with those of bacteria, and fungi are assumed to utilise more recalcitrant carbon sources than bacteria (Moore et al., 2003; Paterson et al., 2008) fitting to the view of endogeic earthworms using old carbon resources (Marhan et al., 2007a; Hyodo et al., 2008).

\section{Incorporation of neutral lipid ${ }^{13} \mathrm{C}$ into earthworm fatty acids}

Confirming our second hypothesis bulk $\delta^{13} \mathrm{C}$ signatures of soil particle size fractions increased with decreasing fraction size suggesting that carbon of smaller size fractions, which were least abundant, are of higher age as compared to carbon of larger fractions (Rethemeyer et al., 2004). In contrast, organic matter of large particle size fractions, containing most of the organic matter in our soils, comprises predominantly plant residues of recent origin being depleted in $\delta^{13} \mathrm{C}$ (Gunina and Kuzyakov, 2014). Close resemblance to plant material was also reflected by high amounts of plant and fungal marker FAs.

Notably, FA $\delta^{13} \mathrm{C}$ profiles of three endogeic earthworm species differed from those of each of the four particle size fractions. However, these differences were mainly due to differences in $\delta^{13} \mathrm{C}$ signatures of non-marker FAs, such as $16: 0$ and 18:0, suggesting that these FAs of earthworms originated from other sources than microorganisms associated with soil particle size fractions. Indeed, these FAs are ubiquitous and known to be synthesised from other FAs or de-novo by animals (Ruess and Chamberlain, 2010). However, except the bacterial marker a15:0, FA marker $\delta^{13} \mathrm{C}$ signatures of neutral lipids in endogeic earthworms and in soil particle size fractions did not differ. This suggests that endogeic earthworms predominantly utilised neutral lipids (and to a certain amount also other hydrophobic lipids) and not bulk soil phospholipids, i.e. microorganisms. Neutral lipids in soil comprise FAs from both neutral lipids and phospholipids of a variety of organisms. Such lipids may be physically associated with soil particle size fractions and incorporated into organo-mineral complexes increasing in stability and age with decreasing particle size (Gleixner et al., 2002). Similarly, stable isotope analyses showed that endogeic earthworm species were enriched in ${ }^{13} \mathrm{C}$ signatures indicating utilisation of carbon resources of higher age (Marhan et al., 2007a; Pollierer et al., 2012). In the present study $\delta^{13} \mathrm{C}$ signatures of the bacterial marker a15:0 in 
endogeic earthworm species corresponded with signatures of this marker in the $<0.1 \mu \mathrm{m}$ fraction. This confirms our hypothesis and supports earlier suggestions that endogeic earthworms use carbon associated with small soil particle size fractions, i.e., mobilise carbon enclosed in clay-humus complexes (Martin et al., 1992; Skjemstad et al., 1993; Collins et al., 2000; Marhan et al., 2007a). Interestingly, the results suggest that bacterial FAs associated with clay particle size fractions form part of the food resources assimilated by endogeic earthworms. Bacterial residues are known to be stabilised in soil and significantly contribute to soil organic matter (Miltner et al., 2012).

\section{Conclusions}

Overall, using novel techniques the results suggest that earthworms of different ecological groups utilise carbon pools of different origin and stability. The seven earthworm species studied differed markedly in assimilation of carbon resources. However, earthworms did not differ in mobilisation of carbon pools between beech and spruce forests, presumably due to similar decomposition and humification processes in these systems. FA $\delta^{13} \mathrm{C}$ profiles of earthworms, litter and soil indicated that endogeic earthworms incorporate little carbon of bacterial or plant origin, but are more closely associated with the fungal channel. Comparisons of $\mathrm{FA} \delta^{13} \mathrm{C}$ signatures of particle size fractions and earthworms suggest that endogeic earthworms utilise carbon enclosed in organo-mineral complexes of small particle size fractions. Specific gut associated processes including grinding of soil particles in the gizzard and enrichment of the food material with mucus in the midgut presumably contribute to the mobilisation of these compounds (Barois, 1992; Marhan and Scheu, 2005). The results confirm our hypothesis that stabilised FAs of bacterial origin contribute to earthworm nutrition indicating that also other stable soil carbon pools are utilised by endogeic earthworms.

\section{Acknowledgements}

The work has been funded by the DFG Priority Program 1374 "Infrastructure-BiodiversityExploratories". Field work permits were given by state environmental office of Thuringia according to $\S 72 \mathrm{BbgNatSchG.} \mathrm{We} \mathrm{thank} \mathrm{the} \mathrm{managers} \mathrm{of} \mathrm{the} \mathrm{three} \mathrm{Exploratories,} \mathrm{Swen}$ Renner, Sonja Gockel, Kerstin Wiesner and Martin Gorke for their work in maintaining the 
plot and project infrastructure; Simone Pfeiffer and Christiane Fischer giving support through the central office, Michael Owonibi for managing the central data base, and Markus Fischer, Eduard Linsenmair, Dominik Hessenmöller, Jens Nieschulze, Daniel Prati, Ingo Schöning, François Buscot, Ernst-Detlef Schulze, Wolfgang W. Weisser and the late Elisabeth Kalko for their role in setting up the Biodiversity Exploratories project. We thank Guido Humpert and Mark Maraun for support during lab work and statistics. Sincere thanks to Martin Blumenberg and Jens Dyckmans for GC-MS and fatty acid- ${ }^{13} \mathrm{C}$ measurements. Helpful comments by two anonymous reviewers are gratefully acknowledged.

\section{References}

Balabane, M., 1997.Turnover of clay-associated nitrogen in the different aggregate size classes of a cultivated silty loam. European Journal of Soil Science 47, 285 - 292.

Barois, I., 1992. Mucus production and microbial activity in the gut of 2 species of Amynthas (Megascolecidae) from cold and warm tropical climates. Soil Biology \& Biochemistry 24, 1507 $-1510$.

Blem, C.R., 1976. Patterns of lipid storage and utilization in birds. American Zoologist 16, $671-684$.

Bonkowski, M., Schaefer, M., 1997. Interactions between earthworms and soil protozoa: A trophic component in the soil food web. Soil Biology \& Biochemistry 29, 499- 502.

Bouché, M.B., 1977. Stratégies lombriciennes. In: Lohm, U., Persson, T. (Eds.), Soil Organisms as Components of Ecosystems. Ecological Bulletins, Stockholm, pp. 122 - 132.

Briones, M.J.I., Garnett, M.H., Piearce, T.G., 2005. Earthworm ecological groupings based on ${ }^{14} \mathrm{C}$ analysis. Soil Biology \& Biochemistry 37, 2145-2149.

Briones, M.J.I., Schmidt, O., 2004. Stable isotope techniques in studies of the ecological diversity and functions of earthworm communities in agricultural soils. Recent Research Developments in Crop Science 1, 11-26.

Chamberlain, P.M., Bull, I.D., Black, H.I.J., Ineson, P., Evershed, R.P., 2004. Lipid content and carbon assimilation in Collembola: implications for the use of compound-specific carbon isotope analysis in animal dietary studies. Oecologia 139, $325-335$.

Collins, H.P., Elliott, E.T., Paustian, K., Bundy, L.G., Dick, W.A., Huggins, D.R., Smucker, A.J.M., Paul, E.A., 2000. Soil carbon pools and fluxes in long-term corn belt agroecosystems. Soil Biology \& Biochemistry 32, $157-168$.

Curry, J.P., Schmidt, O., 2007. The feeding ecology of earthworms - a review. Pedobiologia 50, 463 $-477$. 
Denef, K., Six, J., 2005. Clay mineralogy determines the importance of biological versus abiotic processes macroaggregate formation and stabilization. European Journal of Soil Science 56, $469-479$.

Dungait, J.A.J., Briones, M.J.I., Bol, R., Evershed, R.P., 2008. Enhancing the understanding of earthworm feeding behaviour via the use of fatty acid $\delta^{13} \mathrm{C}$ values determined by gas chromatography-combustion-isotope ratio mass spectrometry. Rapid Communications in Mass Spectrometry 22, $1643-1652$.

Edwards, C.A., Fletcher, K.E., 1988. Interactions between earthworms and microorganisms in organic-matter breakdown. Agriculture Ecosystems \& Environment 24, 235 - 247.

Eisenhauer, N., Marhan, S., Scheu, S., 2008. Assessment of anecic behavior in selected earthworm species: Effects on wheat seed burial, seedling establishment, wheat growth and litter incorporation. Applied Soil Ecology 38, 79 - 82.

Fischer, M., Bossdorf, O., Gockel, S., Hansel, F., Hemp, A., Hessenmoeller, D., Korte, G., Nieschulze, J., Pfeiffer, S., Prati, D. et al., 2010. Implementing large-scale and long-term functional biodiversity research: the biodiversity exploratories. Basic and Applied Ecology 11, $473-485$.

Fonte, S.J., Kong, A.Y.Y., van Kessel, C., Hendrix, P.F., Six, J., 2007. Influence of earthworm activity on aggregate-associated carbon and nitrogen dynamics differs with agroecosystem management. Soil Biology \& Biochemistry 39, $1014-1022$.

Fox, O., Vetter, S., Ekschmitt, K., Wolters, V., 2006. Soil fauna modifies the recalcitrance-persistence relationship of soil carbon pools. Soil Biology \& Biochemistry 38, $1353-1363$.

Frostegård, A., Baath, E., Tunlid, A., 1993. Shifts in structure of soil microbial communities in limed forests as revealed by phospholipid fatty acid analysis. Soil Biology \& Biochemistry 25, $723-$ 730.

Gleixner, G., Poirier, N., Bol, R., Balesdent, J., 2002. Molecular dynamics of organic matter in a cultivated soil. Organic Geochemistry 33, $357-366$.

Gunina, A., Kuzyakov, Y., 2014. Pathways of litter C by formation of aggregates and SOM density fractions: Implications from ${ }^{13} \mathrm{C}$ natural abundance. Soil Biology \& Biochemistry 71, $95-104$.

Gunn, A., 1992. The use of mustard to estimate earthworm populations. Pedobiologia 36, 65 - 67.

Haubert, D., Häggblom, M.M., Scheu, S., Ruess, L., 2004. Effects of fungal food quality and starvation on the fatty acid composition of Protaphorura fimata (Collembola). Comparative Biochemistry and Physiology B 138, $41-52$.

Hyodo, F., Tayasu, I., Konaté, S., Tondoh, J.E., Lavelle, P., Wada, E., 2008. Gradual enrichment of ${ }^{15} \mathrm{~N}$ with humification of diets in a below-ground food web: relationship between ${ }^{15} \mathrm{~N}$ and diet age determined using ${ }^{14} \mathrm{C}$. Functional Ecology 22, 516- 522.

Jones, C.G., Lawton, J.H., Shachak, M., 1994.Organisms as Ecosystem Engineers. Oikos 69, 373 $-386$. 
Liu, Q.M., Cao, Y.L., Huang, Y.F., Zhang, Y.P., Lin, J.Q., Lin, J.M., Xu, L.S., 2013. Soil organic matter dynamics after C-3-C-4 vegetation change of red soil in Southern, China: Evidence from natural C-13 abundance. Contemporary Problems of Ecology 6, 513- 519.

Marhan, S., Langel, R., Kandeler, E., Scheu, S., 2007a. Use of stable isotopes $\left({ }^{13} \mathrm{C}\right)$ for studying the mobilisation of old soil organic carbon by endogeic earthworms (Lumbricidae). European Journal of Soil Biology 43, $201-208$.

Marhan, S., Kandeler, E., Scheu, S., 2007b. Phospholipid fatty acid profiles and xylanase activity in particle size fractions of forest soil and casts of Lumbricus terrestris L. (Oligochaeta, Lumbricidae). Applied Soil Ecology 35, 412 - 422.

Marhan, S., Scheu, S., 2005. Effects of sand and litter availability on organic matter decomposition in soil and in casts of Lumbricus terrestris L. Geoderma 128, 155-166.

Marschner, B., Brodowski, S., Dreves, A., Gleixner, G., Gude, A., Grootes, P.M., Hamer, U., Heim, A., Jandl, G., Ji, R. et al., 2008. How relevant is recalcitrance for the stabilization of organic matter in soils? Journal of Plant Nutrition and Soil Science 171, 91 - 110.

Martin, A., Mariotti, A., Balesdent, J., Lavelle, P., 1992. Soil organic matter assimilation by a geophagous tropical earthworm based on ${ }^{13} \mathrm{C}$ measurements. Ecology 73, $118-128$.

Miltner, A., Bombach, P., Schmidt-Brücken, B., Kästner, M., 2012. SOM genesis: microbial biomass as a significant source. Biogeochemistry 111, $41-55$.

Monroy, F., Aira, M., Dominguez, J., 2008. Changes in density of nematodes, protozoa and total coliforms after transit through the gut of four epigeic earthworms (Oligochaeta). Applied Soil Ecology 39, $127-132$.

Moore, J.C., McCann, K., Setälä, H., de Ruiter, P.C., 2003. Top-down is bottom-up: does predation in the rhizosphere regulate aboveground dynamics? Ecology 84, 846 - 857.

Neilson, R., Boag, B., Smith, M., 2000. Earthworm $\delta^{13} \mathrm{C}$ and $\delta^{15} \mathrm{~N}$ analyses suggest that putative functional classifications of earthworms are site-specific and may also indicate habitat diversity. Soil Biology \& Biochemistry 32, 1053 - 1061.

Paterson, E., Osler, G., Dawson, L.A., Gebbing, T., Sim, A., Ord, B., 2008. Labile and recalcitrant plant fractions are utilised by distinct microbial communities in soil: Independent of the presence of roots and mycorrhizal fungi. Soil Biology \& Biochemistry 40, $1103-1113$.

Pollierer, M.M., Dyckmans, J., Scheu, S., Haubert, D., 2012. Carbon flux through fungi and bacteria into the forest soil animal food web as indicated by compound-specific ${ }^{13} \mathrm{C}$ fatty acid analysis. Functional Ecology 26, 978 - 990.

Pond, C.M., 1981. Storage. In: Townsend, C.R., Calow, P. (Eds.), Physiological Ecology: an Evolutionary Approach to Resource Use. Blackwell, London, pp. 190 - 219.

Rethemeyer, J., Grootes, P.M., Bruhn, F., Andersen, N., Nadeau, M.J., Kramer, C., Gleixner, G., 2004. Age heterogeneity of soil organic matter. Nuclear Instruments and Methods in Physics Research B 223-224, 521-527. 
Ruess, L., Chamberlain, P.M., 2010. The fat that matters: soil food web analysis using fatty acids and their carbon stable isotope signature. Soil Biology \& Biochemistry 42, 1898 - 1910.

Ruess, L., Schütz, K., Migge-Kleian, S., Häggblom, M.M., Kandeler, E., Scheu, S., 2007. Lipid composition of Collembola and their food resources in deciduous forest stands - implications for feeding strategies. Soil Biology \& Biochemistry 39, $1990-2000$.

Sampedro, L., Jeannotte, R., Whalen, J.K., 2006. Trophic transfer of fatty acids from gut microbiota to the earthworm Lumbricus terrestris L. Soil Biology \& Biochemistry 38, $2188-2198$.

Scheu, S., 1991. Mucus excretion and carbon turnover of endogeic earthworms. Biology and Fertility of Soils $12,217-220$.

Schmidt, O., Scrimgeour, C.M., Handley, L.L., 1997. Natural abundance of ${ }^{15} \mathrm{~N}$ and ${ }^{13} \mathrm{C}$ in earthworms from a wheat and a wheat-clover field. Soil Biology \& Biochemistry 29, $1301-1308$.

Schulmann, O.P., Tiunov, A.V., 1999. Leaf litter fragmentation by the earthworm Lumbricus terrestris L. Pedobiologia 43, $453-458$.

Skjemstad, J.O., Janik, L.J., Head, M.J., Mc Clure, G., 1993. High energy ultraviolet photooxidation: a novel technique for studying physically protected organic matter in clay and silt-sized aggregates. Journal of Soil Science 44, $485-499$.

Stemmer, M., Gerzabek, M.H., Kandeler, E., 1998. Organic matter and enzyme activity in particlesize fractions of soils obtained after low-energy sonication. Soil Biology \& Biochemistry 30, 9 -17 .

Suzuki, Y., Matsubara, T., Hoshino, M., 2003.Breakdown of mineral grains by earthworms and beetle larvae. Geoderma 112, 131 - 142.

Swift, M.J., Heal, O.W., Anderson, J.M., 1979. Decomposition in terrestrial ecosystems. University of California Press, Berkeley.

Thoms, C., Gleixner, G., 2013. Seasonal differences in tree species' influence on soil microbial communities. Soil Biology \& Biochemistry 66, $239-248$.

Tiunov, A.V., Scheu, S., 2004. Carbon availability controls the growth of detritivores (Lumbricidae) and their effect on nitrogen mineralization. Oecologia 138, $83-90$.

White, D.C., Stair, J.O., Ringelberg, D.B., 1996. Quantitative comparisons of in situ microbial biodiversity by signature biomarker analysis. Journal of Industrial Microbiology 17, 185-196.

Wolters, V., 2000. Invertebrate control of soil organic matter stability. Biology and Fertility of Soils 31 , 1-19. 


\section{Supplementary}
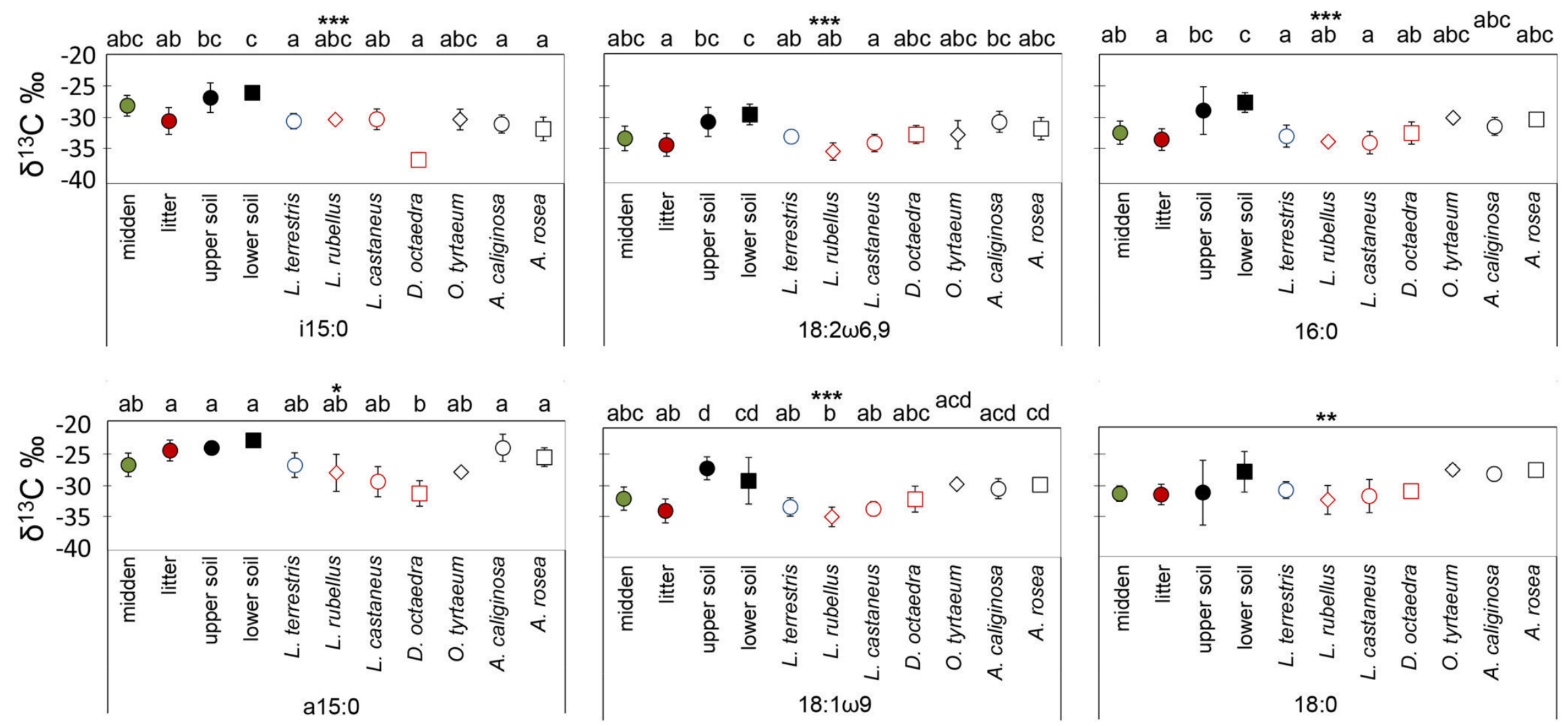

Fig. S1 | Mean ${ }^{13} \mathrm{C}$ stable isotope signatures ( \pm SD) of NLFA markers and NLFAs in resources and earthworm species (pooled for forest type). Asterisks (ANOVA) and different letters (Tukey's HSD test; $P<0.05$ ) represent significant differences. 
Table S1 | Concentrations (percentages of total \pm SD) of six target NLFAs of the four soil particle size fractions (pooled for forest type).

\begin{tabular}{lllll}
\hline & $>0.1 \mu \mathrm{m}$ & $>2 \mu \mathrm{m}$ & $>63 \mu \mathrm{m}$ & $>250 \mu \mathrm{m}$ \\
\hline i15:0 & $1.01 \pm 0.02$ & $0.35 \pm 0.01$ & $0.86 \pm 0.01$ & $0.62 \pm 0.01$ \\
a15:0 & $4.9 \pm 0.05$ & $4.22 \pm 0.05$ & $3.31 \pm 0.03$ & $1.55 \pm 0.01$ \\
$16: 0$ & $12.42 \pm 0.08$ & $12.72 \pm 0.06$ & $15.3 \pm 0.05$ & $23.85 \pm 0.31$ \\
$18: 2 \omega 6,9$ & $4.89 \pm 0.07$ & $6.28 \pm 0.05$ & $6.85 \pm 0.04$ & $19.09 \pm 0.14$ \\
$18: 1 \omega 9$ & $6.34 \pm 0.06$ & $12.55 \pm 0.13$ & $18.69 \pm 0.06$ & $24.64 \pm 0.13$ \\
$18: 0$ & $19.2 \pm 0.34$ & $17.89 \pm 0.32$ & $3.62 \pm 0.03$ & $2.85 \pm 0.03$ \\
\hline
\end{tabular}

Table S2 | Squared Mahalanobis distances between group centroids and reliability of discrimination for PLFA composition of litter, earthworm middens, upper soil and lower soil in beech and spruce forests, respectively. Significant effects are in bold.

\begin{tabular}{|c|c|c|c|c|c|c|}
\hline & \multicolumn{3}{|c|}{ beech } & \multicolumn{3}{|c|}{ spruce } \\
\hline & litter & upper soil & lower soil & litter & upper soil & lower soil \\
\hline midden & 4.6 & $30.7^{* *}$ & $67.7^{* * *}$ & 6.6 & 15.2 & 18.6 \\
\hline litter & - & 16 * & $42.8^{* * *}$ & - & 21.7 * & 27.7 * \\
\hline upper soil & & - & 7.5 & & - & 3.4 \\
\hline
\end{tabular}

${ }^{*} P<0.05,{ }^{* *} P<0.01,{ }^{* * *} P<0.001$

Table S3 | Squared Mahalanobis distances between group centroids and reliability of discrimination for NLFA composition of earthworm species (pooled for forest type). Significant effects are in bold.

\begin{tabular}{|c|c|c|c|c|c|c|}
\hline & $\begin{array}{l}L \\
\text { terrestris }\end{array}$ & $\begin{array}{l}\text { O. } \\
\text { tyrtaeum }\end{array}$ & $\begin{array}{l}\text { A } \\
\text { caliginosa }\end{array}$ & $\begin{array}{l}\text { A. } \\
\text { rosea }\end{array}$ & $\begin{array}{l}\text { L. } \\
\text { castaneus }\end{array}$ & $\begin{array}{l}\text { D. } \\
\text { octaedra }\end{array}$ \\
\hline O. tyrtaeum & $38.1^{* *}$ & - & & & & \\
\hline A. caliginosa & $74.7^{* * *}$ & 21.7 & - & & & \\
\hline A. rosea & $61.9^{* * *}$ & 21.5 & $26.3 *$ & - & & \\
\hline L. castaneus & $17.0 *$ & $32.1 *$ & $83.0^{* * *}$ & $50.0^{* * *}$ & - & \\
\hline D. octaedra & 32.6 ** & $40.9 * *$ & $93.2^{* * *}$ & $41.5^{* *}$ & 15.0 & - \\
\hline L. rubellus & 14.1 & $35.9 *$ & $50.4^{* *}$ & $56.9 * *$ & $36.3 *$ & $51.0^{* *}$ \\
\hline
\end{tabular}

${ }^{*} P<0.05,{ }^{* *} P<0.01,{ }^{* * *} P<0.001$ 


\section{Chapter 5}

Trophic niche differentiation and utilisation of food resources in collembolans based on complementary analyses of fatty acids and stable isotopes

Olga Ferlian, Bernhard Klarner, Annika E. Langeneckert, Stefan Scheu Soil Biology \& Biochemistry (2015), published 


\section{Abstract}

Feeding on a variety of resources, collembolans have been assumed to be food generalists. However, recent stable isotope analyses documented that collembolan species occupy different trophic levels, but detailed studies on species-specific food resources are sparse. Further, it still is little understood whether food resources of collembolan species are constant or shift, e.g., with habitats. Fatty acid (FA) and stable isotope analysis allow insight into utilisation of basal resources and trophic levels of consumers, respectively. We combined these methods to investigate variations in trophic niches of six collembolan species (Lepidocyrtus lanuginosus, Folsomia quadrioculata, Parisotoma notabilis, Ceratophysella denticulata, Isotomiella minor and Protaphorura armata) in beech and spruce forests. We correlated collembolan FAs with that of litter microorganisms at the respective study sites to identify links to resources. FA composition and stable isotope signatures in collembolan species did not differ significantly between forest types but between species suggesting pronounced trophic niche differentiation between species. The trophic niche of $C$. denticulata and $P$. armata was similar and significantly differed from the other species with ${ }^{13} \mathrm{C}$ and ${ }^{15} \mathrm{~N}$ signatures being least depleted. We suggest that $C$. denticulata has a predatory life style feeding on nematodes. Due to intermediate to low ${ }^{13} \mathrm{C}$ and ${ }^{15} \mathrm{~N}$ levels and specific FA compositions the other collembolan species could be ascribed to secondary decomposers with I. minor being more closely associated with bacterial resources and $F$. quadrioculata, L. lanuginosus and $P$. notabilis with fungal resources. However, dietary niches presumably comprise a mixture of resources rather than single resources. FAs in collembolan species correlated poorly with those in litter suggesting that the diet of collembolan species is rather independent of the structure of microbial communities in bulk litter. The results suggest that collembolans consume resources of microsites rather than bulk material thereby benefitting from the small-scale heterogeneity in resource distribution in soil. Low variation in trophic niches with forest type suggests that these microsites are similar across different forests and provide similar food resources despite marked differences in e.g., litter materials and humus structure.

Keywords: Carbon, Decomposers, Forest types, Fungivores, Lipids, Trophic level 


\section{Introduction}

Collembolans are among the most widespread and abundant arthropods in forest soils (Peterson and Luxton, 1982). Being litter-dwellers they play an important role in decomposition processes directly by feeding on organic material and indirectly by stimulating microbial activity (Visser, 1985; Scheu et al. 2005). Acting at the base of the food web, collembolans contribute to nutrient cycling and also channel carbon to higher trophic levels of the soil food web (Moore et al., 1987; Chahartaghi et al., 2005; Oelbermann et al., 2008; Crotty et al., 2011). As documented in laboratory studies collembolans may feed on a variety of resources, such as detritus, bacteria, fungi and algae (Hopkin, 1997; Rusek, 1998; Scheu, 2002) with fungi being the most important diet (Scheu and Simmerling, 2004; Jørgensen and Hedlund, 2013). Moreover, collembolans act as predators of nematodes and enchytraeids in soil food webs (Lee and Widden, 1996; Hopkin, 1997; Ruess et al., 2004). Therefore, they have been assumed to be food generalists. However, this contrasts more recent findings based on natural variations in stable isotope signatures that collembolan species occupy distinct trophic niches suggesting that they have species-specific diets (Chahartaghi et al., 2005). To resolve this discrepancy more detailed information on the diet of collembolans under natural conditions in soil is needed.

The soil food web essentially relies on plant-derived resources. There are two pathways through which plant carbon fuels the soil food web. On the one hand dead organic matter, i.e. leaf litter and dead roots, serve as carbon resources. On the other hand root exudates predominantly comprising recently fixed carbon fuel the soil food web. Most studies assume the litter pathway to be most important, however, recent studies suggest decomposer food webs to essentially rely on carbon resources derived from living roots (Albers et al., 2006; Ruf et al., 2006; Pollierer et al., 2007, 2012; Endlweber et al., 2009). Similar to plant litter, root derived resources serve as food substrate for fungi and bacteria which themselves serve as food resource, thereby collembolans function as secondary decomposers. Generally, it is assumed that the soil food web is compartmentalised into a bacterial and fungal energy channel with associated soil animal taxa (Moore et al., 2005). Recent studies suggest collembolans to heavily rely on root-derived carbon in grasslands and forests (Larsen et al., 2007; Pollierer et al., 2007; Bonkowski et al., 2009) via feeding on mycorrhizal fungi (Pollierer et al., 2012). Carbon in plant phloem sap and presumably also in root exudates is more enriched in ${ }^{13} \mathrm{C}$ as compared to leaf litter carbon (Gessler et al., 2004). Consequently, soil biota relying on root-derived resources are more enriched in ${ }^{13} \mathrm{C}$ as 
compared to those relying on litter derived carbon (Endlweber et al., 2009; Ngosong et al., 2011).

The structure of microbial communities in forests varies with tree species as it sensitively responds to changes in biotic and abiotic characteristics (Bardgett, 2005; Salamon et al., 2008; Fierer et al., 2009). One of the driving factors is litter chemistry, such as concentrations of polyphenols being particularly abundant in coniferous leaf litter (Hättenschwiler and Vitousek, 2000). Litter chemistry driven changes in microbial community composition likely propagate into microbial consumers such as collembolans. Indeed, litter quality changes with soil depth and this has implications for (i) the ratio of fungi over bacteria, and (ii) the species composition of bacteria and fungi in the different layers. All can affect feeding patterns in collembolans which are grouped into epedaphic (surface living), hemiedaphic (living at the litter-soil interface) and euedaphic species (soil living) (Hopkin, 1997). However, changes in resource quantity and quality are only one part of the story. Vertical stratification is also fostered by strong microclimatic gradients (Krab et al., 2010). Fatty acid (FA) analysis has been shown to allow disentangling links between basal resources, such as microorganisms, and microbial feeders in belowground food webs (Ruess et al., 2005a, 2007). Unfortunately, in particular in soil detritivore microarthropods, such as collembolans, trophic niches and mechanisms responsible for variations in trophic niches between habitats still are little understood.

Phospholipid fatty acid (PLFA) analysis has been intensively used to characterise the structure of soil microbial communities. PLFAs of microbial origin are assimilated and incorporated into consumer neutral lipids without or with little change thereby reflecting the composition of the diet ('dietary routing'; Blem, 1976; Pond, 1981). The analysis of neutral lipid FAs (NLFAs) in consumers is increasingly used as tool to uncover food web links in belowground systems (Ruess et al., 2002; Ruess and Chamberlain, 2010). It allows tracking the channelling of carbon from basal resources to higher trophic levels and differentiating trophic niches of different consumers of similar trophic level (Pollierer et al., 2010; Ferlian and Scheu, 2014). Certain NLFAs serve as absolute biomarkers that exclusively originate from the diet and thereby reflect certain prey taxa allowing detection of feeding on e.g., gram-positive bacteria, gram-negative bacteria and algae (Ruess et al., 2005a; Buse et al., 2013). Further, certain FAs serve as relative biomarkers that are synthesised by consumers but reach higher concentrations if present in the diet. They allow detection of e.g., feeding on plants and fungi (Ruess et al., 2007; Ruess and Chamberlain, 2010). Most studies on consumer - resource interrelationships in decomposer invertebrates were performed in the 
laboratory (Haubert et al., 2004, 2006, 2008; Ruess et al., 2004, 2005b), few studies have been done in the field targeting at understanding differences in trophic niches between habitats or changes in trophic niches with time (Ruess et al., 2005a; Haubert et al., 2009). Combining FA and stable isotope analysis is particularly promising as the two techniques complement each other in that the first allows insight into the channelling of food resources through food webs whereas the latter allows insight into the trophic structure of food webs (Tiunov, 2007). Combining both techniques Ferlian and Scheu (2014) uncovered distinct trophic niches of two abundant coexisting centipede species.

We investigated variations in trophic niches of collembolans in different forests by combining FA and stable isotope analysis. We correlated FAs in collembolan species with those of litter microorganisms at the respective study sites to identify links between consumers and resources. We hypothesised (1) that different collembolan species occupy distinct trophic niches with species present in upper soil layers predominantly relying on fungi and plant litter material, being more abundant in upper layers, and species present in lower soil layers predominantly relying on bacteria associated with root-derived resources due to stratification of resources. (2) Further, we expected NLFA compositions of collembolan species to vary with forest type and NLFA patterns in collembolans to correspond to microbial PLFA patterns in the litter layer.

\section{Material and methods}

\section{Study sites}

The study formed part of the 'Biodiversity Exploratories', an interdisciplinary research project on biodiversity and ecosystem functioning (Fischer et al., 2010). It was set-up in three forest regions in Germany: Schorfheide-Chorin, Hainich and Schwäbische Alb. The SchorfheideChorin is a forest region in Brandenburg (North-eastern Germany, 52 $54^{\prime} \mathrm{N}, 13^{\circ} 52^{\prime} \mathrm{E}$ ) of an altitude of $2-139 \mathrm{~m}$ a.s.l. Parent rock is represented by young glacial till. The soil type is predominantly Cambisol; $\mathrm{pH}$ ranges between 3.3 and 6.7, and mean annual temperature is about $8^{\circ} \mathrm{C}$. The Hainich is a hilly range in Thuringia (Central Germany, $51^{\circ} 6^{\prime} \mathrm{N}, 10^{\circ} 23^{\prime}$ E) of an altitude of $330-490 \mathrm{~m}$ a.s.I. Triassic limestone is overlain by loess. The soil type is predominantly Luvisol; $\mathrm{pH}$ ranges between 4.0 and 5.5, and mean annual temperature is about $7{ }^{\circ} \mathrm{C}$. The Schwäbische Alb is situated in the low-mountain ranges in BadenWürttemberg (South-western Germany, $48^{\circ} 23^{\prime} \mathrm{N}, 9^{\circ} 27^{\prime} \mathrm{E}$ ) of an altitude of $693-817 \mathrm{~m}$ 
a.s.I. Parent rock is represented by Jurassic shell limestone with karst phenomena. The soil type is Cambisol and Leptosol; $\mathrm{pH}$ ranges between 4.5 and 5.9, and mean annual temperature is about $6.5^{\circ} \mathrm{C}$. Eight different forest sites per region of an age of about 70 years were investigated: four beech forest sites and four coniferous forest sites (24 forest sites in total). Within regions the distance between sites varied between 2 and $20 \mathrm{~km}$. The beech forest sites are dominated by European beech (Fagus sylvatica L.) interspersed with single Common ash (Fraxinus excelsior L.) and Sycamore maple trees (Acer pseudoplatanus L.). The coniferous forest sites comprise Norway spruce (Picea abies L.) in Hainich and Schwäbische Alb, whereas they comprise Scots pine (Pinus sylvestris L.) in Schorfheide-Chorin. The amount of litter in the litter layer of beech forests in the Schorfheide-Chorin, Hainich and Schwäbische Alb was $0.34,0.38$ and $0.63 \mathrm{~g} \mathrm{~cm}^{-2}$, respectively, respective amounts in coniferous forests were $0.93,0.65$ and $0.79 \mathrm{~g} \mathrm{~cm}^{-2}$.

\section{Sampling}

For FA analysis, collembolans were sampled at each forest site by collecting leaf litter (L/F horizon) and upper mineral soil (upper $0-3 \mathrm{~cm}$ of the $A_{h}$ horizon) randomly by hand into plastic bags (about 80 I per site). In the laboratory collembolans were extracted by heat (Kempson et al., 1963) into large plastic containers with water for seven days. Living collembolans were transferred into $20 \%$ sodium chloride solution and stored at $-12{ }^{\circ} \mathrm{C}$ until identification (cf. Hopkin, 2007). The following common collembolan species were selected occurring in different soil strata and differing in morphological characteristics: Lepidocyrtus lanuginosus Gmelin, Folsomia quadrioculata Tullberg, Parisotoma notabilis Schäffer, Ceratophysella denticulata Bagnall, Isotomiella minor Schäffer and Protaphorura armata Tullberg. Four replicates per forest type and region were analysed in most of the species (one per forest site); in less abundant species fewer replicates were analysed. Using forceps and a small paint-brush, animals were cleared from attached particles prior to analysis. Depending on body size for each sample 20 - 100 individuals per species and sample were pooled to gain sufficient amounts of FAs.

In addition to animal sampling, for analysis of microbial FAs three soil cores (5 $\mathrm{cm} \varnothing)$ were taken at each forest site. The litter layer (L/F horizon) was separated from soil and merged to one sample per forest site. Samples were stored at $-21^{\circ} \mathrm{C}$ in the laboratory until further processing. 
For stable isotope analysis of collembolans two larger soil cores $(20 \mathrm{~cm} \varnothing, \mathrm{L} / \mathrm{F}$ and 0-3 cm $A_{h}$ horizon) were taken at each forest site and merged. In the laboratory collembolans were extracted by heat (Kempson et al., 1963), collected in diethylene glycerol and preserved in ethanol. As not all species were found in sufficient numbers in each of the samples, some sites had to be excluded from stable isotope analysis. Therefore, data of stable isotope signatures were not tested for forest type. Additionally, leaf litter (L/F horizon, see above) as basal resource was collected randomly from each site for calibration accounting for local variability in stable isotope signatures.

\section{Analysis of fatty acids}

For characterisation of collembolan feeding strategies neutral lipids were extracted as described in Haubert et al. (2004). For the analysis of microbial FAs in litter phospholipids were extracted as described in Frostegård et al. (1993). Phospholipid and neutral lipid fractions were dried at $50{ }^{\circ} \mathrm{C}$ using a rotation vacuum concentrator (RVC 2-25, Christ, Osterode am Harz, Germany). Then, lipid fractions were saponified, methylated and washed according to the protocols for the Sherlock Microbial Identification System (MIDI Inc., Newark, USA). Obtained FA methyl esters of litter and collembolans were transferred into vials, capped and stored at $-21{ }^{\circ} \mathrm{C}$ until analysis via gas chromatography. The gas chromatograph (Clarus 500, Perkin Elmer, Waltham, USA) was equipped with a flame ionisation detector (PE-5 capillary column, $30 \mathrm{~m} \times 0.32 \mathrm{~mm}$ i.d., $0.25 \mathrm{~mm}$ film thickness, Perkin Elmer, Waltham, USA) and helium as carrier gas. More details on the analysis programme are given in Ferlian and Scheu (2014). FA methyl esters were identified by comparing retention times of samples and standard mixtures comprising unbranched and branched (bacterial) FA methyl esters. The following FAs served as biomarkers for bacteria: the methyl-branched FAs i15:0, a15:0, i16:0 and i17:0, and the cyclic FAs cy 17:0 and cy19:0.

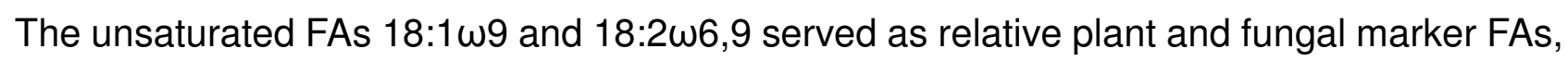
respectively, using the ratio of both to distinguish between plant und fungal dominated diet

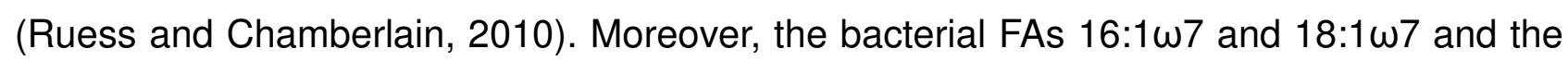
non-specific FAs 16:0 and 18:0 were included in data analyses. 


\section{Stable isotope analysis}

Prior to analysis of natural variations in ${ }^{13} \mathrm{C} /{ }^{12} \mathrm{C}$ and ${ }^{15} \mathrm{~N} /{ }^{14} \mathrm{~N}$ ratios, collembolans were transferred into tin capsules and dried for $24 \mathrm{~h}\left(105^{\circ} \mathrm{C}\right)$. Litter of each forest site was homogenised, dried for $24 \mathrm{~h}\left(105^{\circ} \mathrm{C}\right)$, ground with a ball mill and transferred into tin capsules. Isotope analyses were performed using an elemental analyser (NA 1500, Carlo Erba, Milano, Italy) coupled with a mass spectrometer (MAT 251, Finnigan, Bremen, Germany). Stable isotope signatures are expressed by the $\Delta$ notation representing the difference between the collembolan stable isotope ratio and the respective ratio of leaf litter. Ratios were calculated as $\delta X(\%)=\left[\left(R_{\text {sample }}-R_{\text {standard }}\right) / R_{\text {standard }}\right] \times 1000$, with X the target isotope and $R_{\text {sample }}$ and $R_{\text {standard }}$ the heavy-to-light isotope ratio $\left({ }^{13} \mathrm{C} /{ }^{12} \mathrm{C}\right.$ or $\left.{ }^{15} \mathrm{~N} /{ }^{14} \mathrm{~N}\right)$ of the sample and standard, respectively. PD belemnite and atmospheric nitrogen served as primary standard for ${ }^{13} \mathrm{C}$ and ${ }^{15} \mathrm{~N}$, respectively. Acetanilide was used for internal calibration.

\section{Statistical analysis}

FA amounts were converted into percentage values and logit-transformed to improve normal distribution. Homogeneity of variance and distribution of the data were inspected using Levene test and Shapiro-Wilk test, respectively. To test for differences in utilisation of basal resources between collembolan species ( $L$. lanuginosus, F. quadrioculata, $P$. notabilis, $C$. denticulata, I. minor and P. armata), forest types (beech and coniferous forests) and regions (Schorfheide-Chorin, Hainich and Schwäbische Alb), FA compositions were compared using multivariate analysis of variance (MANOVA) and discriminant function analysis (DFA) using region as block. In case of significant DFA, concentrations of individual FAs were compared between species using analysis of variance (ANOVA). Means were compared using Tukey's honestly significant difference (HSD) test. Regression analyses of marker FAs in litter with the respective FAs in each collembolan species were employed to test whether FA concentrations in collembolans correspond to microbial FA concentrations in the litter layer. Stable isotope signatures $\left(\Delta^{13} \mathrm{C}\right.$ and $\left.\Delta^{15} \mathrm{~N}\right)$ of different collembolan species were compared by MANOVA and ANOVA to test for differences in utilisation of carbon resources and trophic levels. Statistical analyses were conducted using STATISTICA 10 for Windows (StatSoft, Inc.;Tulsa, OK, USA). 


\section{Results}

\section{Fatty acid composition of collembolans}

As indicated by MANOVA the FA composition of collembolans differed significantly between regions $\left(F_{24,130}=3.60, P<0.001\right)$ and species $\left(F_{60,308}=2.20, P<0.001\right)$, but not between forest types $\left(F_{12,65}=1.72, P=0.083\right)$. DFA showed FA composition of $C$. denticulata and $P$. armata to be similar differing significantly from that of each of the other species (Table 1, Fig. 1). Further, the FA composition of $I$. minor differed significantly from that of $F$. quadrioculata and $L$. lanuginosus, whereas the other collembolan species differed little. Concentrations of the bacterial FAs 16:1 $\omega 7$ and 18:1 $\omega 7\left(F_{5,76}=4.41, P=0.001 ; F_{5,76}=3.11\right.$, $P=0.012)$ as well as the marker FAs i15:0, i16:0,i17:0 and cy19:0 $\left(F_{5,76}=3.62, P=0.005\right.$; $F_{5,76}=2.49, P=0.036 ; F_{5,76}=5.69, P<0.001 ; F_{5,76}=2.54, P=0.033$, respectively) were responsible for differences between collembolan species (Fig. 2). Overall, concentrations were highest in $C$. denticulata and $P$. armata, whereas they were lowest in $L$. lanuginosus (Table 1, Fig. 2: " $\Sigma$ bacterial FAs"). In $F$. quadrioculata, I. minor and $P$. notabilis concentrations of bacterial FAs and bacterial marker FAs were in between those of the other species. Concentrations of the relative fungal marker FA 18:2w6,9 were highest in $C$. denticulata and lowest in $I$. minor, whereas they were intermediate in the other species. The plant-to-fungal marker ratio decreased in the order $I$. minor $>P$. notabilis $>P$. armata $>L$. lanuginosus $>F$. quadrioculata $>C$. denticulata $(5.60 \pm 2.76,4.90 \pm 2.11,4.42 \pm 1.48,4.38 \pm$ $1.88,3.57 \pm 1.65$ and $2.55 \pm 0.69$, respectively). 
Table 1/Squared Mahalanobis distances between group centroids and reliability of discrimination for NLFA composition of collembolan species (pooled for region and forest type). Significant effects are given in bold. Arrows represent high ( $\uparrow$ ), intermediate $(\rightarrow)$ and low $(\downarrow)$ concentrations of marker FAs according to Fig. 2 . bac: bacterial marker FAs, fun: fungal marker FA, pl/fun: plant-to-fungal marker ratio.

\begin{tabular}{|c|c|c|c|c|c|c|c|c|c|}
\hline bac & fun & $\mathrm{pl} /$ fun & & C. denticulata & F. quadrioculata & I. minor & L. lanuginosus & P. notabilis & P. armata \\
\hline$\uparrow$ & $\uparrow$ & $\downarrow$ & C. denticulata & - & & & & & \\
\hline$\rightarrow$ & $\rightarrow$ & $\downarrow$ & F. quadrioculata & $8.31^{\star * *}$ & - & & & & \\
\hline$\rightarrow$ & $\downarrow$ & $\uparrow$ & I. minor & $10.54^{\star \star \star}$ & $2.89^{*}$ & - & & & \\
\hline$\downarrow$ & $\rightarrow$ & $\rightarrow$ & L. lanuginosus & $9.07^{\star \star \star}$ & 1.66 & $2.67^{*}$ & - & & \\
\hline$\rightarrow$ & $\rightarrow$ & $\uparrow$ & P. notabilis & $11.54^{\star \star \star}$ & 0.9 & 1.7 & 1.97 & - & \\
\hline$\uparrow$ & $\rightarrow$ & $\rightarrow$ & P. armata & 2.5 & $2.92^{*}$ & $6.22^{\star \star \star}$ & $3.96^{\star \star}$ & $5.2^{\star \star *}$ & - \\
\hline
\end{tabular}

${ }^{*} P<0.05,{ }^{* *} P<0.01,{ }^{* * *} P<0.001$ 


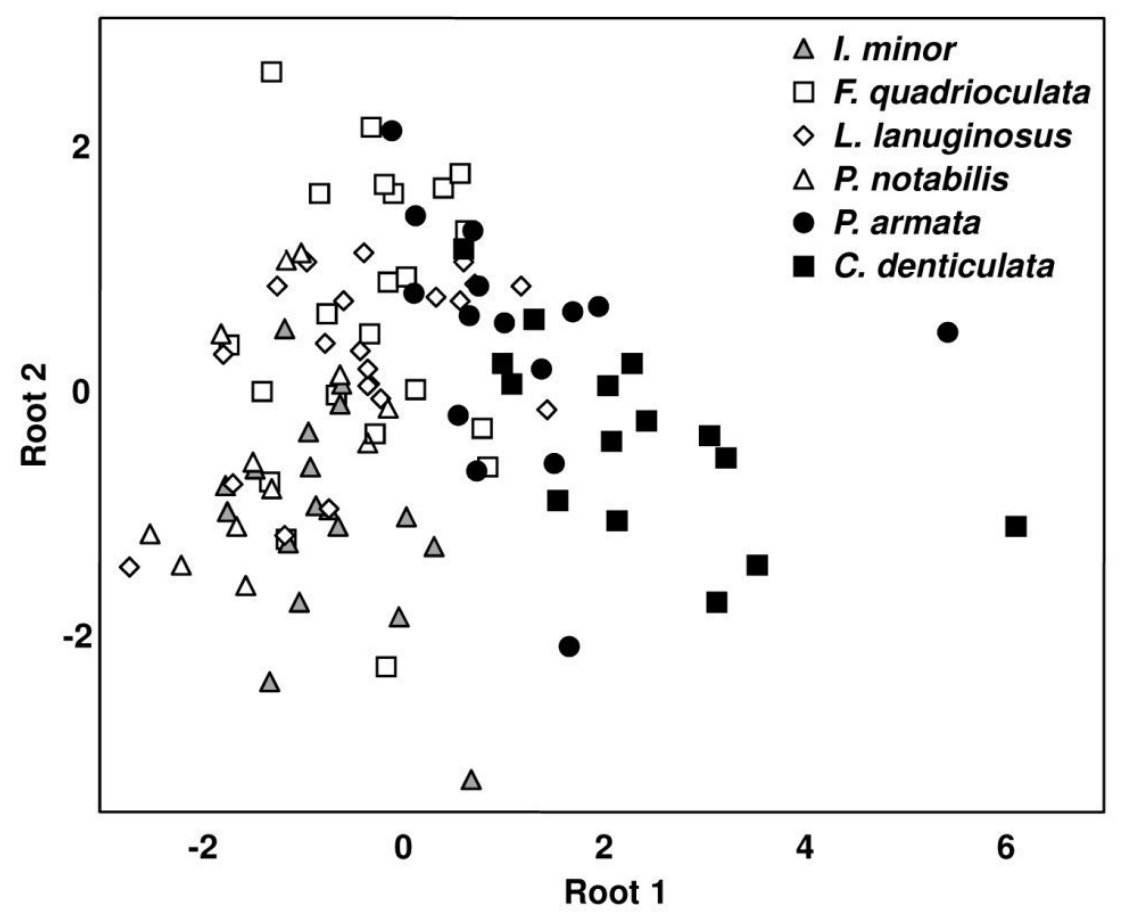

Fig. 1. Discriminant function analysis of NLFAs of collembolan species (pooled for region and forest type).

\section{Resources of collembolans}

FA composition of collembolans did not differ significantly between forest types (see previous section). As indicated by regression analyses concentrations of the relative plant marker FAs (18:1w9 in collembolans and litter, respectively) correlated positively in $C$. denticulata (Table 2). Correlations among other FAs in the other collembolan species were not significant indicating that the relationship between collembolan FAs and PLFAs of litter was weak.

\section{Stable isotope signatures of collembolans}

Mean $\delta^{13} \mathrm{C}$ and $\delta^{15} \mathrm{~N}$ signatures of leaf litter were $-27.71 \pm 1.59 \%$ and $-4.90 \pm 1.37 \%$, respectively. Stable isotope signatures $\left(\Delta^{13} \mathrm{C}\right.$ and $\left.\Delta^{15} \mathrm{~N}\right)$ differed significantly between collembolan species (MANOVA; $F_{10,110}=20.89, P<0.001$ ) with differences being stronger in $\Delta^{15} \mathrm{~N}$ as compared to $\Delta^{13} \mathrm{C}\left(F_{5,56}=63.31, P<0.001\right.$ and $F_{5,56}=4.95, P<0.001$, respectively $)$. P. armata, I. minor and C. denticulata were most enriched, whereas F. quadrioculata, $L$. 
lanuginosus and $P$. notabilis were least enriched in $\Delta^{13} \mathrm{C}(6.12 \pm 0.56$ and $4.27 \pm 0.64 \%$, respectively; Fig. 3). In contrast, $\Delta^{15} \mathrm{~N}$ signatures were low in F. quadrioculata, $P$. notabilis and $L$. lanuginosus $(0.73$ to $1.71 \%$ ), and increased in the order $I$. minor $<P$. armata $<C$. denticulata, with the latter reaching a $\Delta^{15} \mathrm{~N}$ signature of $6.62 \pm 1.66 \%$.

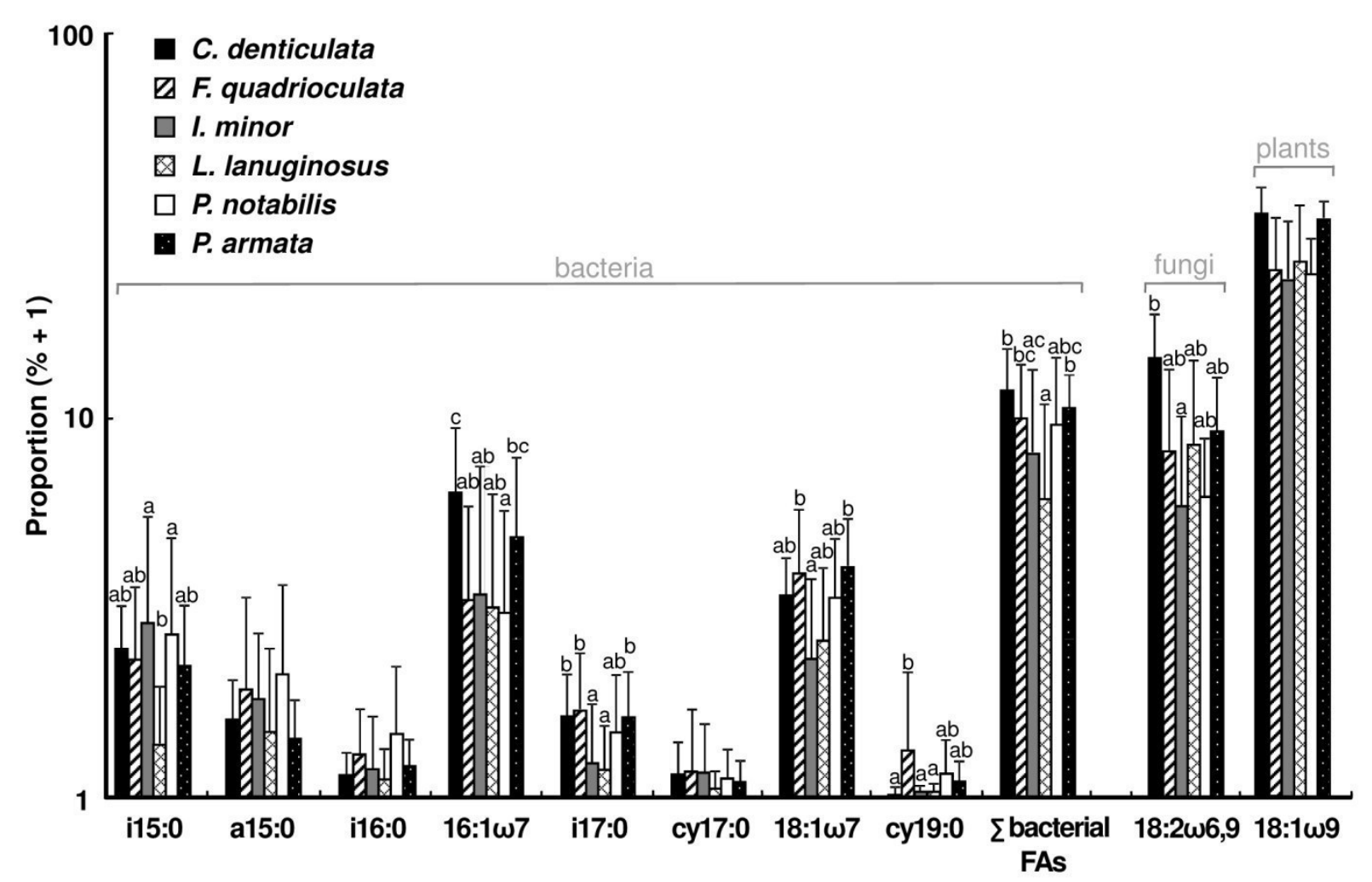

Fig. 2. Concentrations (percentages of total \pm SD; note log scale) of bacterial (individual and sum of all), fungal and plant NLFAs of collembolan species (pooled for region and forest type). Different letters represent significant differences (Tukey's HSD test, $\mathrm{P}<0.05$ ).

\section{Discussion}

\section{Trophic niches}

FA composition and stable isotope signatures in collembolans differed significantly between species with isotope signatures spanning approximately two delta units in ${ }^{13} \mathrm{C}$ and six delta units in ${ }^{15} \mathrm{~N}$. This suggests pronounced trophic niche differentiation between species which is consistent with earlier studies using stable isotopes (Chahartaghi et al., 2005; Jørgensen et al., 2005; Hishi et al., 2007).FA composition in the two collembolan species $C$. denticulata and $P$. armata were similar and significantly differed from that of each of the other species, 
Table $2 \mid F$-values, degrees of freedom and correlation coefficients of regressions between logit-transformed marker FA concentrations [sum of bacterial markers (see Materials and methods), fungal marker $(18: 2 \omega 6,9)$ and plant marker (18:1w9)] of litter and collembolans. Significant effects are given in bold.

\begin{tabular}{|c|c|c|c|c|c|c|c|}
\hline & \multirow[b]{2}{*}{ df } & \multicolumn{2}{|c|}{$\Sigma$ bacterial markers } & \multicolumn{2}{|c|}{$18: 2 \omega 6,9$} & \multicolumn{2}{|c|}{$18: 1 \omega 9$} \\
\hline & & $\mathrm{R}^{2}$ & $\mathrm{~F}$ & $\mathrm{R}^{2}$ & $\mathrm{~F}$ & $\mathrm{R}^{2}$ & $\mathrm{~F}$ \\
\hline C. denticulata & 1,13 & 0.04 & 0.56 & 0.04 & 0.51 & 0.55 & $15.86^{\star *}$ \\
\hline F. quadrioculata & 1,20 & 0.06 & 1.32 & 0.02 & 0.49 & 0.02 & 0.38 \\
\hline I. minor & 1,16 & 0.01 & 1.10 & 0.01 & 0.08 & 0.00 & 0.00 \\
\hline L. lanuginosus & 1,19 & 0.00 & 0.09 & 0.02 & 0.43 & 0.04 & 0.73 \\
\hline P. notabilis & 1,20 & 0.02 & 0.33 & 0.01 & 0.10 & 0.01 & 0.28 \\
\hline P. armata & 1,13 & 0.11 & 1.68 & 0.04 & 0.52 & 0.00 & 0.04 \\
\hline
\end{tabular}

${ }^{* *} P<0.01$

with concentrations of bacterial and fungal marker FAs being high. This suggests resources of bacterial and fungal origin to be of similar importance and thereby association with both the bacterial and the fungal energy channel. However, these two species are known to colonise different soil strata with $P$. armata being euedaphic and $C$. denticulata being epedaphic (Hopkin, 1997; Salamon et al., 2008) which suggests the utilisation of similar basal resources in different soil depths and a separate trophic position as compared to the other species. Moreover, $C$. denticulata and $P$. armata were less depleted in ${ }^{13} \mathrm{C}$ compared to the other species suggesting utilisation of root-derived carbon resources (cf. Klarner et al., 2013) which could add to the slight increase in ${ }^{13} \mathrm{C}$ values with trophic level (Tiunov, 2007).

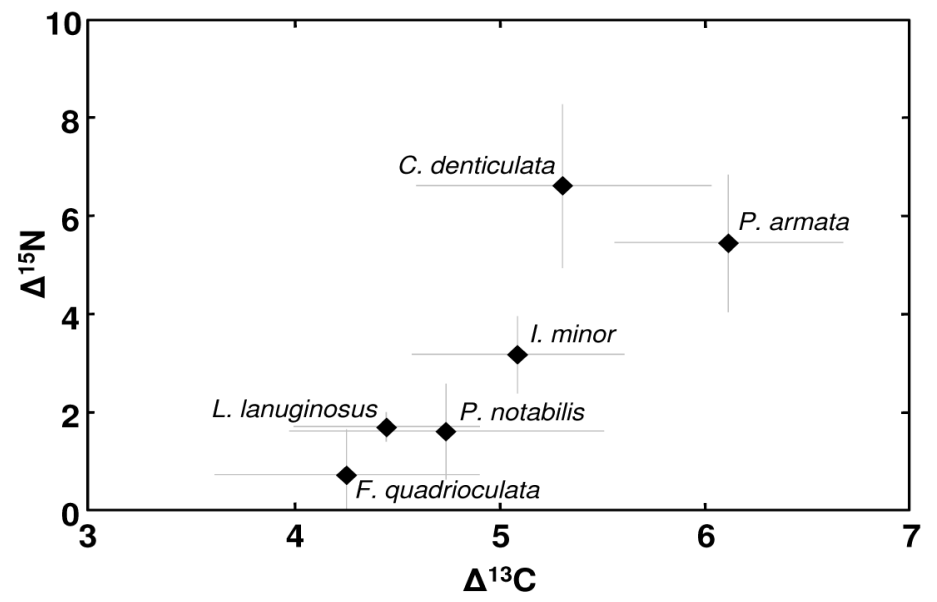

Fig. 3. Mean stable isotope signatures $\left(\Delta^{13} C\right.$ and $\left.\Delta^{15} \mathrm{~N}\right)$ of collembolan species (pooled for region and forest type). Values are given as differences between stable isotope signatures of collembolans and the respective leaf litter of the sites. 
Similar conclusions have been drawn by Larsen et al. (2007) and Ostle et al. (2007). ${ }^{15} \mathrm{~N}$ values of $C$. denticulata and $P$. armata markedly exceeded those of the other collembolan species studied with $C$. denticulata being enriched by about 6.6 delta units compared to litter. Chahartaghi et al. (2005) also found $\delta^{15} \mathrm{~N}$ values of $C$. denticulata to be high and assumed this species to function as secondary decomposer. However, due to the high $\delta^{15} \mathrm{~N}$ values we suggest $C$. denticulata to also feed on living or dead animals presumably nematodes. Supporting this conclusion Hypogastruridae have been reported to live as predators feeding on protozoans, nematodes and rotifers (Hopkin, 1997; Crotty et al., 2012). This may also explain the presence of both bacterial and fungal marker FAs, e.g. by consuming both bacterial and fungal feeding animal species. Dennon and Fagan (2003) suggested that to meet their nutritional requirements soil arthropods broaden their dietary spectrum by including animal prey or carrion. High plant-to-fungal marker FA ratio in $P$. armata as compared to $C$. denticulata suggests the diet of the former species to include more plant material potentially via feeding more heavily on root feeding nematodes or via directly feeding on roots as documented before (Endlweber et al., 2009).

I. minor comprised low concentrations of the fungal marker FA, intermediate concentrations of bacterial marker FAs and a high plant-to-fungal marker ratio suggesting bacteria and plant material as major food source. Isotomiella minor had an intermediate $\delta^{13} \mathrm{C}$ value as compared to the other species suggesting that it relies on both plant litter and root-derived carbon sources. Based on $\delta^{15} \mathrm{~N}$ values $I$. minor has been ascribed to secondary decomposers before (Maraun et al., 2011; Klarner et al., 2014), but laboratory studies suggested I. minor to mainly feed on fungi (Tranvik and Eijsackers, 1989; Rusek 1998).

F. quadrioculata, L. lanuginosus and $P$. notabilis had similar low $\delta^{13} \mathrm{C}$ and $\delta^{15} \mathrm{~N}$ signatures indicating a basal trophic position and similar trophic niches. Concentrations of fungal marker FAs were intermediate and plant-to-fungal marker ratios indicated preferential feeding on fungi over plant material (Ruess et al., 2007). Concentrations of bacterial marker FAs were intermediate to low in the three species suggesting these species to function as secondary decomposers preferably feeding on fungi supporting earlier conclusions (Chen et al., 1996; Berg et al., 2004; Pollierer et al., 2007). Supporting their similar trophic position, these three species often co-occur in the same soil stratum (hemiedaphic species; Chauvat et al., 2014). Overall, the hypothesis that different collembolan species occupy different trophic niches is strongly corroborated disproving assumptions that collembolans uniformly 
feed on fungi (Hunt et al., 1987; de Ruiter et al., 1993; Bengtsson et al., 1998). Different species were also found to utilise different energetic pathways, i.e., leaf and root litter resources as well as root exudates comprising labile carbon resources.

\section{Food resources of collembolans}

FA composition of collembolan species differed between the three regions suggesting variability in their diet. In particular species from Schorfheide-Chorin were separated from those of the other two regions. The Schorfheide-Chorin differs from the other two regions by its young glacial till covered by Cambisols of low soil $\mathrm{pH}$ with moder humus and specific microbial communities as indicated by PLFA patterns. Similar to results of the present study, Ruess et al. (2005a, 2007) found differences in FA composition of collembolan species of forests stocking on different parent rock. In contrast to region, FA composition of collembolans did not differ between forest types. This is in line with earlier studies suggesting that tree species composition and stand age exert limited influence on collembolan communities (Hågvar, 1982; Scheu et al., 2003; Chahartaghi et al., 2005; Salamon et al., 2004, 2008). In fact, non-trophic interactions, in particular the burrowing activity of earthworms and the associated incorporation of litter into the soil (bioturbation), have been identified as major driving forces of soil mesofauna communities (Maraun et al., 2003; Milcu et al., 2006; Eisenhauer, 2010). Furthermore, abiotic factors, such as $\mathrm{pH}$ of the organic layer and soil water content, play an important role (Loranger et al., 2001; Salamon, 2001; Salamon et al., 2008; Sterzyńska et al., 2014). Interestingly, only the FA composition of $F$. quadrioculata differed between forest types suggesting that in particular in this species trophic links change with changes in abiotic and biotic factors which supports earlier studies suggesting that this species is opportunistically feeding on a variety of resources (Chahartaghi et al., 2005; Krab et al., 2013). The majority of studies investigating the response of collembolan communities to changes in forest type is based on densities and biomass of collembolans but did not dig into the mechanisms responsible for the observed changes. Results of the present study suggest that these differences at least in part are due to changes in trophic interrelationships of collembolan species.

Unexpectedly, regression analyses suggested that the FA patterns of collembolan species are not closely linked to the composition of the microbial community in the litter layer as indicated by marker PLFAs. This suggests that the diet of collembolan species is rather 
independent of the structure of microbial communities in bulk litter material as potential major food resource. This lack of relationship supports results of M.M. Pollierer (pers. communication) indicating that changes in collembolan species composition do not correspond to changes in PLFA patterns of microorganisms in leaf litter. In contrast, Ruess et al. (2007) found microbial PLFA and collembolan NLFA patterns to be closely linked suggesting that collembolans adjust their diet to changes in resource availability. Indeed, collembolans have been shown to be able to shift diet in response to changes in resource availability (Parkinson, 1988; Rusek, 1998; Endlweber et al., 2009). However, shifts in diet may only occur if conditions change markedly, e.g., as is the case in forests of different parent rock, soils and plant communities (Ruess et al., 2007) or between regions as in the present study. Generally, results of the present study indicate that the diet of collembolan species varies little between forest types stocking on similar parent rock. This suggests that collembolans search for favourable microsites in soil where preferred food resources are present resulting in constant FA patterns, with these microsites differing little between deciduous and coniferous forests.

\section{Conclusions}

The results suggest trophic niche differentiation between coexisting collembolan species, however, dietary niches presumably comprise a mixture of resources rather than single resources. Further, collembolan species likely differ in the degree they consume animal prey or carrion as $\delta^{15} \mathrm{~N}$ values suggest them to occupy different trophic levels and feed on animal species affiliated with both litter and root carbon resources. Further, the results suggest that feeding preferences for bacteria vs. fungi in collembolan species are little related to their vertical stratification, whereas trophic level is. Consistent with earlier studies collembolans respond little to shifts in forest type although they include leaf litter and microorganisms into their diet which change with forest type. Due to the small-scale heterogeneous distribution of resources in soil, collembolans may feed on a preferred diet at certain microsites to cover their dietary needs thereby keeping their trophic niche constant. Analysing microbial communities in bulk leaf litter and soil using PLFA profiles likely misses the characteristics of the microsites actually used as food substrate by collembolans. Further research is needed to identify variability in the composition of microbial communities on the microscale considering soil microsites, such as the rhizoplane and microaggregates. This may allow to link food resources and trophic niches of decomposer microarthropods such as 
collembolans, and to ultimately understand the way carbon and nutrients are channelled from basal resources to higher trophic levels of soil food webs.

\section{Acknowledgements}

We thank the managers of the three Exploratories, Swen Renner, Sonja Gockel, KerstinWiesner, and Martin Gorke for their work in maintaining the plot and project infrastructure; Simone Pfeiffer and Christiane Fischer giving support through the central office, Michael Owonibi for managing the central data base, and Markus Fischer, Eduard Linsenmair, Dominik Hessenmöller, Jens Nieschulze, Daniel Prati, Ingo Schöning, François Buscot, Ernst-Detlef Schulze, Wolfgang W. Weisser and the late Elisabeth Kalko for their role in setting up the Biodiversity Exploratories project. The work has been (partly) funded by the DFG Priority Program 1374 "Infrastructure-Biodiversity-Exploratories" (SCHE 376/223). Field work permits were issued by the responsible state environmental offices of BadenWürttemberg, Thüringen, and Brandenburg (according to $\S 72$ BbgNatSchG). Special thanks to Guido Humpert, Mark Maraun, Bernhard Eitzinger and Christian Bluhm for support during field work, lab work and statistical analyses.

\section{References}

Albers, D., Schaefer, M., Scheu, S., 2006. Incorporation of plant carbon into the soil animal food web of an arable system. Ecology, 87, 235-245.

Bardgett, R.D., 2005. The biology of soil. Oxford University Press, Oxford.

Bengtsson, J., Lundquist, H., Saetre, P., Sohlenius, B., Solbreck, B., 1998. Effects of organic matter removal on the soil food web: forestry practice meets ecological theory. Applied Soil Ecology 9, 137-143.

Berg, M.P., Stoffer, M., van den Heuvel, H.H., 2004. Feeding guilds in Collembola based on digestive enzymes. Pedobiologia 48, $589-601$.

Blem, C.R., 1976. Patterns of lipid storage and utilization in birds. American Zoologist 16, $671-684$.

Bonkowski, M., Villenave, C., Griffiths, B., 2009. Rhizosphere fauna: the functional and structural diversity of intimate interactions of soil fauna with plant roots. Plant and Soil 321, 213- 233.

Buse, T., Ruess, L., Filser, J., 2013. New trophic biomarkers for Collembola reared on algal diets. Pedobiologia $56,153-159$.

Chahartaghi, M., Langel, R., Scheu, S., Ruess, L., 2005. Feeding guilds in Collembola based on nitrogen stable isotope ratios. Soil Biology \& Biochemistry 37, 1718-1725.

Chauvat, M., Perez, G., Ponge, J.F., 2014. Foraging patterns of soil springtails are impacted by food resources. 
Applied Soil Ecology 82, 72-77.

Chen, B., Snider, R.J., Snider, R.M., 1996. Food consumption by Collembola from northern Michigan deciduous forest. Pedobiologia 40, 149-161.

Crotty, F.V., Adl, S.M., Blackshaw, R.P., Murray, P.J., 2012: Protozoan pulses unveil their pivotal position within the soil food web. Microbial Ecology 63, $905-918$.

Crotty, F.V., Blackshaw, R.P., Murray, P.J., 2011. Tracking the flow of bacterially derived ${ }^{13} \mathrm{C}$ and ${ }^{15} \mathrm{~N}$ through soil faunal feeding channels. Rapid Communications in Mass Spectrometry 25, 1503-1513.

de Ruiter, P.C., Moore, J.C., Zwart, K.B., Bouwman, L.A., Hassink, J., Bloem, J., de Vos, J.A., Marinissen, J.C.Y., Didden, W.A.M., Lebbink, G., Brussard, L., 1993. Simulation of nitrogen mineralization in the below-ground food webs of two winter-wheat fields. Journal of Applied Ecology 30, 96-106.

Dennon, R.F., Fagan, W.F., 2003. Might nitrogen limitation promote omnivory among carnivorous arthropods? Ecology 84, 2522-2531.

Eisenhauer, N., 2010. The action of an animal ecosystem engineer: Identification of the main mechanisms of earthworm impacts on soil microarthropods. Pedobiologia 53, 343-352.

Endlweber, K., Ruess, L., Scheu, S., 2009. Collembola switch diet in presence of plant roots thereby functioning as herbivores. Soil Biology \& Biochemistry 41, $1151-1154$.

Ferlian, O., Scheu, S., 2014. Shifts in trophic interactions with forest type in soil generalist predators as indicated by complementary analyses of fatty acids and stable isotopes. Oikos, doi: 10.1111/j.16000706.2013.00848.x.

Fierer, N., Strickland, M.S., Liptzin, D., Bradford, M.A., Cleveland, C.C., 2009. Global patterns in belowground communities. Ecology Letters 12, 1238 - 1249.

Fischer, M., Bossdorf, O., Gockel, S., Hänsel, F., Hemp, A., Hessenmöller, D., Korte, G., Nieschulze, J., Pfeiffer, S., Prati, D., Renner, S. et al. 2012. Implementing large-scale and long-term functional biodiversity research: The Biodiversity Exploratories. Basic and Applied Ecology 11, $473-485$.

Frostegård, A., Baath, E., Tunlid, A., 1993. Shifts in structure of soil microbial communities in limed forests as revealed by phospholipid fatty acid analysis. Soil Biology \& Biochemistry 25, 723-730.

Gessler, A., Rennenberg, H., Keitel, C., 2004. Stable isotope composition of organic compounds transported in the phloem of European beech - evaluation of different methods of phloem sap collection and assessment of gradients in carbon isotope composition during leaf-to-stem transport. Plant Biology 6 , 721-729.

Hågvar, S., 1982. Collembola in Norwegian coniferous forests soils, 1. Relations to plant communities and soil fertility. Pedobiologia 24, 255-296.

Hättenschwiler, S., Vitousek, P.M., 2000. The role of polyphenols in terrestrial ecosystem nutrient cycling. Trends in Ecology and Evolution 15, 238-243.

Haubert, D., Birkhofer, K., Fliessbach, A., Gehre, M., Scheu, S., Ruess, L., 2009. Trophic structure and major trophic links in conventional versus organic farming systems as indicated by carbon stable isotope ratios of fatty acids. Oikos 118, 1579-1589.

Haubert, D., Häggblom, M.M., Langel, R., Scheu, S., Ruess, L., 2006. Trophic shift of stable isotopes and fatty acids in Collembola on bacterial diets. Soil Biology \& Biochemistry 38, $2004-2007$.

Haubert, D., Häggblom, M.M., Scheu, S., Ruess, L., 2004. Effects of fungal food quality and starvation on the 
fatty acid composition of Protaphorura fimata (Collembola). Comparative Biochemistry and Physiology Part B 138, 41-52.

Haubert, D., Häggblom, M.M., Scheu, S., Ruess, L., 2008. Effects of temperature and life stage on the fatty acid composition of Collembola. European Journal of Soil Biology 44, 213-219.

Hishi, T., Hyodo, F., Saitoh, S., Takeda, H., 2007. The feeding habits of Collembola along decomposition gradients using stable carbon and nitrogen isotope analyses. Soil Biology \& Biochemistry 39, 1820 1823.

Hopkin, S.P., 1997. Biology of the Springtails (Insecta: Collembola). Oxford University Press, Oxford.

Hopkin, S.P., 2007. A Key to the Collembola (Springtails) of Britain and Ireland. Field Studies Council (AIDGAP Project), Telford.

Hunt, H.W., Coleman, D.C., Ingham, E.R., Ingham, R.E., Elliott, E.T., Moore, J.C., Rose, S.L., Reid, C.P.P., Morley, C.R., 1987. The detrital food web in a shortgrass prairie. Biology and Fertility of Soils 3, 57-68.

Jørgensen, H.B., Hedlund, K., 2013. Organic amendment and fungal species in combination can alter collembolan fitness. Soil Biology \& Biochemistry 65, $316-321$.

Jørgensen, H.B., Johansson, T., Canbäck, B., Hedlund, K., Tunlid, A., 2005. Selective foraging of fungi by collembolans in soil. Biology Letters 1, $243-246$.

Kempson, D., Lloyd, M., Ghelardi, R., 1963. A new extractor for woodland litter. Pedobiologia 3, 1-21.

Klarner, B., Ehnes, R.B., Erdmann, G., Eitzinger, B., Pollierer, M.M., Maraun, M., Scheu, S., 2014. Trophic shift of soil animal species with forest type as indicated by stable isotope analysis. Oikos, doi: 10.1111/j.16000706.2013.00939.x.

Klarner, B., Maraun, M., Scheu, S., 2013. Trophic diversity and niche partitioning in a species rich predator guild - natural variations in stable isotope ratios $\left({ }^{13} \mathrm{C} /{ }^{12} \mathrm{C},{ }^{15} \mathrm{~N} /{ }^{14} \mathrm{~N}\right.$ ) of mesostigmatid mites (Acari, Mesostigmata) from central European beech forests. Soil Biology \& Biochemistry 57, 327-333.

Krab, E.J., Berg, M.P., Aerts, R., van Logtestijn, R.S.P., Cornelissen, J.H.C., 2013. Vascular plant litter input in subarctic peat bogs changes Collembola diets and decomposition patterns. Soil Biology \& Biochemistry $63,106-115$.

Krab, E.J., Oorsprong, H., Berg, M.P., Cornelissen, J.H.C., 2010. Turning northern peatlands upside down: disentangling microclimate and substrate quality effects on vertical distribution of Collembola. Functional Ecology 24, 1362 - 1369.

Larsen, T., Gorissen, A., Krogh, P., Ventura, M., Magid, J., 2007. Assimilation dynamics of soil carbon and nitrogen by wheat roots and Collembola. Plant and Soil 295, 253-264.

Lee, Q., Widden, P., 1996. Folsomia candida, a fungivorous collembolan, feeds preferentially on nematodes rather than soil fungi. Soil Biology \& Biochemistry 28, $689-690$.

Loranger, G., Bandyopadhyaya, I., Razaka, B., Ponge, J.F., 2001. Does soil acidity explain altitudinal sequences in collembolan communities? Soil Biology \& Biochemistry 33, $381-393$.

Maraun, M., Erdmann, G., Fischer, B.M., Pollierer, M.M., Norton, R.A., Schneider, K., Scheu, S., 2011. Stable isotopes revisited: their use and limits for oribatid mite trophic ecology. Soil Biology \& Biochemistry 43 , $877-882$.

Maraun, M., Martens, H., Migge, M., Theenhaus, A., Scheu, S., 2003. Adding to the 'enigma of soil animal diversity': fungal feeders and saprophagous soil invertebrates prefer similar food substrates. European 
Journal of Soil Biology 39, $85-95$.

Milcu, A., Partsch, S., Langel, R., Scheu, S., 2006. The response of decomposers (earthworms, springtails and microorganisms) to variations in species and functional group diversity of plants. Oikos $112,513-$ 524.

Moore, J.C., Ingham, E.R., Coleman, D.C., 1987. Inter- and intraspecific feeding selectivity of Folsomia candida (Willem) (Collembola, Isotomidae) on fungi. Biology and Fertility of Soils 5, 6-12.

Moore, J.C., McCann, K., de Ruiter, P.C., 2005. Modeling trophic pathways, nutrient cycling, and dynamic stability in soils. Pedobiologia 49, 499-510.

Ngosong, C., Raupp, J., Richnow, H.-H., Ruess, L., 2011. Tracking Collembola feeding strategies by the natural ${ }^{13} \mathrm{C}$ signal of fatty acids in an arable soil with different fertilizer regimes. Pedobiologia 54, $225-$ 233.

Oelbermann, K., Langel, R., Scheu, S., 2008. Utilization of prey from the decomposer system by generalist predators of grassland. Oecologia 155, $605-617$.

Ostle, N., Briones, M.J.I., Ineson, P., Cole, L., Staddon, P., Sleep, D., 2007. Isotopic detection of recent photosynthate carbon flow into grassland rhizosphere fauna. Soil Biology \& Biochemistry 39, $768-777$.

Parkinson, D., 1988. Linkages between resource availability, microorganisms and soil invertebrates. Agriculture, Ecosystems and Environment 24, 21-32.

Petersen, H., Luxton, M., 1982. Quantitative ecology of microfungi and animals in soil and litter. Oikos 39, 287388.

Pollierer, M.M., Dyckmans, J., Scheu, S., Haubert, D., 2012. Carbon flux through fungi and bacteria into the forest soil animal food web as indicated by compound-specific ${ }^{13} \mathrm{C}$ fatty acid analysis. Functional Ecology 26, $978-990$.

Pollierer, M.M., Langel, R., Körner, C., Maraun, M., Scheu, S., 2007. The underestimated importance of belowground carbon input for soil animal food webs. Ecology Letters 10, $729-736$.

Pollierer, M.M., Scheu, S., Haubert, D., 2010. Taking it to the next level: trophic transfer of marker fatty acids from basal resource to predators. Soil Biology \& Biochemistry 42, $919-925$.

Pond, C.M., 1981. Storage. In: Townsend, C.R., Calow, P. (Eds.), Physiological Ecology: an Evolutionary Approach to Resource Use. Blackwell, London, pp. 190 - 219.

Ruess, L., Chamberlain, P.M., 2010. The fat that matters: soil food web analysis using fatty acids and their carbon stable isotope signature. Soil Biology \& Biochemistry 42, $1898-1910$.

Ruess, L., Häggblom, M.M., Grazía Zapata, E.J., Dighton, J., 2002. Fatty acids of fungi and nematodes: possible biomarkers in the soil food chain? Soil Biology \& Biochemistry 34, $745-756$.

Ruess, L., Langel, R., Häggblom, M.M., Scheu, S., 2004. Nitrogen isotope ratios and fatty acids composition as indicators of animal diet in belowground systems. Oecologia 139, 336-346.

Ruess, L., Schütz, K., Haubert, D., Häggblom, M.M., Kandeler, E., Scheu, S., 2005a. Application of lipid analysis to understand trophic interactions in soil. Ecology 86, 2075- 2082.

Ruess, L., Schütz, K., Migge-Kleian, S., Häggblom, M.M., Kandeler, E., Scheu, S., 2007. Lipid composition of Collembola and their food resources in deciduous forest stands - implications for feeding strategies. Soil Biology \& Biochemistry 39, $1990-2000$.

Ruess, L., Tiunov, A., Haubert, D., Richnow, H.-H., Häggblom, M.M., Scheu, S., 2005b. Carbon isotope 
fractionation and trophic transfer of fatty acids in fungal based soil food chains. Soil Biology \& Biochemistry 37, $945-953$.

Ruf, A., Kuzyakov, Y., Lopatovskaya, O., 2006. Carbon fluxes in soil food webs of increasing complexity revealed by ${ }^{14} \mathrm{C}$ labelling and ${ }^{13} \mathrm{C}$ natural abundance. Soil Biology \& Biochemistry $38,2390-2400$.

Rusek, J., 1998. Biodiversity of Collembola and their functional role in the ecosystem. Biodiversity and Conservation 7, 1207-1219.

Salamon, J.-A., 2001. Die Collembolengemeinschaften in Buchen- und Fichtenwäldern des Sollings: Der Einfluss von Baummischung, Nahrung und mechanischer Störung. Berichte des Forschungszentrums Waldökosysteme, Göttingen, Reihe A, 176, pp. 1-166.

Salamon, J.-A., Schaefer, M., Alphei, J., Schmid, B., Scheu, S., 2004. Effects of plant diversity on Collembola in an experimental grassland ecosystem. Oikos 106, 51-60.

Salamon, J-A., Scheu, S., Schaefer, M., 2008. The Collembola community of pure and mixed stands of beech (Fagus sylvatica) and spruce (Picea abies) of different age. Pedobiologia 51, 385 - 396.

Scheu, S., 2002. The soil food web: structure and perspectives. European Journal of Soil Biology 38, 11-20.

Scheu, S., Albers, D., Alphei, J., Buryn, R., Klages, U., Migge, S., Platner, C., Salamon, J.-A., 2003. The soil fauna in pure and mixed stands of beech and spruce of different age: trophic structure and structuring forces. Oikos 101, 225-238.

Scheu, S., Ruess, L., Bonkowski, M., 2005. Interactions between micro-organisms and soil micro- and mesofauna. In: Buscot, F., Varma, A. (Eds.), Soil Biology, Volume 3 - Microorganisms in soils: Roles in genesis and functions. Springer, New York, pp. 253-275.

Scheu, S., Simmerling, F., 2004. Growth and reproduction of fungal feeding Collembola as affected by fungal species, melanin and mixed diets. Oecologia 139, 347-353.

Sterzyńska, M., Shrubovych, J., Kaprus. I., 2014. Effect of hydrologic regime and forest age on Collembola in riparian forests. Applied Soil Ecology 75, 199 - 209.

Tiunov, A. V. 2007. Stable isotopes of carbon and nitrogen in soil ecological studies. Biology Bulletin 34, 395407.

Tranvik, L., Eijsackers, H., 1989. On the advantage of Folsomia fimetarioides over Isotomiella minor (Collembola) in a metal polluted soil. Oecologia 80, $195-200$.

Visser, S., 1985. Role of soil invertebrates in determining the composition of soil microbial communities. In: Fitter, A.H., Atkinson, D., Read, D.J., Usher, M.B. (Eds.), Ecological Interactions in Soil. Blackwell Scientific, Oxford, pp. 297-317. 


\section{Chapter 6}

\section{General Discussion}

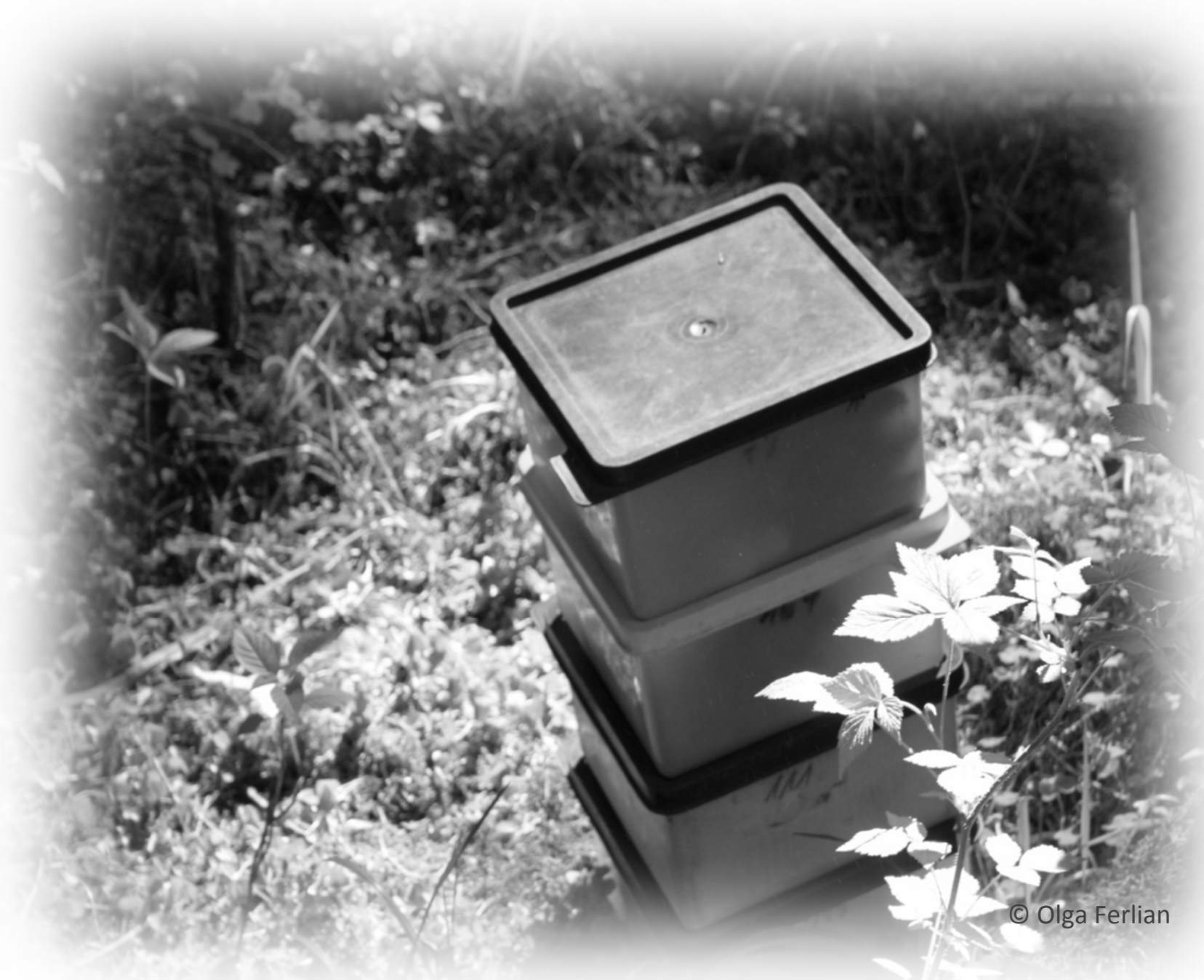


Investigating feeding strategies of abundant soil invertebrates that are trophically linked, we delivered insight into utilisation of resources across different trophic levels and variations therein. Combining novel techniques in the analysis of trophic interactions in soil, i.e., molecular gut content, stable isotope, fatty acid and compound-specific ${ }^{13} \mathrm{C}$ stable isotope analyses, allowed delineating trophic structure of the soil food web, channelling of resources therein and provided fine scale resolution of trophic links between species.

Results of Chapters 2 and 3 indicated distinct trophic niches between centipede species due to different body sizes and restrictions by habitat structure. In rich structured habitats body size is suggested to determine accessibility to root-derived resources in deeper soil layers were bacterial communities are assumed to dominate over fungal communities. This suggests association of small species with the bacterial energy channel. The contribution of the two centipede species to the different energy channels (bacterial, fungal) varied with habitat which challenges the idea of fixed energy channels in soil food webs.

In Chapter 4 earthworm species of different ecological groups were found to rely on carbon resources of different stability. Epigeic and anecic earthworms utilised resources of recent origin, such as microorganisms and litter material. Analysing soil particle size fractions, endogeic earthworms were found to utilise carbon enclosed in organo-mineral complexes of small particle size fractions. Studying mobilisation of this carbon is essential as it results in reintegration of old carbon into soil element cycling.

Results of Chapter 5 documented trophic niche differentiation between coexisting collembolan species. We found species to utilise both litter- and root-derived carbon resources. ${ }^{15} \mathrm{~N}$ stable isotope signatures suggested collembolan species to occupy different trophic levels up to predators. So far collembolans have been categorised as fungivores. In contrast to centipedes collembolans responded little to shifts in habitats. Presumably, this is due to the small-scale heterogeneity of resources in soil. By feeding on specific microsites that are present in different habitats, they keep their trophic niche constant. Considering such microsites instead of bulk soil is essential to understand the way nutrients are channelled in soil food webs.

Utilisation of food resources by soil animals

Trophic niches of centipedes depend on habitat structure due to restrictions of body size to 
specific resources. Body size and diet of the species corresponded well to microbial community structures in different soil layers. This suggests that feeding strategies of large invertebrate soil predators are essentially controlled by allometric characteristics. Body size may contribute to coexistence of predator species in soil and also alter predation pressure on prey species (Kalinkat et al., 2013). In contrast, trophic niches of collembolan species did not shift with forest type (Chapter 5). Soil habitats are known to be heterogeneous with respect to resources and may comprise small-scale microsites of distinct microbial and animal communities (Saetre and Baath, 2000; Wolters, 2000). One of the driving factors forming these microsites is the release of root exudates fostering rhizosphere bacteria and their consumers, such as Protozoa and collembolans (Hopkin, 1997; Bonkowski et al., 2009; Blagodatskaya et al., 2014). We assume that in different habitats equivalent microsites are present resulting in constant feeding strategies of collembolan species across different forests. Contrary to assumptions, feeding strategies of collembolans are able to balance variations in basal resources in different habitats, whereas resource availability in centipedes is more restricted. In Chapter 4 the trophic niche of earthworms was also found to vary little with habitat. In contrast to other decomposers, epigeic earthworm species feed on a broad spectrum of resources ranging from litter material to microorganisms. Endogeic species even feed on carbon resources that are enclosed in soil aggregates. Such resources likely vary little between habitats and this may contribute to constant feeding strategies in earthworm species. Consistent with our studies habitat structure has been shown to control predator-prey interactions in soil invertebrates (Langellotto and Denno, 2004). Interestingly, leaf litter, primarily providing habitat structure, simultaneously represents the basal resource of the belowground system which hampers disentangling of trophic and non-trophic effects in soil food webs (Kalinkat et al., 2013). Overall, investigating utilisation of resources by consumers in forest soil in combination with habitat structure can improve understanding trophic interrelationships.

Soil animals as generalists

Based on fatty acid compositions, it is assumed that the three invertebrate taxa investigated in this study, centipedes, earthworms and collembolans, have broad resource spectra suggesting that they are food generalists. Most earthworm and collembolan species fed on litter material colonised by microorganisms and likely assimilate both plant and microbial resources which implies feeding on different trophic levels, i.e., omnivory. Also centipedes 
were found to be generalists feeding on earthworms and collembolans (Chapter 3); earlier they were even documented to feed on intraguild prey (Hickerson et al., 2005). Furthermore, earthworms and collembolans have markedly different body masses and mobility requiring diverse strategies of predators to subdue their prey. A characteristic adaptation to large prey is poison and extra-intestinal digestion, whereas adaptation to small and mobile prey typically comprises a sit-and-wait strategy. Indeed, it is well-documented that the majority of soil animals are generalists, from a network perspective, being reflected in a multitude of trophic links within the soil food web (Ponsard and Arditi, 2000; Scheu, 2002; Scheu and Setälä, 2002; Digel et al., 2014). Reasons for the high number of generalists may be close spatial association of organisms and opacity of the soil habitat which contrasts the aboveground system (Scheu and Falca, 2000). Opacity of soil and the coexistence of species may, further, contribute to the importance of bottom-up control in soil food webs (Scheu and Schaefer, 1998; Ponsard et al., 2000). In addition, in each of the three taxa trophic niche differentiation was pronounced. We even documented collembolan species to live as predators although collembolans generally have been assumed to be fungivorous. Overall, this suggests a kind of 'specialised generalism' in soil invertebrates: Soil invertebrates feed on a broad range of resources (see above) but specialise on a specific mixture of different resources which differs from that of other coexisting species. In this respect soil food webs are unique and contrast aboveground food webs. However, the definition of 'generalist' in the context of soil systems remains vague as the composition of food resources is still poorly understood. In particular more detailed knowledge on the physical structure and composition of microsites soil invertebrates feed on is needed.

\section{Energy channels within the soil food web}

Results of Chapter 2 indicated fatty acid compositions to differ between centipede species with the smaller species comprising higher proportions of bacterial markers and the larger species comprising higher proportions of the fungal marker suggesting differences in associations with energy channels. In addition, due to variations between habitats, the theory of fixed energy channels is equivocal (Goncharov and Tiunov, 2013). Similarly, recent studies documented shifts in energy channels with ontogenetic development and season in centipedes (Ferlian et al., 2012). However, fatty acid analysis in predators does not allow distinguishing whether a shift of prey or a shift of resources by the prey drives variations in association with energy channels. However, the former seems more likely as predators may 
capture morphologically similar prey associated with different energy channels (Moore and Hunt, 1988). In collembolans species could be ascribed to the bacterial or fungal energy channel. One species contributed equally to both energy channels and, due to high ${ }^{15} \mathrm{~N}$ values, was ascribed to predators. This resembles findings in centipedes of converging energy channels at higher trophic levels (Moore and Hunt, 1988). Interestingly, endogeic earthworms may not contribute to any of the energy channels as they presumably rely little on microorganisms or litter material.

\section{Conclusions and outlook}

This thesis documented feeding strategies and associations with energy channels of soil food generalists of different trophic level. Centipedes are restricted to certain resources by habitat structure and their body size resulting in prey shifts with habitats, whereas collembolan species occupying very different trophic niches retained constant feeding strategies presumably due to utilising specific microsites in soil. Earthworm species were found to rely on carbon resource of different stability with endogeic earthworms utilising soil aggregates associated with clay and bacterial residues.

The results of the thesis advanced the understanding of soil food web structure and functioning. It presented insights into trophic interactions on different trophic levels in forest soil food webs known for its complexity and opacity. By investigating abundant soil animal taxa that are trophically linked, we examined a realistic compartment of the soil food web. The high number of species analysed in each of the studies allowed delineating differences between species but also generalities which contrasts former studies oversimplifying food web structure by using data of low taxonomic resolution. The results advanced understanding of trophic interrelationships and documented the value of novel techniques in opening the black box of soil food webs. Especially compound-specific stable isotope analyses provide an indispensible tool for studying the structure of and the channelling of carbon through soil food webs which needs to be broadened in future studies.

\section{References}

Blagodatskaya, E., Blagodatsky, S., Anderson, T.H., Kuzyakov, Y., 2014. Microbial growth and carbon use efficiency in the rhizosphere and root-free soil. PLoSONE 9.

Bonkowski, M., Villenave, C., Griffiths, B., 2009. Rhizosphere fauna: the functional and 
structural diversity of intimate interactions of soil fauna with plant roots. Plant and Soil $321,213-233$.

Digel, C. et al. Unraveling the complex structure of forest soil food webs: high omnivory and more trophic levels. Oikos, in press.

Ferlian, O., Scheu, S., Pollierer, M.M., 2012. Trophic interactions in centipedes (Chilopoda, Myriapoda) as indicated by fatty acid patterns: Variations with life stage, forest age and season. Soil Biology \& Biochemistry 52, $33-42$.

Goncharov, A.A., Tiunov, A.V., 2013. Trophic chains in soil. Zhurnal Obshchei Biologii 74, $450-462$.

Hickerson, C.A.M., Anthony, C.D., Walton, B.M., 2005. Edge effects and intraguild predation in native and introduced centipedes: evidence from the field and from laboratory microcosms. Oecologia 146, $110-119$.

Hopkin, S.P., 1997. Biology of the Springtails (Insecta: Collembola). Oxford University Press, Oxford.

Kalinkat, G., Brose, U., Rall, B.C., 2013. Habitat structure alters top-down control in litter communities. Oecologia 172, 877 - 887.

Langellotto, G.A., Denno, R.F., 2004. Responses of invertebrate natural enemies to complex-structured habitats: a meta-analytical synthesis. Oecologia 139, 1 - 10.

Moore, J.C., Hunt, H.W., 1988. Resource compartmentation and the stability of real ecosystems. Nature 333, $261-263$.

Ponsard, S., Arditi, R., 2000. What can stable isotopes $\left(\delta^{15} \mathrm{~N}\right.$ and $\left.\delta^{13} \mathrm{C}\right)$ tell about the food web of soil macro-invertebrates? Ecology 81, $852-864$.

Ponsard, S., Arditi, R., Jost, C., 2000. Assessing top-down and bottom-up control in a litterbased soil macroinvertebrate food chain. Oikos 89, $524-540$.

Saetre, P., Baath, E., 2000. Spatial variation and patterns of soil microbial community structure in a mixed spruce-birch stand. Soil Biology \& Biochemistry 32, $909-917$.

Scheu, S., 2002. The soil food web: structure and perspectives. European Journal of Soil Biology 38, $11-20$.

Scheu, S., Falca, M., 2000. The soil food web of two beech forests (Fagus sylvatica) of contrasting humus type: stable isotope analysis of a macro- and a mesofaunadominated community. Oecologia 123, $285-296$.

Scheu, S., Schäfer, M., 1998. Bottom-up control of the soil macrofauna community in a beechwood on limestone: Manipulation of food resources. Ecology 79, 1573 - 1585.

Scheu, S., Setälä, H., 2002. Multitrophic interactions in decomposer food-webs. In: Tscharntke, T., Hawkins, B.A. (Eds.), Multitrophic Level Interactions. Cambridge University Press, Cambridge, pp. $233-264$.

Wolters, V., 2000. Invertebrate control of soil organic matter stability. Biology and Fertility of Soils $31,1-19$. 


\section{Acknowledgements}

First, I would like to thank Stefan Scheu for the kind integration into the group and the brilliant supervision of my thesis. He was always willing to share his incredibly large expertknowledge and always had an open door for my questions and individual issues.

Many thanks to Mark Maraun whose statistical consultation office I could visit whenever there was a question or puzzle. He created a technical and scientific environment that made working here easygoing.

Bernhard Eitzinger was an excellent partner for fruitful discussions on general ecological topics in the institute as well as on long journeys to the furthermost plots in the national park. His valuable advice supported me in daily PhD life. Melanie Maraun was a reliable contact person concerning specific questions on lipids and fatty acids from the very beginning. Thank you!

My thanks to Guido Humpert, the 'Gott' of the 'Fatty Lab'. He became a good friend and his technical assistance and valuable advice during fatty acid extractions prevented catastrophes. Thanks to my office and field colleague Christian Bluhm for his calm and meditative nature that enabled concentrated working in the office, but also for the chats in between. During field work he always exhilarated the bugged out group with tasty smoked sausages.

Thanks to Christel Fischer, Andrea Lambertz, Ingrid Kleinhans and Susanne Böning-Klein for their technical and organisational support. Further, thanks go to Jens Dyckmans, Rainer Langel and Martin Blumenberg for always prompt help with fatty acid and isotope analyses.

I would like to thank the team of the Biodiversity Exploratories, especially the local management teams and the office team, for brilliant organisation of this huge project and engaged help with problems and questions related to sampling and experiments. Thanks also go to all other Explorers who were involved in our gigantic samplings and measurements.

Special thanks to Georgia Erdmann, Kathleen Lemanski and Evelyn Gerund whose friendship accompanied me through my whole time in the AG Scheu. You added not only to my office but also my private life in a very special way. Thanks for all the help especially during the final phase of my thesis. Hopefully, finally one day all of you will settle in Leipzig. 
Furthermore, I would like to thank the whole AG Scheu for expert help with specific questions and for creating an atmosphere that sweetened my everyday life in the institute.

The most important at the end: I thank my parents for giving me the opportunity to follow my interests and dreams and for supporting me during its realisation. Very special thanks go to Simone Cesarz for being the most valuable partner in scientific conversations on analyses and manuscripts, proof-reader of my creations, helper concerning organisation of our move, and especially for being the most precious fruit of my time in the AG Scheu. 


\section{List of Publications}

\section{Published in peer-reviewed journals:}

Ferlian, O., Scheu, S., Pollierer, M.M., 2012. Trophic interactions in centipedes (Chilopoda, Myriapoda) as indicated by fatty acid patterns: Variations with life stage, forest age and season. Soil Biology \& Biochemistry 52, 33-42.

Ferlian, O. and Scheu, S., 2014. Shifts in trophic interactions with forest type in soil generalist predators as indicated by complementary analyses of fatty acids and stable isotopes. Oikos 123, 1192-1198.

Günther, B., Rall, B.C., Ferlian, O., Scheu, S., Eitzinger, B., 2014. Variations in prey choice of invertebrate soil predators with forest type as indicated by molecular gut content analysis. Oikos 123, 1192-1198.

Ferlian, O., Cesarz, S., Marhan, S., Scheu, S., 2014. Carbon food resources of earthworms of different ecological groups as indicated by ${ }^{13} \mathrm{C}$ compound-specific stable isotope analysis. Soil Biology \& Biochemistry 77, 22-30.

Ferlian, O., Klarner, B., Langeneckert, A.E., Scheu, S., 2015. Trophic niche differentiation and utilisation of food resources in collembolans based on complementary analyses of fatty acids and stable isotopes. Soil Biology \& Biochemistry 82, 28-35. 


\section{Thesis Declaration}

Declaration of the author's own contribution to manuscripts with multiple authors:

Chapters 2 and 3 comprise manuscripts that are published in peer-reviewed journals. Chapters 4 and 5 comprise manuscripts that are currently submitted to peer-reviewed journals.

Chapter 2: I am the first author of this manuscript. I contributed significantly to the study design, collected and analysed the data, wrote the manuscript and created figures, tables and appendices.

Chapter 3: I am co-author of this manuscript. The manuscript was mainly written by B. Günther; I contributed to the development of the study design and the collection of data.

Chapter 4: I am the first author of this manuscript. S. Cesarz and I contributed equally to the study design, data collection and data analysis. S. Marhan contributed to data collection. I wrote the manuscript and created figures, tables and appendices.

Chapter 5: I am the first author of this manuscript. I contributed significantly to the study design, collected and analysed the data, wrote the manuscript and created figures, tables and appendices. B. Klarner and A.E. Langeneckert contributed to data collection and analysis.

Co-authors of all manuscripts contributed to the final version of the manuscripts. All persons contributing to the manuscripts have been named so.

\section{Plagiarism Declaration}

I declare that I have written this doctoral thesis independently. All persons contributing to the manuscripts have been named so. All sentences or passages quoted from other people's work have been specifically acknowledged by clear cross-referencing. I have not submitted this thesis in any form for another degree at any university or institution.

Olga Ferlian

Göttingen, May 2014 


\section{Curriculum vitae}

\section{Dipl. Biol. Olga Ferlian}

Personal details

Address

Petrikirchstraße 30, 37077 Göttingen, Germany

Email

oferlia@gwdg.de

Birthday

May $11^{\text {th }}, 1986$ in Wrocław, Poland

Nationality

German

Family status

unmarried

Current position

$\mathrm{PhD}$ student (animal ecology) at the Institute of Zoology and

Anthropology, Georg August University Göttingen, Germany

Scientific career

2011

$\mathrm{PhD}$ at the Georg August University Göttingen, Germany, under the Supervision of Prof. Dr. Stefan Scheu, topic: Trophic interactions in soil arthropods as indicated by fatty acid analysis (DFG Priority Program 1374 "InfrastructureBiodiversity- Exploratories)"

2011 Diploma thesis: "Analysing trophic interactions in centipedes (Chilopoda, Myriapoda) using fatty acid patterns: effects of life stage, forest type and season" under the supervision of Prof. Dr. Stefan Scheu at the Georg August University Göttingen, Germany, grade: excellent

2011 Student assistant in various projects/courses at the Georg August University Göttingen, Germany

2010 Student assistant in various projects/courses at the University of Bergen, Norway

2010 Six-month stay abroad (Erasmus programme) at the University of Bergen, Norway 
2005 - 2011 Study of Biology (major: zoology, microbiology and nature conservation) at the Georg August University Göttingen, Germany

2005 Abitur at the Gymnasium im Schloß, Wolfenbüttel, Germany

\section{Papers in peer-reviewed journals}

Ferlian, O., Scheu, S., Pollierer, M.M., 2012. Trophic interactions in centipedes (Chilopoda, Myriapoda) as indicated by fatty acid patterns: Variations with life stage, forest age and season. Soil Biology \& Biochemistry 52, 33-42.

Ferlian, O. and Scheu, S., 2014. Shifts in trophic interactions with forest type in soil generalist predators as indicated by complementary analyses of fatty acids and stable isotopes. Oikos, in press.

Günther, B., Rall, B.C., Ferlian, O., Scheu, S. Eitzinger, B., 2014. Variations in prey choice of invertebrate soil predators with forest type as indicated by molecular gut content analysis. Oikos, in press.

Ferlian, O., Cesarz, S., Marhan, S., Scheu, S. Carbon food resources of earthworms of different ecological groups as indicated by ${ }^{13} \mathrm{C}$ compound-specific stable isotope analysis. Soil Biology \& Biochemistry, major revisions requested.

Ferlian, O., Klarner, B., Langeneckert, A.E., Scheu, S. Trophic niche differentiation and utilisation of food resources in collembolans based on complementary analyses of fatty acids and stable isotopes. Soil Biology \& Biochemistry, under review.

\section{Teaching experience}

2013

2012 -

2008 -

2008 -

$2007-2008$
Food Web Workshop, Univ. Göttingen, Research Training Group 1086 (talk)

Praktikum terrestrische Wirbellose, Univ. Göttingen (assistant) Zoologische Bestimmungsübungen, Geländepraktikum, Univ. Göttingen (leader)

Zoologische Bestimmungsübungen, Univ. Göttingen (assistant) Zoologisches Grundpraktikum, Univ. Göttingen (assistant)

\section{Workshop attendance}


Göttingen, Germany

2012

Multitrophic interactions Workshop, Univ. Göttingen, Germany

2012

Path analysis/structural equation modelling for ecologists, Eisenach, Germany

2012

Statistics for Ecology and Conservation Biology, Univ. Göttingen, Germany

2011

Statistics for Ecology and Conservation Biology, Univ. Göttingen, Germany

2011

Scientific writing and Publishing (M. Hochberg), Univ. Göttingen, Germany

2010

Analysis and management of ecological and evolutionary data using $\mathrm{R}$ (C.

2010

Dormann), Univ. Göttingen, Germany

2009

Ordination and gradient analysis in R (R. Telford), Univ. Bergen, Norway Introduction in R, Univ. Göttingen, Germany 